\title{
Livermore Big Trees Park: 1998 Results
}

D. Mac Queen, G. Gallegos, K. Surano

April 18, 2002

Lawrence

Livermore

National

Laboratory 


\section{DISCLAIMER}

This document was prepared as an account of work sponsored by an agency of the United States Government. Neither the United States Government nor the University of California nor any of their employees, makes any warranty, express or implied, or assumes any legal liability or responsibility for the accuracy, completeness, or usefulness of any information, apparatus, product, or process disclosed, or represents that its use would not infringe privately owned rights. Reference herein to any specific commercial product, process, or service by trade name, trademark, manufacturer, or otherwise, does not necessarily constitute or imply its endorsement, recommendation, or favoring by the United States Government or the University of California. The views and opinions of authors expressed herein do not necessarily state or reflect those of the United States Government or the University of California, and shall not be used for advertising or product endorsement purposes.

This work was performed under the auspices of the U. S. Department of Energy by the University of California, Lawrence Livermore National Laboratory under Contract No. W-7405-Eng-48.

This report has been reproduced directly from the best available copy.

Available electronically at http://www.dee.gov/bridge

Available for a processing fee to U.S. Department of Energy and its contractors in paper from

U.S. Department of Energy

Office of Scientific and Technical Information

P.O. Box 62

Oak Ridge, TN 37831-0062

Telephone: (865) 576-8401

Facsimile: (865) 576-5728

E-mail: reports@adonis.osti.gov

Available for the sale to the public from

U.S. Department of Commerce

National Technical Information Service

5285 Port Royal Road

Springfield, VA 22161

Telephone: (800) 553-6847

Facsimile: (703) 605-6900

E-mail: orders@ntis.fedworld.gov

Online ordering: http://wwww.ntis.gov/ordering.htm

OR

Lawrence Livermore National Laboratory

Technical Information Department's Digital Library

http://www.llnl.gov/tid/Library.html 


\title{
Livermore Big Trees Park: 1998 Results
}

\author{
Don Mac Queen \\ Gretchen -Gallegos \\ Kris Surano
}

April 18, 2002

Lawrence Livermore National Laboratory University of California Livermore, California 94551 
This work was performed under the auspices of the U.S. Department of Energy by the University of California, Lawrence Livermore National Laboratory under contract No. W-7405-Eng-48. 


\section{Table of Contents}

1. Introduction .1

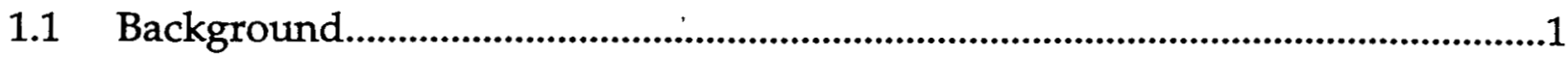

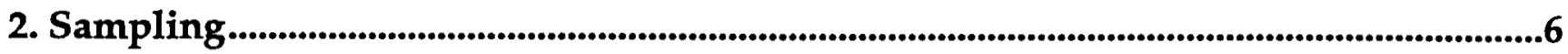

2.1 Extent of Plutonium at Big Trees Park...................................................................9

2.1.1 Data Analysis and Interpretation .............................................................10

2.1.1.1 Depth Distribution.....................................................................10

2.1.1.2 Lateral Distribution ..............................................................13

2.1.2 Conclusions regarding extent of plutonium at Big Trees Park..............19

2.2 Distribution Pathways .............................................................................19

2.2.1 Arroyo-waterborne Pathway ................................................................19

2.2.1.1 Review of Evidence Prior to the 1998 Sampling ......................19

2.2.1.2 Sampling for the arroyo-waterborne hypothesis......................22

2.2.1.3 Data Analysis and Interpretation .................................................23

2.2.1.4 Conclusions Regarding the Arroyo-waterborne Pathway .....24

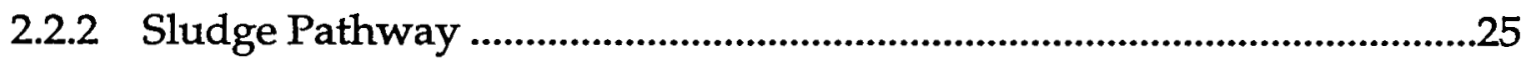

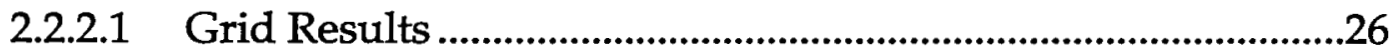

2.2.2.2 Tree Results: Plutonium-239+240 …..........................................26

2.2.2.3 Tree Results: Plutonium, Americium, and Metals.....................28

2.2.2.4 Tree Results: Plutonium-238 ...................................................30

2.2.2.5 Tree Results: Americium-241 ..................................................30

2.2.2.6 Tree Results: Metals.....................................................................32

2.2.2.7 Comparison of grid results with tree well results.......................35

2.2.2.8 Correlations between tree well ratios ........................................36

2.2.2.9 Conclusions Regarding the Sludge Pathway.............................39

2.2.3 Aerial Distribution Pathway .......................................................................39

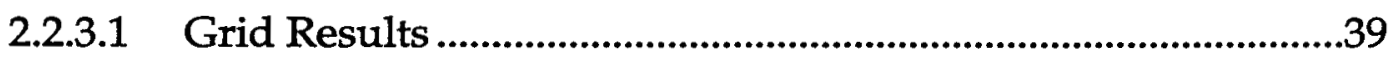

2.2.3.2 Air Surveillance Monitoring .....................................................40

2.2.3.3 Soil Surveillance Monitoring.......................................................42

2.2.3.4 Conclusions Regarding the Aerial Distribution Pathway ......45

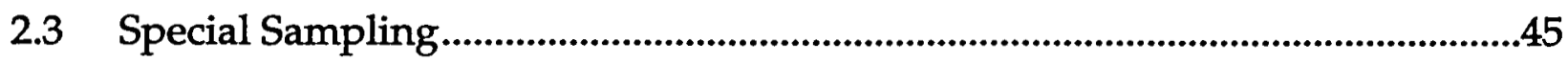

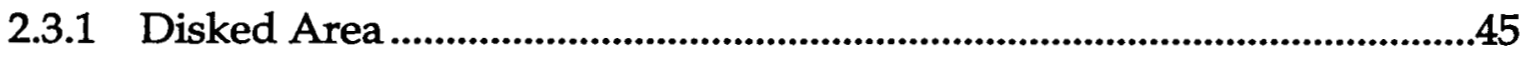

2.3.2 Playing Field ....................................................................................................46 
2.3.3 Special Sampling of the Big Trees Park Eastern Extension........................47

2.3.4 Special Sampling of 1995 Locations 1,7 , and 8..........................................4

2.3.5 Summary of Results from Special Sampling...........................................51

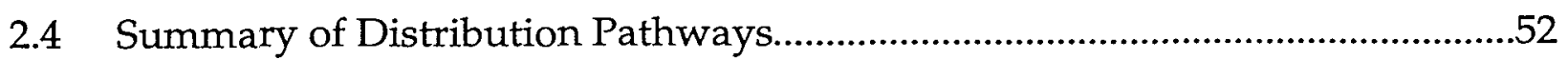

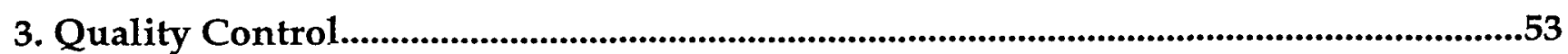

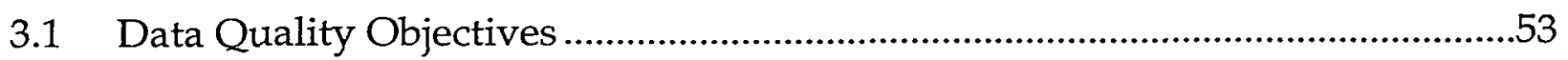

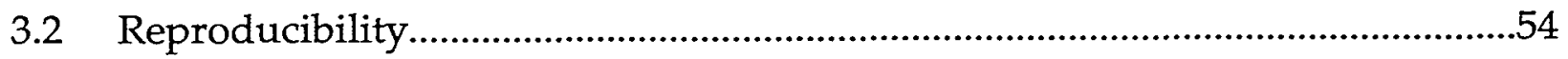

3.2.1 Within-laboratory Reproducibility ………..............................................55

3.2.2 Intra-laboratory Field-Split Reproducibility ............................................56

3.2.3 Small Scale Spatial Reproducibility ..........................................................56

3.2.4 Inter-laboratory Field-Split Reproducibility ..............................................56

3.2.5 Sources of Variability ...........................................................................56

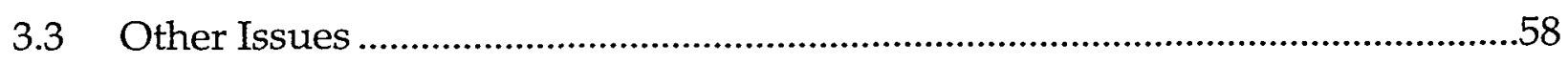

3.3.1 Ion-exchange columns .........................................................................58

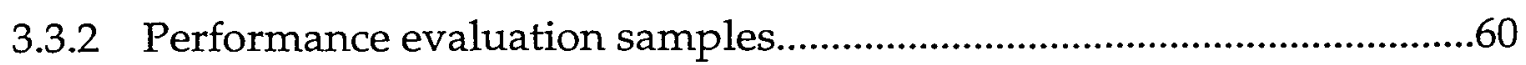

3.3.3 Sample preparation …………............................................................62

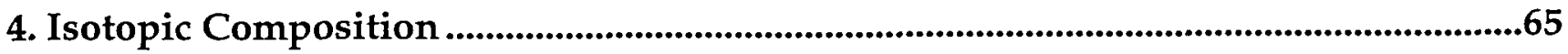

4.1 Isotopic Composition of Fallout-background.......................................................65

4.2 Isotopic Composition of Big Trees Park Samples ...............................................66

4.3 Summary of Isotopic Composition Results.......................................................69

5. Sample Collection ..........................................................................................................70

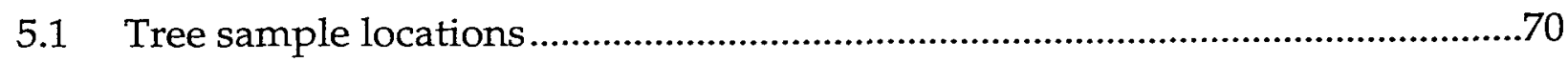

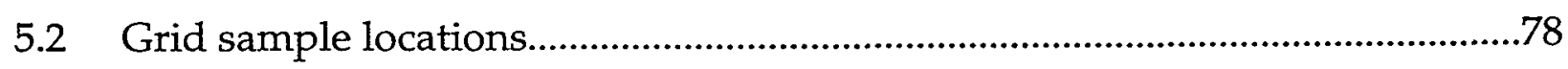

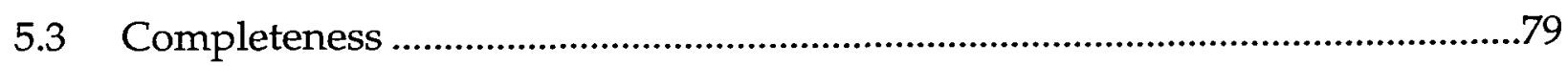

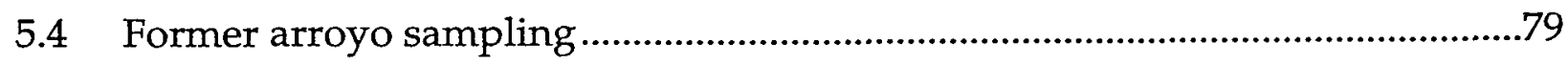

6. Review of 1995 Results...........................................................................................................8

6.1 CDHS-EHIB Interpretation of a Subset of the 1995 Data.....................................81

6.2 Interpretation of 1995 Results, Using All of the 1995 Data.................................81

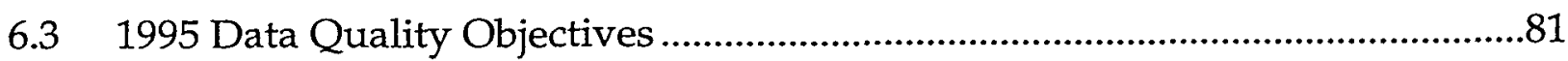

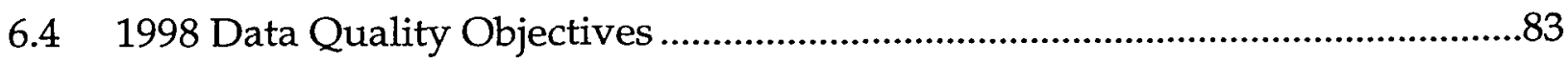

7. Review of 1993 Samples......................................................................................................84

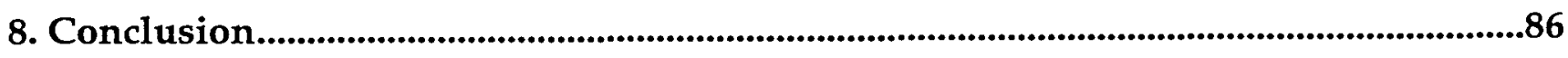

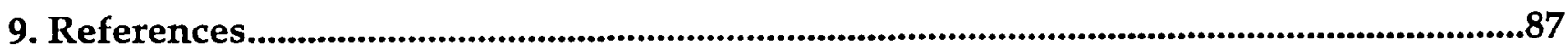

10. Acknowledgments .........................................................................................................92 


\section{List of Tables}

Table 1.1 Chronology of events at Big Trees Park....................................................................... 4

Table 2.1 Big Trees Park sampling plan.................................................................................. 8

Table 2.2 Plutonium-239+240 concentration values for samples taken in 1998 on a grid at Big Trees Park. ${ }^{a}$ Values in shaded boxes are the highest measured activities. Values in boldface type are above $0.012 \mathrm{pCi} / \mathrm{g}$ falloutbackground; those in regular typeface are detections at fallout-background level; and those in italic are nondetections. (See Section 2.1.1 for discussion.)

Table 2.3 Analysis of variance for the lateral distribution of $\mathrm{Pu}-239+240$ in the top 10 $\mathrm{cm}^{\mathbf{a}} 15$

Table 2.4 Simultaneous 95\% confidence intervals for the ratios of Pu-239+240 concentrations, radials one through four.

Table 2.5 Simultaneous 95\% confidence intervals for the ratios of $\mathrm{Pu}-239+240$ concentrations, perpendiculars $\mathrm{A}$ through $\mathrm{H}$......................................................16

Table 2.6 Analysis of variance for lateral distribution of Pu-238 in the top $10 \mathrm{~cm}$....... 17

Table 2.7 Simultaneous 95\% confidence intervals for the ratios of $\mathrm{Pu}-238$ concentrations, radials one through four.

Table 2.8 Analysis of variance for lateral distribution of Am-241 in the top $5 \mathrm{~cm}$....... 18

Table 2.9 Simultaneous 95\% confidence intervals for the ratios of Am-241 concentrations, radials one through four. 18

Table 2.10 Current Arroyo Sampling Results. ${ }^{a}$......................................................................... 24

Table 2.11 Former Arroyo Seco Sampling Results. ${ }^{a}$..................................................................2 24

Table 2.12 Results of sampling inside and outside of ornamental tree wells. ${ }^{a}$................. 27

Table 2.13 Statistical significance levels of comparisons of radionuclide concentrations inside the tree wells vs. outside the tree wells.

Table 2.14 Statistical significance levels of comparisons of metal concentrations inside tree wells vs. outside tree wells.

Table 2.15 Correlation matrix of metal inside:outside tree well ratios

Table 2.16 Average $\mathrm{Pu}-239+240$ concentrations at surveillance monitoring locations and grid locations, $0-5 \mathrm{~cm}$

Table 2.17 Analysis of variance comparing surveillance monitoring locations and grid locations, $0-5 \mathrm{~cm}^{\mathrm{a}}$

Table 2.18 Simultaneous 95\% confidence intervals for the ratios of surveillance monitoring locations with grid locations, $0-5 \mathrm{~cm}$

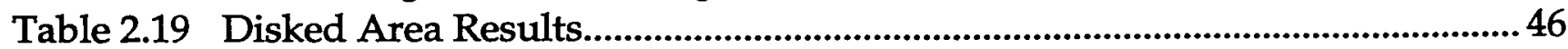

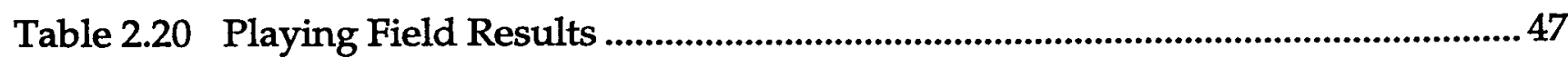

Table 2.21 Eastern Extension Results...............................................................................48 
Table 2.22 Results of Sampling at and near 1995 Location 7, 0-5 cm. 49

Table 2.23 Results of sampling at and near 1995 Location $8,0-5 \mathrm{~cm}$ .50

Table 2.24 Pu-239+240 results from special sampling, 40-85 cm depth interval. ${ }^{\mathrm{a}, \mathrm{b}}$......... 51

Table 2.25 Pu-238 results from special sampling, 40-85 cm depth interval. ${ }^{\text {a.b }}$................... 51

Table 3.1 Analytical Data Quality Objectives for $\mathrm{Pu}-239+240 \ldots \ldots \ldots \ldots \ldots \ldots \ldots \ldots \ldots \ldots \ldots . . . . . . . . .53$

Table 3.2 Analytical Data Quality Objectives for Pu-238..............................................53

Table 3.3 Intra-laboratory relative error ratio (RER) results for $\mathrm{Pu}-239+240$ for the primary laboratory, outliers removed.

Table 3.4 Inter-laboratory relative error ratio (RER) results for Pu-239+240, outliers removed.

Table 3.5 Two-sigma relative uncertainty (\%Unc) for various concentration ranges and sources of variability. ${ }^{\mathrm{a}}$.................................................................................5

Table 3.6 Analysis of Variance of Pu-238 results from field-split samples. ${ }^{a}$...................60 60

Table 3.7 Results for the EML performance evaluation samples ( $\mathrm{pCi} / \mathrm{g})$......................60

Table 3.8 Results for the NIST performance evaluation sample. ${ }^{a}$....................................61

Table 3.9 GEL NIST performance evaluation results. .................................................61

Table 3.10 Analysis of Variance of Pu-239+240 results from field-split samples. ${ }^{a}$.......... 62

Table 3.11 Comparison of sample preparation methods ${ }^{a}$...................................................6 63

Table 4.1 Pu-238: Pu-239+240 isotopic ratios of fallout-background. ${ }^{a}$............................. 65

Table 4.2 Geometric means of Pu-238: Pu-239+240 ratios of background and Big Trees

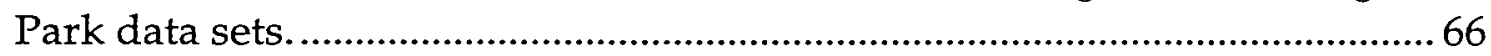

Table 4.3 1973 Results from LLNL Employee Residences. . ..............................................67

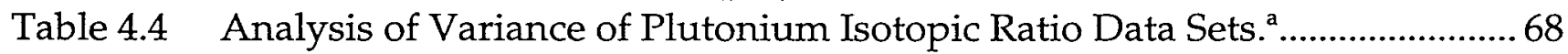

Table 4.5 Simultaneous $95 \%$ confidence intervals comparing isotopic ratio data sets.68

Table 5.1 Approximate distances from ornamental trees (center of trunk) to ornamental tree sample locations...................................................................... 70

Table 5.2 Distances from ornamental trees to grid locations.............................................. 79

Table 7.1 Results from 1993 NAREL Park Samples............................................................ 84

\section{List of Figures}

Figure 1.1 Big Trees Park and its location with respect to LLNL, Arroyo Seco, and Arroyo Seco School.

Figure 2.1 Map showing 1998 sampling locations in and near Big Trees Park................ 9

Figure 2.2 Average plutonium concentrations $(\mathrm{pCi} / \mathrm{g})$ at various depth intervals at $\mathrm{Big}$ Trees Park (error bars are one standard deviation of the mean)

Figure 2.3 Bar graphs of relative radionuclide concentrations at grid locations. Plutonium results are the averages for the $0-10 \mathrm{~cm}$ depth interval, and americium results are averages for the $0-5 \mathrm{~cm}$ depth interval........................ 14 
Figure 2.4 Geometric mean concentrations of $\mathrm{Pu}-239^{\circ}+240$ on perpendiculars $\mathrm{A}$ through $\mathrm{H}, 0-10 \mathrm{~cm}$

Figure 2.5 Photograph of the Arroyo Seco Channel Slope Walls, taken from the same location as Health Consultation Figure 6a.

Figure 2.6 Photograph of toe of Arroyo Seco slope similar to Health Consultation Figure $6 \mathrm{~b}$, showing a typical erosion pattern..................................................... 21

Figure 2.7 Arroyo Seco sampling locations, 1998.......................................................... 23

Figure 2.8 Geometric mean concentrations of Pu-239+240 from sampling-locations inside and outside tree wells. Error bars are \pm one standard error.

Figure 2.9 Tree well results for all eight analytes 29

Figure 2.10 Geometric mean concentrations of $\mathrm{Pu}-238$ from sampling locations inside and outside tree wells. Error bars are \pm one standard error.

Figure 2.11 Geometric mean concentrations of Am-241 from sampling locations inside and outside tree wells. Error bars are \pm one standard error.

Figure 2.12 Geometric mean concentrations of Am-241 from sampling locations inside and outside tree wells, omitting two suspect results. Error bars are \pm one standard error.

Figure 2.13 Average concentrations of chromium from sampling locations inside and outside of tree wells. Error bars are \pm one standard error.

Figure 2.14 Average concentrations of copper from sampling locations inside and outside of tree wells. Error bars are \pm one standard error.

Figure 2.15 Average concentrations of lead from sampling locations inside and outside of tree wells. Error bars are \pm one standard error.

Figure 2.16 Average concentrations of nickel from sampling locations inside and outside of tree wells. Error bars are \pm one standard error.

Figure 2.17 Average concentrations of zinc from sampling locations inside and outside of tree wells. Error bars are \pm one standard error.

Figure 2.18 Pu-239+240 concentrations measured at grid locations on Radial 1 and in tree wells. Tree samples were collected at $0-45 \mathrm{~cm}$ depth intervals and grid samples were normalized to the same depth interval.

Figure 2.19 Correlation between copper ratios and chromium ratios.................................38

Figure 2.20 Correlation between nickel ratios and zinc ratios.........................................38

Figure 2.21 Monthly resuspension of Pu-239+240 and wind direction data, 1992 through 1996.41

Figure 2.22 Monthly average resuspension of $\mathrm{Pu}-239+240$ and wind direction data, 1992 through 1996.

Figure 2.23 Soil surveillance monitoring locations near to and west and northwest of LLNL.

Figure 2.24 Comparison of surveillance monitoring locations with grid locations, 0-5 cm. 44 
Figure 3.1 Comparison of CES with GEL and GIT Pu-238 field-split results. 59

Figure 4.1 Pu-238: Pu-239+240 ratios of Big Trees Park, fallout-background, and residence samples, decay corrected to September 1998. .66

Figure 5.1 Schematic diagram of borehole locations at Trees 2 and 3 ............................ 72

Figure 5.2 Schematic diagram of borehole locations at Trees 4 and 5 ............................ 73

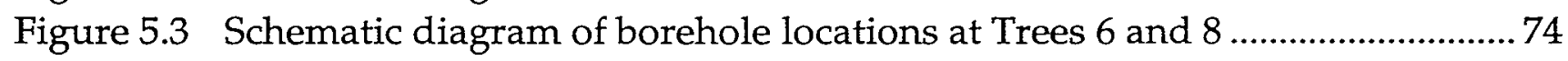

Figure 5.4 Schematic diagram of borehole locations at Trees 11 and 12 ........................ 75

Figure 5.5 Schematic diagram of borehole locations at Trees 14 and 15 .........................76

Figure 5.6 Photograph of borehole inside the tree well at Tree 8 ...................................77

Figure 5.7 Photograph of borehole being drilled inide the tree well at Tree 2 $2 \ldots \ldots \ldots \ldots . . . . . .78$

Figure 6.1 $1995 \mathrm{Pu}-239+240$ Split Sample Results.............................................................. 80

Figure 6.2 $1998 \mathrm{Pu}-239+240$ Split Sample Results............................................................. 83 


\section{Introduction}

This report is an in-depth study of results from environmental sampling conducted in 1998 by the Lawrence Livermore National Laboratory (LLNL) at Big Trees Park in the city of Livermore. The purpose of the sampling was to determine the extent and origin of plutonium found in soil at concentrations above fallout-background levels in the park. ${ }^{1}$

This report describes the sampling that was conducted, the chemical and radio-chemical analyses of the samples, the quality control assessments and statistical analyses of the analytical results, and LLNL's interpretations of the results. It includes a number of data analyses not presented in LLNL's previous reports on Big Trees Park.

\subsection{Background}

Big Trees Park is a 4.23-acre public park in the city of Livermore located about one-half mile west of LLNL (see Figure 1.1). Plutonium was discovered at higher-than-expected but below levels-of-health-concern concentrations in Big Trees Park soil in 1993 during a U.S. Environmental Protection Agency (EPA) check of background plutonium values in the vicinity of LLNL (NAREL, 1994). In 1995, LLNL, in collaboration with EPA, state regulators, and the public, collected additional soil samples from Big Trees Park to verify the 1993 finding and evaluate any potential hazards to the public (LLNL, 1998).

After this 1995 sampling, the EPA and the California Department of Health Services, Radiologic Health Branch (CDHS-RHB) concluded that the plutonium in soil at Big Trees Park was below the EPA residential preliminary remediation goal (PRG; 2.5 picocuries per gram $[\mathrm{pCi} / \mathrm{g}])$, presented "no unacceptable risk to human health," and required no further action (EPA, 1995).

In February, 1998 a draft health consultation prepared by the California Department of Health Services, Environmental Health Investigations Branch (CDHS-EHIB), under contract with the federal Agency for Toxic Substances and Disease Registry (ATSDR), suggested further sampling (CSHS-EHIB, 1998). LLNL volunteered to conduct additional sampling and analysis and to work with the regulatory agencies to ensure public concerns were addressed. In August and September 1998, soil samples were collected in Big Trees Park

\footnotetext{
${ }^{1}$ Those wishing more background information, a copy of LLNL's companion summary report "LLNL Big Trees Park Summary Results" (Gallegos et al., 1999), or other related reports, may go to http://wwwenvirinfo.llnl.gov and find the section "Off-site Environmental Studies," or contact LLNL Environmental Community Relations at 925-424-4026.
} 
using a sampling plan developed with public and regulatory input. The sampling plan was formally approved by the U.S. EPA and the California Department of Health Services, Radiologic Health Branch (LLNL, 1998).

The 1998 sampling project addressed Recommendation 1 of the draft health consultation by determining the vertical and lateral extent of plutonium-239+240 in soil in the park. It also provided data with which to evaluate the likelihood of each of three potential pathways-arroyo water-borne, sewage sludge used as a soil amendment, and aerial distribution-proposed in the draft health consultation as ways plutonium could have reached the park.

In addition to Big Trees Park, sampling was conducted at (1) an area adjacent to the park that is disked annually for weed abatement (the "disked area"); (2) an area behind the Arroyo Seco Elementary School, which is immediately west of the park (the "playing field"); (3) the eastern extension of Big Trees Park; and (4) three locations (1, 7, and 8) identified in 1995 as having concentrations of plutonium in soil above or possibly above fallout-background levels (see Figure 1.1 and Figure 2.1). The number of samples collected in the "disked area" was increased from the draft plan in response to public concerns.

The final version of the CDHS-EHIB health consultation was released in May, 1999 (CDHSEHIB, 1999).

ATSDR headquarters released its final pathway analysis in January 2000. This report states that "...the most credible pathway by which plutonium radioisotopes reached Big Trees Park was the application of plutonium contaminated sewage sludge as a soil amendment" and that "no other pathway appears to be a viable pathway for the presence of plutonium in the park" (ATSDR, 2000).

Both reports reiterated that the levels of plutonium found in the park soil are below levels of health concern.

A chronology of events, including the development of Big Trees Park and the various sampling efforts at the park, is presented in Table 1.1. 


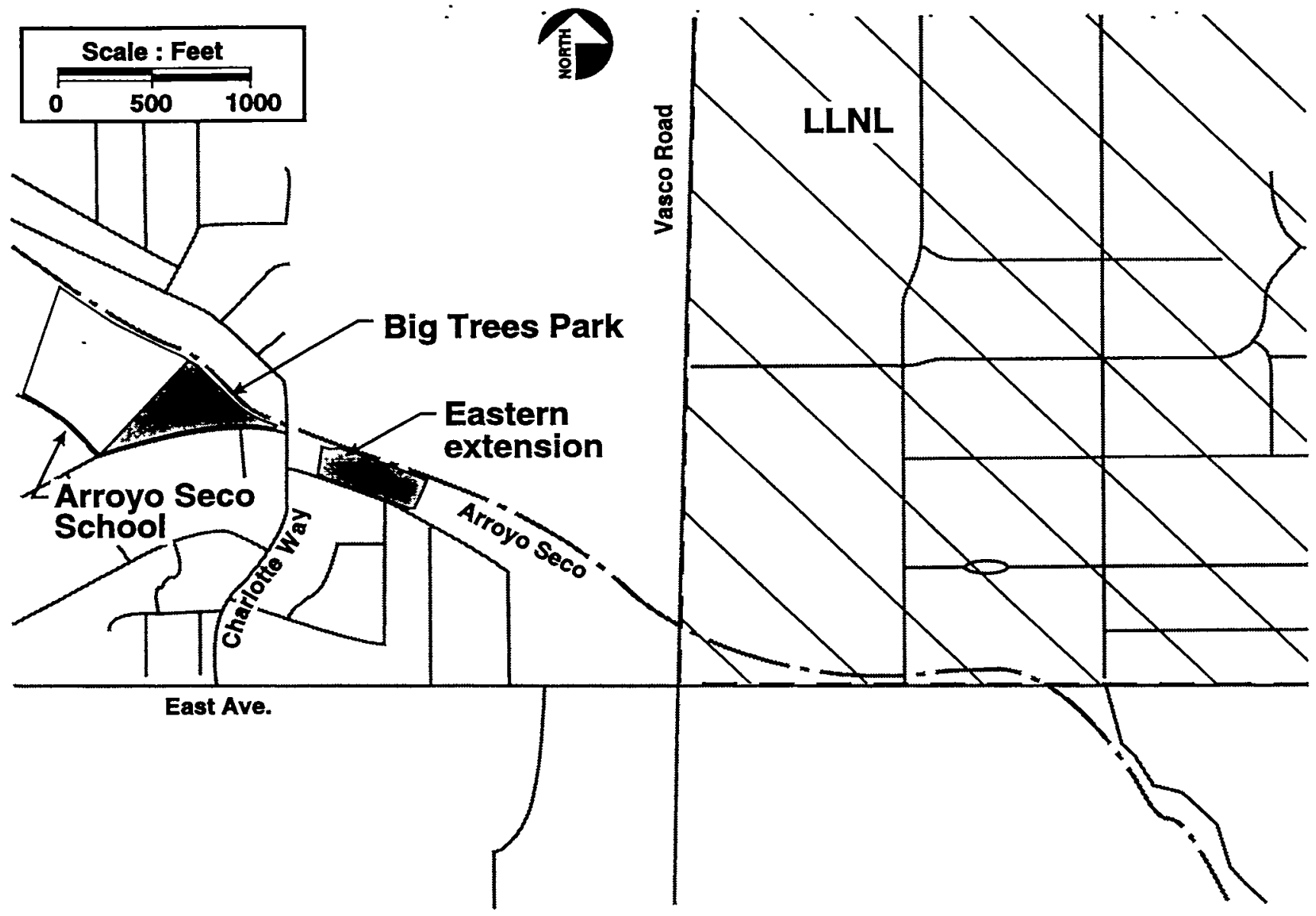

ERD-LSR-98-0156

Figure 1.1 Big Trees Park and its location with respect to LLNL, Arroyo Seco, and Arroyo Seco School. 
Table 1.1 Chronology of events at Big Trees Park.

\begin{tabular}{|c|c|c|}
\hline Date & Activity & Source \\
\hline July 17,1969 & $\begin{array}{l}\text { Property, which becomes Big Trees Park, deeded to City of } \\
\text { Livermore. }\end{array}$ & $\begin{array}{l}\text { County Tax Assessor's } \\
\text { map and Metroscan }^{\mathrm{a}}\end{array}$ \\
\hline 1970 & $\begin{array}{l}\text { New Arroyo Seco channel excavated and concrete lined } \\
\text { from just east of Charlotte Way to connect the already } \\
\text { concrete-lined arroyo west of Big Trees Park. }\end{array}$ & $\begin{array}{l}\text { Kaufman and Broad } \\
1969,1970\end{array}$ \\
\hline 1970 & $\begin{array}{l}\text { Excavation for the new concrete-lined arroyo generates } \\
\text { approximately } 9500 \text { cubic yards of excess soil. }\end{array}$ & $\begin{array}{l}\text { R. M. Galloway and } \\
\text { Associates, } 1970\end{array}$ \\
\hline 1970 & $\begin{array}{l}\text { Excess soil generated from preparing roadbeds for street } \\
\text { construction and lots for foundations was stockpiled in the } \\
\text { area that would become the park. }\end{array}$ & $\begin{array}{l}\text { R. M. Galloway and } \\
\text { Associates, } 1970\end{array}$ \\
\hline 1969-1970 & Subdivision graded per city specifications. & $\begin{array}{l}\text { Kaufman and Broad } \\
1969,1970\end{array}$ \\
\hline Mar 23, 1971 & $\begin{array}{l}\text { Concrete-lined portion of arroyo deeded to Alameda County } \\
\text { Flood Control and Water Conservation District Zone } 7 .\end{array}$ & $\begin{array}{l}\text { County Tax Assessor's } \\
\text { map and Metroscan }\end{array}$ \\
\hline $\begin{array}{l}\text { April and June } \\
1971\end{array}$ & $\begin{array}{l}\text { Big Trees Park constructed per the terms of the LARPD }{ }^{b} \text { for } \\
\text { the installation of the irrigation system and turf. No imported } \\
\text { fill or soils other than fertilizer were to be used in installing } \\
\text { the irrigation system and turf. }\end{array}$ & LARPD, 1971 \\
\hline 1972 & $\begin{array}{l}\text { No trees are apparent adjacent to the south side of the } \\
\text { concrete-lined portion of the arroyo. }\end{array}$ & Aerial photograph, 1972 \\
\hline $1970-1972$ & Arroyo Seco Elementary School constructed. & $\begin{array}{l}\text { Aerial photos of the area } \\
1970 \text { and } 1972\end{array}$ \\
\hline 1975 & $\begin{array}{l}\text { Trees are apparent adjacent to the south side of the } \\
\text { concrete-lined portion of the Arroyo Seco channel. }\end{array}$ & $\begin{array}{l}\text { Aerial photos of the area } \\
1975\end{array}$ \\
\hline 1986 & $\begin{array}{l}\text { Play area and picnic tables upgraded. LARPD indicates that } \\
\text { sand was brought in and gravel and soil from the older, } \\
\text { smaller play area (dimensions not defined) was removed to } \\
\text { make room for the larger play area. }\end{array}$ & $\begin{array}{l}\text { Ingledue, 1997, } 1998 \\
\text { LARPD drawing, } 1988\end{array}$ \\
\hline 1986 & Big Trees Park eastern extension was constructed. & $\begin{array}{l}\text { Ingledue, } 1997,1998 \\
\text { Aerial photograph, } 1985\end{array}$ \\
\hline 1988 & Asphalt added to improve Big Trees Park paths. & LARPD drawing, 1988 \\
\hline 1993 & $\begin{array}{l}\text { EPA collects a background sample from Big Trees Park that } \\
\text { exceeds plutonium- } 239+240 \text { global fallout-background } \\
\text { levels for this area. }\end{array}$ & NAREL, 1994 \\
\hline Oct-Dec 1994 & $\begin{array}{l}\text { LLNL meets with and develops sampling plan with } \\
\text { representatives of a homeowner's association near the } \\
\text { park, City of Livermore, Livermore schools, LARPD, EPA, } \\
\text { CDHS-RHB, and others. }\end{array}$ & $\begin{array}{l}\text { EPA, 1995; } \\
\text { McConachie, } 1998\end{array}$ \\
\hline
\end{tabular}

a Commercial online service for determination of property ownership.

b Livermore Area Recreation and Park District. 
Table 1.1 Chronology of events at Big Trees Park (continued)

\begin{tabular}{|c|c|c|}
\hline Date & Activity & Source \\
\hline Jan 1995 & $\begin{array}{l}\text { LLNL samples soil in Big Trees Park, Big Trees eastern } \\
\text { extension, schoolyard, and vicinity. Samples split with EPA } \\
\text { and CDHS-RHB for independent analyses. }\end{array}$ & MacQueen, 1995 \\
\hline July 1995 & $\begin{array}{l}\text { LLNL report published and distributed. Pathway for } \\
\text { plutonium from LLNL to park not definitive. All plutonium } \\
\text { concentrations less than EPA residential preliminary } \\
\text { remediation goal (PRG, } 2.5 \mathrm{pCi} / \mathrm{g} \text { ). }\end{array}$ & MacQueen, 1995 \\
\hline Sept 1995 & $\begin{array}{l}\text { EPA fact sheet on plutonium published-"The levels of } \\
\text { plutonium detected off site do not pose an unacceptable risk } \\
\text { to local residents." }\end{array}$ & EPA, 1995 \\
\hline Feb 1998 & $\begin{array}{l}\text { CDHS-EHIB recommends that LLNL sample deeper and } \\
\text { investigate pathways. }\end{array}$ & CDHS-EHIB 1998, 1999 \\
\hline $\begin{array}{l}\text { Feb-Aug } \\
1998\end{array}$ & $\begin{array}{l}\text { In response to regulator recommendations, LLNL develops } \\
\text { a sampling plan with the cognizant regulatory agencies and } \\
\text { stakeholder input. }\end{array}$ & LLNL, 1998; Liddle, 1998 \\
\hline $\begin{array}{l}\text { Aug and } \\
\text { Sept } 1998\end{array}$ & $\begin{array}{l}\text { Samples collected at Big Trees Park in accordance with } \\
\text { negotiated sampling plan. }\end{array}$ & LLNL, 1998 \\
\hline Feb 1999 & $\begin{array}{l}\text { EPA finds "no unacceptable risk" from plutonium levels at } \\
\text { Big Trees Park. All plutonium concentrations less than EPA } \\
\text { residential preliminary remediation goal (PRG, } 2.5 \mathrm{pCi} / \mathrm{g} \text { ). }\end{array}$ & Heffner, 1999 \\
\hline May 1999 & CDHS-EHIB releases final health consultation. & CDHS-ÉHIB; 1998/1999 \\
\hline Sept 1999 & $\begin{array}{l}\text { LLNL releases summary report of } 1998 \text { sampling results. } \\
\text { ldentifies sewage sludge as the most likely pathway. }\end{array}$ & Gallegos et al., 1999 \\
\hline Jan 2000 & $\begin{array}{l}\text { ATSDR releases final report with results of pathway } \\
\text { analysis. Selects sewage sludge as most likely pathway, } \\
\text { and concludes that no further work regarding plutonium from } \\
\text { sewage sludge in Big Trees Park or elsewhere is necessary. }\end{array}$ & ATSDR, 2000 \\
\hline
\end{tabular}

- Califomia Department of Health Services, Radiologic Health Branch 


\section{Sampling}

The sampling strategy was based on choosing sample locations and analytes that would provide data to (1) determine the vertical and lateral extent of plutonium in soil at Big Trees Park, (2) determine the most likely plutonium distribution pathway, and (3) add data at locations identified in 1995 as exhibiting plutonium concentrations in soil that were above or possibly above fallout-background concentrations.

Samples were collected, handled, and analyzed as specified in the sampling plan (LLNL, 1998; Liddle, 1998).

A summary of sampling locations, numbers of samples collected, sampling depths, and analytes is presented in Table 2.1. Sampling locations within Big Trees Park are shown in Figure 2.1. Section 5 contains additional information about sample collection.

All samples were analyzed for plutonium isotopes ( $\mathrm{Pu}-239+240$ and $\mathrm{Pu}-238)$. Some samples were analyzed for americium-241 (Am-241) because it was reported to have been a constituent of the 1967 release, and because it is a decay product of plutonium241 , which is present in fallout and in weapons-grade plutonium. Some samples were analyzed for five metals typically found in municipal sewage sludge.

After the analytical results were received in late November of 1998, the EPA, ATSDR, and LLNL evaluated the quality control data and concluded that the data were appropriate for determining the levels of plutonium in soil at the park and for making decisions about public health and safety (Eidelberg, 1998).

In summarizing the data for this report, the following conventions were followed.

- A detectable quantity was defined as a measured result larger than the measured uncertainty (two standard deviations), even if the measured result was below the analytical minimum detectable concentration reported by the analytical laboratory or the detection limit specified in the sampling plan.

- Unless otherwise indicated, where samples collected at any given location were split, an average of the values of the splits, whether analyzed by the same or different analytical laboratories, was used to represent the location.

- Average values were calculated using both detectable and non-detectable quantities; that is, in calculating averages for split samples or for any data set, all measured results, including those identified as non-detectable, were used (DOE, 1991; Gilbert, 1987). 
- The radiological counting uncertainty associated with individual results has been omitted from some tables in order to fit all of the results on a single page. ${ }^{1}$

- The uncertainty among analytical laboratories was similar; no one laboratory was noticeably more precise, and consideration of analytical uncertainty does not change any of the conclusions reached in the report.

An approximate upper limit for fallout-background in the Livermore Valley for $\mathrm{Pu}-239+240$ was defined as $0.012 \mathrm{pCi} / \mathrm{g}$, which is the $80 \%$ upper confidence level on the 95th percentile of annual surveillance data upwind of the LLNL Livermore site (LLNL, 1998, Appendix D). This estimate is consistent with other estimates of global fallout-background for similar latitudes in the Northern Hemisphere (EPRI 1981, HASL 1975, Perkins and Thomas 1980, EPA 1994b, Kim et al. 1998). In addition, this estimate is based on sampling and analytical protocols that are designed to measure atmospheric deposition (Tate et al., 1999). It is therefore conservative, i.e., lower, than would be expected from point-samples as requested by the regulatory agencies for the Big Trees Park sampling.

Note that human exposure to natural radiation from all sources is at least 10,000 to 100,000 times greater than exposure due to plutonium from global fallout (see Appendix 3).

\footnotetext{
${ }^{1}$ A complete data listing, including uncertainties, is available at http://www-envirinfo.llnl.gov in the section "Off-site Environmental Studies," or upon request from LLNL Environmental Community Relations at 925-424-4026.
} 
Table 2.1 Big Trees Park sampling plan.

\begin{tabular}{|c|c|c|c|c|c|}
\hline $\begin{array}{c}\text { Sample } \\
\text { set }\end{array}$ & Analytes ${ }^{a}$ & $\begin{array}{l}\text { Potential } \\
\text { pathways }\end{array}$ & $\begin{array}{c}\text { Depths } \\
(\mathrm{cm})\end{array}$ & $\begin{array}{c}\text { Number of } \\
\text { locations }\end{array}$ & $\begin{array}{c}\text { Number of } \\
\text { samples }\end{array}$ \\
\hline $\begin{array}{l}\text { Current arroyo } \\
\text { channel }\end{array}$ & $\mathrm{Pu}$ & Water & $\begin{array}{l}0-5 \\
0-25\end{array}$ & $\begin{array}{l}2 \text { LLNL } \\
1 \text { SNL } \\
2 \text { Near park } \\
2 \text { Downstream }\end{array}$ & 7 \\
\hline Old arroyo channel & $\mathrm{Pu}$ & Water & $0-15$ & 3 & 3 \\
\hline Ornamental trees & $\begin{array}{c}\text { Am } \\
\text { Pu } \\
\text { Metals }\end{array}$ & $\begin{array}{c}\text { Air } \\
\text { Water } \\
\text { Sludge }\end{array}$ & $\begin{array}{c}0-45 \\
45-90 \\
90-135\end{array}$ & $\begin{array}{c}20 \\
(10 \text { trees, } 2 \\
\text { locations per tree) }\end{array}$ & 60 \\
\hline Grid & $\begin{array}{c}\text { Pu } \\
\text { Am }(0-5 \mathrm{~cm}) \\
\text { Metals } \\
\text { (3 locations) }\end{array}$ & $\begin{array}{l}\text { Air } \\
\text { Water } \\
\text { Sludge }\end{array}$ & $\begin{array}{c}0-5 \\
5-10 \\
10-20 \\
20-30 \\
30-40\end{array}$ & 30 & 150 \\
\hline $\begin{array}{l}\text { Special sampling } \\
\text { at } 1995 \\
\text { Locations } 1,7 \text {, and } 8\end{array}$ & $\begin{array}{c}\mathrm{Pu} \\
\text { Am (Location } 1 \text { at } \\
0-5 \mathrm{~cm} \text { ) } \\
\text { Metals (Locations } \\
7 \& \text { 8) }\end{array}$ & $\begin{array}{c}\text { Air } \\
\text { Water } \\
\text { Sludge }\end{array}$ & $\begin{array}{c}0-5 \\
5-10 \\
10-20 \\
20-30 \\
30-40 \\
40-85 \\
\end{array}$ & $\begin{array}{l}8 \text { (Location 1) }^{\mathrm{b}} \\
1 \text { (Location } 7) \text { (Location } 8)\end{array}$ & 60 \\
\hline $\begin{array}{l}\text { Special sampling of } \\
\text { disked area }\end{array}$ & $\begin{array}{c}\mathrm{Pu} \\
\text { Metals } \\
\text { (1 location) } \\
\end{array}$ & $\begin{array}{l}\text { Water } \\
\text { Air }\end{array}$ & $0-15$ & 4 & 4 \\
\hline $\begin{array}{l}\text { Special sampling of } \\
\text { playing field }\end{array}$ & $\mathrm{Pu}$ & $\begin{array}{c}\text { Air } \\
\text { Water }\end{array}$ & $\begin{array}{c}0-5 \\
5-10 \\
10-20 \\
20-30 \\
30-40\end{array}$ & 2 & 10 \\
\hline $\begin{array}{l}\text { Special sampling of } \\
\text { Big Trees eastern } \\
\text { extension }\end{array}$ & $\mathrm{Pu}$ & $\begin{array}{c}\text { Air } \\
\text { Water }\end{array}$ & $\begin{array}{c}0-5 \\
5-10 \\
10-20 \\
20-30 \\
30-40\end{array}$ & 3 & 15 \\
\hline & & & & Total & $309^{c}$ \\
\hline
\end{tabular}

a Analytes are plutonium (Pu-239+240 and Pu-238), americium-241 (Am-241), and metals (chromium, copper, lead, nickel, and zinc).

b Samples could not be collected at $20-30 \mathrm{~cm}, 30-40 \mathrm{~cm}$, or $40-85 \mathrm{~cm}$ at one of the locations due to lack of sample integrity.

c In addition to these 309 samples, ten percent of the total number of sample locations had an associated collocated sample for quality control. Nine locations were selected for field splits (see Section 2.3.5). 


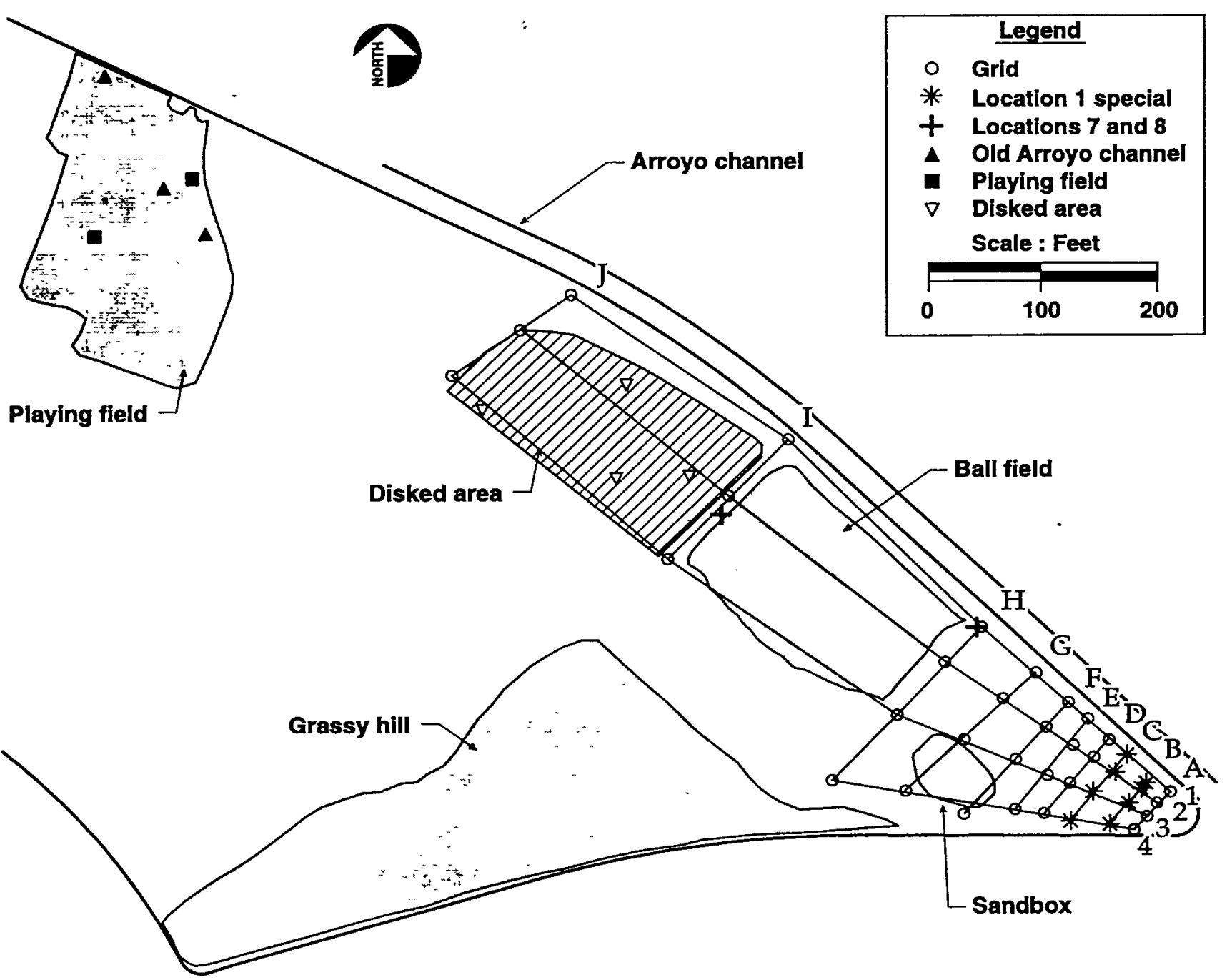

ERD-LSR-99-0067

\section{Figure 2.1 Map showing 1998 sampling locations in and near Big Trees Park.}

\subsection{Extent of Plutonium at Big Trees Park}

Sampling to determine the extent of plutonium at levels above fallout-background was conducted on a grid consisting of 4 radial lines (1-4) and 10 perpendicular cross lines (A-J) shown in Figure 2.1.

For ease of discussion in this document and to underscore that the Location 1 special sampling (perpendiculars $B$ and $C$ ) was also part of the grid sampling, the grid locations are identified in this report by radial (1-4) and perpendicular (A-J), rather than the location naming system used in the sampling plan.

Radial 1 was cast parallel to and about 3 feet from the concrete-lined arroyo channel at the northern edge of the park. The cross lines were drawn perpendicular to Radial 1 and 
the channel where possible. Perpendiculars were placed at gradually increasing intervals with the result that sampling was densest in the southeast corner of the park around 1995 Location 1, where the highest concentrations of plutonium had been found during previous samplings. Physical obstructions sometimes dictated the sample location.

Radial 1 was in roughly line with the trunks of the ornamental trees that grow next to the arroyo channel. Every Radial 1 sample location was within 13 feet of an ornamental tree, and with one exception, was placed between two adjacent trees (the exception, Location $1 \mathrm{~B}$, was moved because the planned location was inaccessible; see Figure 2.3 and Section 5.2). The grid was mapped in this way to encompass 1995 sampling Locations 1, 7, and 8, which had the highest plutonium concentrations in the 1995 study, and to include the ornamental trees, which were important in testing the "sludge pathway hypothesis" (see Section 2.2.2). The 1995 Location 1 and 7 samples were within about 10 feet of an ornamental tree, so that the 1998 Radial 1 samples and the 1995 Location 1 samples are similarly located relative to the trees.

\subsubsection{Data Analysis and Interpretation}

Plutonium-239+240 activity data are displayed in Table 2.2 in entries that correspond to the place on the sample grid where the sample was collected. Analytical uncertainties are omitted from Table 2.2 in order to conserve space. Similar tables for Pu-238 and Am241 are provided in Appendix 6. Results from eight samples collected from the 40-85 cm depth interval on the grid are listed in Section 2.3.4 and omitted from Table 2.2. Results from split samples were averaged for presentation in Table 2.2.

These data fall into four categories: non-detections (italics), detections within the range of fallout-background (regular typeface), detections above the $0.012 \mathrm{pCi} / \mathrm{g}$ falloutbackground determined from annual surveillance data (boldface), and detections of the same order of magnitude as the initial (1993) EPA sample result for the park of 0.16 $\mathrm{pCi} / \mathrm{g}$ (shaded entries).

The data patterns in Table 2.2 indicate the vertical and lateral distribution of Pu- $239+240$ on the sample grid.

\subsubsection{Depth Distribution}

Radiochemical analysis showed that of the 195 samples collected on the grid (188 shown in Table 2.2 plus seven from below $40 \mathrm{~cm}$ ), 18 of the $0-5 \mathrm{~cm}$ samples yielded Pu-239+240 concentrations above fallout-background (i.e., greater than $0.012 \mathrm{pCi} / \mathrm{g}$ ). Nine of the 5-10 cm samples were above fallout-background, and only three samples collected below $10 \mathrm{~cm}$ (locations 1B 30-40 cm, 1E 10-20 cm, and 2H 10-20 cm) were above fallout-background (see Table 2.2 and Table 2.24). Figure 2.2, which shows 
average plutonium concentrations plotted for the different depth intervals, shows that plutonium levels dropped steeply at depths greater than $10 \mathrm{~cm}$ (split samples were averaged first, before calculating the average for each depth interval).

Consequently, the above-fallout-background plutonium levels are confirmed to be at or near the surface. Because above-fallout-background plutonium values were found only rarely, and not in any pattern at depth, the averages of the samples collected at $0-5 \mathrm{~cm}$ and $5-10 \mathrm{~cm}$ were used to assess the lateral extent of plutonium concentrations in the next section. 
Table 2.2 Plutonium-239+240 concentration values for samples taken in 1998 on a grid at Big Trees Park. ${ }^{a}$ Values in shaded boxes are the highest measured activities. Values in boldface type are above $0.012 \mathrm{pCi} / \mathrm{g}$ fallout-background; those in regular typeface are detections at fallout-background level; and those in italic are nondetections. (See Section 2.1.1 for discussion.)

\begin{tabular}{|c|c|c|c|c|c|c|c|c|c|c|c|}
\hline \multirow{3}{*}{ Radial } & \multirow{3}{*}{$\begin{array}{c}\text { Depth } \\
\text { interval } \\
\text { (cm) }\end{array}$} & \multicolumn{10}{|c|}{ Plutonium-239+240 concentration $(\mathrm{pCi} / \mathrm{g})$} \\
\hline & & \multicolumn{10}{|c|}{ Perpendicular ${ }^{b}$} \\
\hline & & J & I & $\mathbf{H}$ & $\mathbf{G}$ & $\mathbf{F}$ & $\mathbf{E}$ & $\mathbf{D}$ & C & B & A \\
\hline \multirow[t]{5}{*}{1} & $0-5$ & 0.042 & $0.12=1$ & 0.28 & 0.32 & $0.64^{-}$ & 0.59 & 0.30 & 0.020 & 0.012 & 0.14 \\
\hline & $5-10$ & -0.00028 & 0.17 & 0.17 & 0.24 & 0.27 & 0.77 & 0.00048 & 0.00023 & 0.035 & -0.00090 \\
\hline & $10-20$ & 0.0012 & 0.0086 & 0.012 & 0.012 & 0.010 & 0.025 & 0.00075 & 0.00081 & 0.0057 & -0.0011 \\
\hline & $20-30$ & -0.00014 & 0.0035 & 0.0051 & 0.0025 & 0.0014 & -0.00014 & -0.00027 & -0.000063 & 0.0011 & 0.0003 \\
\hline & $30-40$ & -0.00014 & 0.0031 & 0.0012 & 0.0022 & 0.0011 & -0.00085 & -0.00047 & -0.000067 & 0.013 & 0.0015 \\
\hline \multirow[t]{5}{*}{2} & $0-5$ & 0.0016 & 0.0084 & 0.023 & 0.0014 & 0.028 & 0.015 & 0.0057 & 0.010 & 0.0078 & 0.0053 \\
\hline & $5-10$ & 0.0011 & 0.012 & 0.32 & 0.012 & -0.000047 & 0.000094 & 0.0040 & -0.000059 & 0.0068 & 0.0026 \\
\hline & $10-20$ & 0.0010 & 0.010 & 0.12 & 0.00080 & 0.000041 & 0.0010 & 0.0023 & 0.0016 & 0.0048 & -0.000093 \\
\hline & $20-30$ & 0.0026 & 0.00030 & 0.0031 & 0.00071 & 0.00084 & -0.000046 & 0.0 & 0.00025 & 0.0025 & 0.00044 \\
\hline & $30-40$ & 0.00030 & 0.00062 & 0.00091 & 0.00072 & 0.000090 & 0.0023 & 0.00097 & -0.00053 & 0.00024 & 0.00081 \\
\hline \multirow[t]{5}{*}{3} & $0-5$ & 0.001 & 0.004 & 0.031 & 0.0028 & 0.027 & 0.0092 & 0.0037 & 0.011 & 0.037 & -0.00081 \\
\hline & $5-10$ & 0.0018 & 0.0028 & 0.00059 & 0.015 & -0.00051 & 0.01 & 0.0033 & 0.0041 & -0.00041 & -0.0015 \\
\hline & $10-20$ & -0.00050 & -0.0016 & -0.00052 & 0.0097 & -0.000050 & 0.000065 & 0.0076 & 0.00045 & 0.00026 & -0.0015 \\
\hline & $20-30$ & 0.0018 & 0.0010 & -0.0014 & 0.0024 & 0.0052 & -0.00058 & 0.0050 & 0.00022 & $c$ & -0.00030 \\
\hline & $30-40$ & 0.00085 & 0.00023 & -0.00018 & 0.0 & 0.0050 & -0.00067 & 0.00019 & -0.00036 & c & -0.0015 \\
\hline \multirow[t]{5}{*}{4} & $0-5$ & d & d & 0.21 & 0.029 & 0.0077 & 0.0048 & 0.00068 & 0.0028 & 0.022 & 0.0053 \\
\hline & $5-10$ & d & $d$ & 0.090 & 0.0025 & 0.0049 & 0.0093 & 0.00093 & 0.0034 & 0.0067 & 0.0055 \\
\hline & $10-20$ & d & d & 0.0082 & 0.0067 & 0.00066 & -0.00089 & 0.00053 & 0.00082 & 0.000053 & 0.00055 \\
\hline & $20-30$ & d & $d$ & 0.00097 & 0.0031 & 0.0046 & 0.00055 & 0.000019 & 0.0019 & 0.00073 & 0.0021 \\
\hline & $30-40$ & d & d & 0.0086 & 0.0 & 0.0050 & 0.0036 & 0.00079 & 0.00039 & -0.000072 & -0.00063 \\
\hline
\end{tabular}

Note: Sampling plan locations G0101-G0401 are assigned 1A-4A; L1S01-L1S04 are assigned 1B-4B; L1S05-L1S08 are assigned 1C-4C; G0102-G0402 are assigned 1D-4D; G0103-G0403 are assigned 1E-4E; G0104-G0404 are assigned 1F-4F; G0105-G0405 are assigned 1G-4G; G0106-G0406 are assigned 1H-4H; G0107-G0307 are assigned 1l-3l; and G0108-G0308 are assigned $1 \mathrm{~J}-3 \mathrm{~J}$

a See Figure 2.1 for a map of sample locations.

b Perpendiculars are listed in reverse alphabetical order to correspond with the physical pattern of the sample locations at the park. See Figure 2.1.

c Lack of core integrity prevented a sample from being obtained.

d No sample planned at this location. 


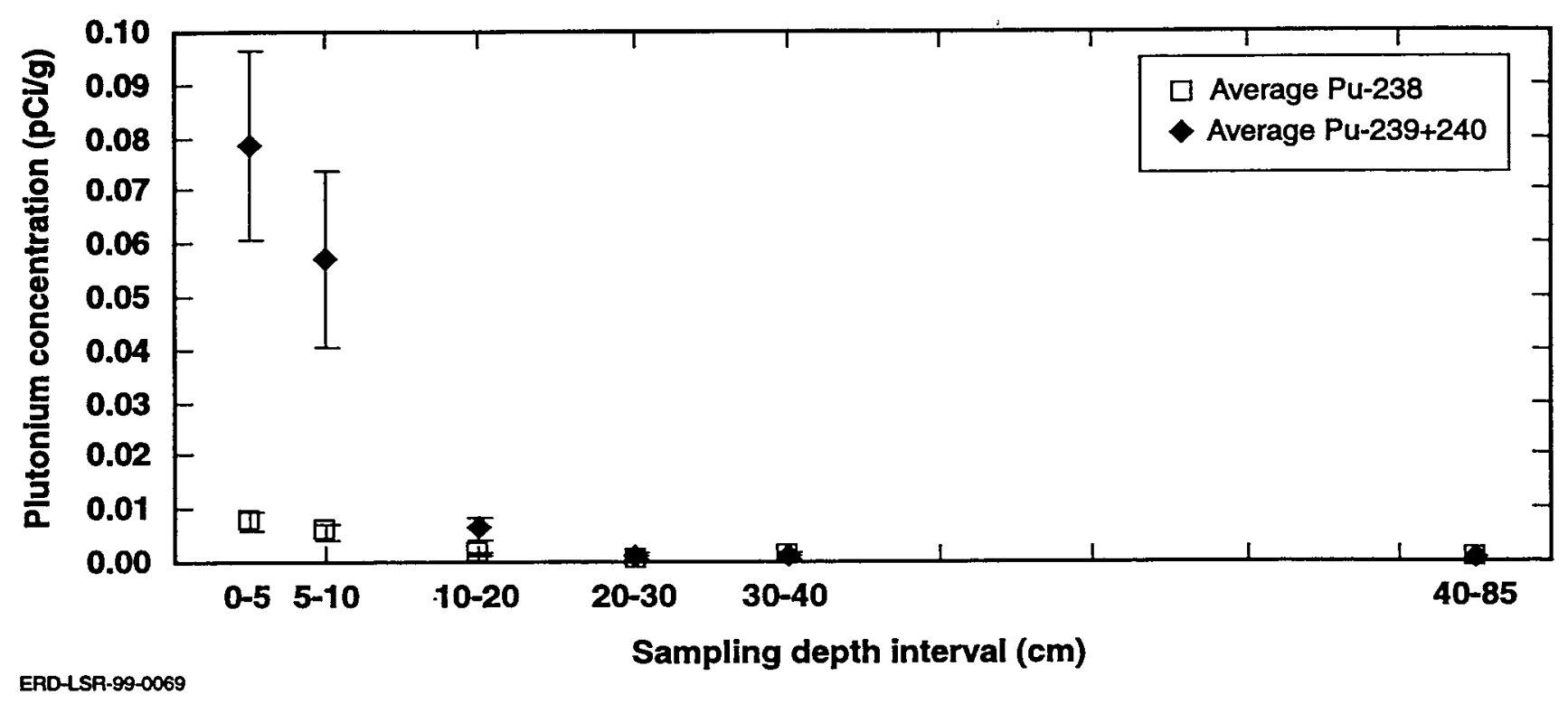

Figure 2.2 Average plutonium concentrations $(\mathrm{pCi} / \mathrm{g})$ at various depth intervals at Big Trees Park (error bars are one standard deviation of the mean).

\subsubsection{Lateral Distribution}

The data show a distinctly higher level of plutonium along Radial 1 closest to the ornamental trees (see Table 2.2). Bar graphs of radionuclide concentrations (relative to the maximum concentration) drawn on the grid in Figure 2.3 clearly depict the higher concentrations along Radial 1 . Elevated $\mathrm{Pu}-239+240$ concentrations also occur along grid perpendicular $\mathrm{H}$, especially at $1 \mathrm{H}$ and $4 \mathrm{H}$. 


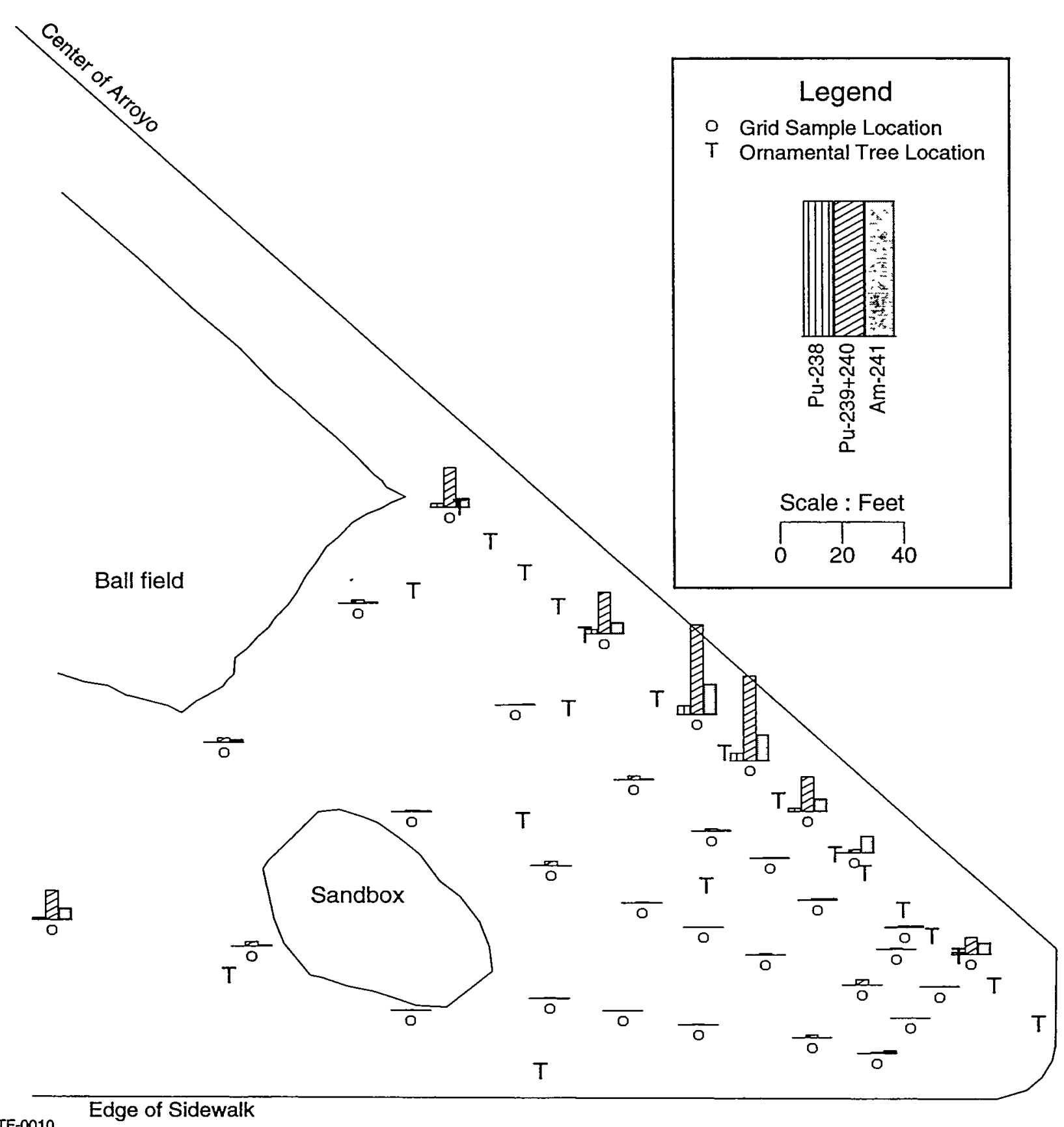

BTF-0010

$$
\text { Edge of Sidewalk }
$$

Figure 2.3 Bar graphs of relative radionuclide concentrations at grid locations'. Plutonium results are the averages for the $0-10 \mathrm{~cm}$ depth interval, and americium results are averages for the $0-5 \mathrm{~cm}$ depth interval.

\footnotetext{
${ }^{1}$ When necessary, sample locations were adjusted from planned grid locations due to physical obstructions.
} 
Statistical analysis of the grid results in the southeast section of the park (the portion shown in Figure 2.3) shows that the four radials have differences (in the top $10 \mathrm{~cm}$ ) that can not be attributed to a random distribution of $\mathrm{Pu}-239+240$ in the grid area. The test comparing the geometric means of the radials is highly significant $(p \leq 0.000068$, see Table 2.3). Further examination with a statistical multiple comparison procedure shows that Radial 1 has a greater concentration than radials 2,3, and 4 (by factors of about 12 to 19), and that radials 2 through 4 are not significantly different from each other (see Table 2.4). ${ }^{1}$

Table 2.3 Analysis of variance for the lateral distribution of Pu-239+240 in the top $10 \mathrm{~cm}$ :

\begin{tabular}{cccccc}
\hline Factor & $\begin{array}{c}\text { Degrees of } \\
\text { Freedom }\end{array}$ & $\begin{array}{c}\text { Sum of } \\
\text { Squares }\end{array}$ & $\begin{array}{c}\text { Mean } \\
\text { Squares }\end{array}$ & F Value & $\begin{array}{c}\text { Significance } \\
\text { Level }\end{array}$ \\
\hline Radials & 3 & 46.3 & 15.4 & 12.4 & 0.000068 \\
Perpendiculars & 7 & 27.7 & 3.96 & 3.19 & 0.018 \\
Residuals & 21 & 26.1 & 1.24 & & \\
\hline "Note: Analysis was performed on the logarithms of the data from the locations displayed in Figure 2.3.
\end{tabular}

Perpendiculars I and J are excluded from this statistical test because they are physically separated from perpendiculars $\mathrm{A}$ through $\mathrm{H}$ by the ball field and the disked area.

Table 2.4 Simultaneous 95\% confidence intervals for the ratios of Pu-239+240 concentrations, radials one through four.

\begin{tabular}{ccc}
\hline Radials & Ratio & Confidence Interval $^{\mathrm{b}}$ \\
\hline 1 vs. 2 & 12.2 & $2.58-57.6$ \\
1 vs. 3 & 19.3 & $4.09-91.2$ \\
1 vs. 4 & 16 & $0.47-77.4$ \\
2 vs. 3 & 1.58 & $0.335-7.47$ \\
2 vs. 4 & 1.34 & $0.284-6.34$ \\
3 vs. 4 & 0.849 & $0.18-4.01$
\end{tabular}

- Ratios shaded gray are statistically significant, as indicated by confidence intervals that exclude the ratio 1.0 .

b Confidence intervals were calculated using Tukey's HSD on differences between the average log concentrations, and are presented in the table after back transformation to data units.

The statistical test comparing the geometric means of the perpendiculars is also statistically significant ( $p \leq 0.018$, Table 2.3). Examination of the perpendiculars using a statistical multiple comparison procedure shows that $A, C$, and D have significantly lower concentrations than $\mathrm{H}$, and that none of the other pairs is significantly different

\footnotetext{
${ }^{1}$ The same result is obtained using an alternate statistical method known as a permutation test; see Appendix 4.
} 
(see Table 2.5). This is consistent with the observation that perpendiculars $A, C$, and D (only) have no results above fallout-background outside in Radials 2, 3, and 4 (see Table 2.2).

Table 2.5 Simultaneous $95 \%$ confidence intervals for the ratios of $\mathrm{Pu}-239+240$ concentrations, perpendiculars A through $\mathrm{H}$

\begin{tabular}{|c|c|c|}
\hline Perpendiculars & Ratio $^{a}$ & Confidence Interval ${ }^{\mathrm{b}}$ \\
\hline A vs. B & 0.323 & $0.023-4.53$ \\
\hline A vs. $C$ & 0.802 & $0.0572-11.3$ \\
\hline A vs. D & 0.706 & $0.0503-9.91$ \\
\hline A vs. $E$ & 0.195 & $0.0139-2.73$ \\
\hline A vs. $F$ & 0.196 & $0.0139-2.75$ \\
\hline A vs. $G$ & 0.22 & $0.0156-3.08$ \\
\hline A vs. $H$ & 0.0486 & $0.00346-0.682$ \\
\hline B vs. C & 2.48 & $0.177-34.9$ \\
\hline B vs. D & 2.19 & $0.156-30.7$ \\
\hline B vs. $E$ & 0.602 & $0.0429-8.46$ \\
\hline B vs. $F$ & 0.606 & $0.0432-8.51$ \\
\hline B vs. G & 0.68 & $0.0484-9.55$ \\
\hline B vs. $\mathrm{H}$ & 0.15 & $0.0107-2.11$ \\
\hline C vs. D & 0.88 & $0.0627-12.4$ \\
\hline C vs. E & 0.242 & $0.0173-3.4$ \\
\hline C vs. F & 0.244 & $0.0174-3.43$ \\
\hline C vs. G & 0.274 & $0.0195-3.84$ \\
\hline C vs. H & 0.0605 & $0.00431-0.85$ \\
\hline D vs. E & 0.276 & $0.0196-3.87$ \\
\hline D vs. F & 0.277 & $0.0198-3.89$ \\
\hline D vs. G & 0.311 & $0.0222-4.37$ \\
\hline D vs. $H$ & $0.0688^{-}$ & $0.0049-0.966$ \\
\hline Evs. $F$ & 1.01 & $0.0717-14.1$ \\
\hline E vs. G & 1.13 & $0.0804-15.8$ \\
\hline Evs. $H$ & 0.25 & $0.0178-3.51$ \\
\hline F vs. $G$ & 1.12 & $0.0799-15.7$ \\
\hline Fvs. H & 0.248 & $0.0177-3.48$ \\
\hline G vs. $H$ & 0.221 & $0.0158-3.11$ \\
\hline
\end{tabular}

The statistical differences between perpendicular $\mathrm{H}$ and perpendiculars $\mathrm{A}, \mathrm{C}$, and $\mathrm{D}$ are illustrated in Figure 2.4, which shows the geometric mean concentrations of Pu-239+240 on perpendiculars $\mathrm{A}$ through $\mathrm{H}$. Note that perpendiculars $\mathrm{A}, \mathrm{C}$, and $\mathrm{D}$ have the three 
lowest geometric means, and $\mathrm{H}$ has the highest. The error bars represent two standard deviations of the geometric mean.

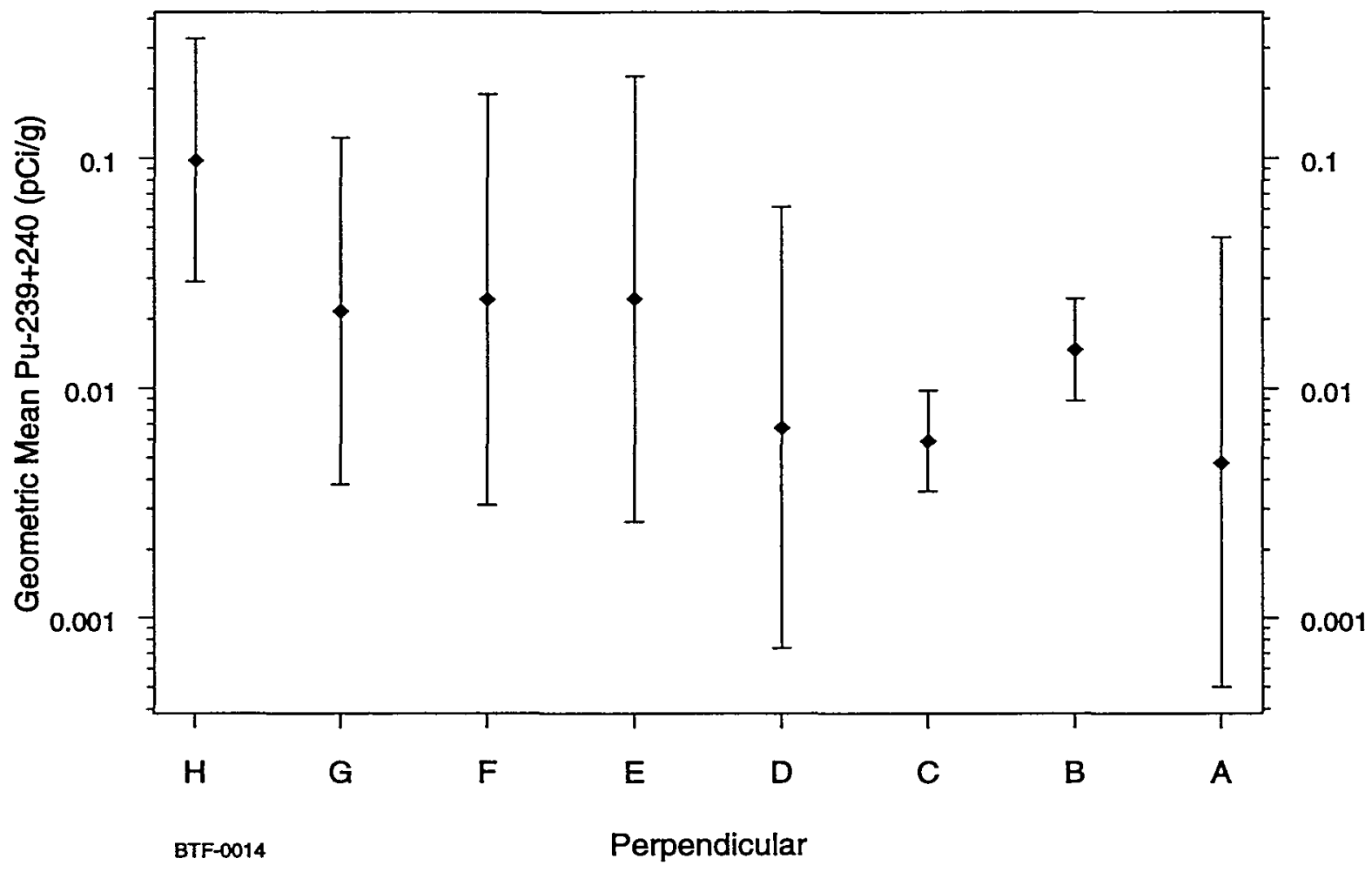

Figure 2.4 Geometric mean concentrations of Pu-239+240 on perpendiculars A through $\mathrm{H}, 0-10 \mathrm{~cm}$.

Except for Radial 1, the Pu-238 results are almost all non-detections (Appendix 6, Table 6.1). This suggests that the $\mathrm{Pu}-238$ data show a pattern similar to that of the $\mathrm{Pu}-239+240$ data. Statistical analysis confirms that Radial 1 has greater concentrations than the other radials (see Table 2.6 and Table 2.7). The test for differences between perpendiculars for $\mathrm{Pu}-238$ is not statistically significant $(p \$ 0.108)$. Confidence intervals for the comparisons of perpendiculars are not shown because the differences are not statistically significant.

Table 2.6 Analysis of variance for lateral distribution of Pu-238 in the top $10 \mathrm{~cm}$."

\begin{tabular}{cccccc}
\hline Factor & $\begin{array}{c}\text { Degrees of } \\
\text { Freedom }\end{array}$ & $\begin{array}{c}\text { Sum of } \\
\text { Squares }\end{array}$ & $\begin{array}{c}\text { Mean } \\
\text { Squares }\end{array}$ & F Value & $\begin{array}{c}\text { Significance } \\
\text { Level }\end{array}$ \\
\hline Radials & 3 & 34.5 & 11.5 & 13.8 & 0.0000336 \\
Perpendiculars & 7 & 11.5 & 1.64 & 1.97 & 0.108 \\
Residuals & 21 & 17.5 & 0.833 & & \\
\hline Note: Analysis was performed on the logarithms of the data from the locations displayed in Figure 2.3.
\end{tabular}


Table 2.7 Simultaneous $95 \%$ confidence intervals for the ratios of Pu-238 concentrations, radials one through four.

\begin{tabular}{ccc}
\hline Radials & Ratio $^{*}$ & Confidence Interval $^{\text {b }}$ \\
\hline 1 vs. 2 & 10 & $2.8-35.7$ \\
1 vs. 3 & 13.4 & $3.75-47.7$ \\
1 vs. 4 & 9.41 & $2.64-33.6$ \\
2 vs. 3 & 1.34 & $0.375-4.77$ \\
2 vs. 4 & 0.941 & $0.264-3.36$ \\
3 vs. 4 & 0.703 & $0.197-2.51$
\end{tabular}

- Ratios shaded gray are statistically significant, as indicated by confidence intervals that exclude the ratio 1.0.

b Confidence intervals were calculated using Tukey's HSD on differences between the average log concentrations, and are presented in the table after back transformation to data units.

Among the grid samples, Americium-241 analyses were performed only on samples collected at the 0-5 cm depth interval (except for one EPA QC sample from the 5-10 cm interval at location $5 \mathrm{E}$ ). Like the plutonium, Am-241 has significantly greater concentrations in Radial 1 than in the other radials (Figure 2.3, Table 2.8, and Table 2.9). Confidence intervals for comparisons of the perpendiculars are not shown because these differences are not statistically significant.

Table 2.8 Analysis of variance for lateral distribution of Am-241 in the top 5 cm. ${ }^{a}$

\begin{tabular}{cccccc}
\hline Factor & $\begin{array}{c}\text { Degrees of } \\
\text { Freedom }\end{array}$ & $\begin{array}{c}\text { Sum of } \\
\text { Squares }\end{array}$ & $\begin{array}{c}\text { Mean } \\
\text { Squares }\end{array}$ & F Value & $\begin{array}{c}\text { Significance } \\
\text { Level }\end{array}$ \\
\hline Radials & 3 & 71.3 & 23.8 & 10.3 & 0.000226 \\
Perpendiculars & 7 & 23.3 & 3.32 & 1.44 & 0.242 \\
Residuals & 21 & 48.5 & 2.31 & & \\
\hline Note: Analysis was performed on the logarithms of the data from the locations displayed in Figure 2.3.
\end{tabular}

Table 2.9 Simultaneous 95\% confidence intervals for the ratios of Am-241 concentrations, radials one through four.

\begin{tabular}{|c|c|c|c|}
\hline Radials & Ratio : & & Confidence Interval ${ }^{b}$ \\
\hline 1 vs. 2 & 19 & . & $2.39-151$ \\
\hline 1 vs. 3 & 56.3 & $=$ & $6.89-433$ \\
\hline 1 vs. 4 & 17.3 & $\because$ & $1.78-112$ \\
\hline 2 vs. 3 & 2.96 & & $0.362-22.8$ \\
\hline 2 vs. 4 & 0.911 & & $0.0938-5.91$ \\
\hline 3 vs. 4 & 0.307 & & $0.0326-2.05$ \\
\hline
\end{tabular}

- Ratios shaded gray are statistically significant, as indicated by confidence intervals that exclude the ratio 1.0.

b Confidence intervals were calculated using Tukey's HSD on differences between the average log concentrations, and are presented in the table after back transformation to data units. 


\subsubsection{Conclusions regarding extent of plutonium at Big Trees Park}

The analyses in this section show that the elevated concentrations of plutonium and americium are at and near the surface, and along the northeastern border of the park near the ornamental trees. The northeastern border of the park is clearly different from the rest of the park.

\subsection{Distribution Pathways}

One of the three goals of the 1998 sampling was to investigate the likelihood of the three proposed pathways-waterborne transport via Arroyo Seco, sludge, or aerial deposition-by which plutonium could have reached Big Trees Park.

\subsubsection{Arroyo-waterborne Pathway}

\subsubsection{Review of Evidence Prior to the 1998 Sampling}

The 1998 draft health consultation (CDHS-EHIB, 1998) hypothesized that traces of plutonium might have reached Big Trees Park in water-borne sediments carried from LLNL down the Arroyo Seco, which crosses the southwestern corner of the LLNL site and flows past Big Trees Park on its northern boundary. Low-level plutonium surface contamination in the southeastern portion of the Livermore site was studied and documented by LLNL as early as 1971 (Gudiksen et al., 1972), studied in more detail in 1974 (Silver et al., 1974), in 1991 (LLNL, 1992), and again in 1993 by the EPA (NAREL 1994). The activities responsible for the contamination at the southeastern portion of the Livermore site occurred between 1962 and 1976. Until 1965, part of the southeastern Livermore site drained to the Arroyo Seco. Since that time the drainage has been directed to the center of the site and then to the Arroyo Las Positas along the north side of LLNL. Arroyo Las Positas joins Arroyo Seco well downstream of Big Trees Park.

More specifically, the health consultation postulated "plutonium-contaminated sediments from the Arroyo Seco were redeposited during the development of the park" (CDHS-EHIB 1998, p. 11 and CDHS-EHIB 1999, p. 16). The mechanism by which this took place, according to the hypothesis, was that "In the areas where the channel was not concreted ([1995] locations \#2, 14, 15) improvements were made to the slopes, as explained in the Soils Report 'where the existing gully bank has a slope ratio steeper than 5 horizontal feet to 1 vertical feet [sic], horizontal benches at least four feet wide shall be cut into the natural slope'..." (Cooper and Clark, 1970, as quoted in CDHSEHIB, 1998 p.11 and CDHS-EHIB, 1999, p.16). The consultation continued, "Cutting into the existing slope would generate excess soil from the banks...that may have been used as fill material for ...Big Trees Park...". 
The health consultation did not present documentation confirming that the improvements actually occurred. Instead, it presented two photographs (CDHS-EHIB 1998 and CDHS-EHIB 1999, Figures 6a and 6b), and stated that CDHS-EHIB staff "observed that improvements to the slopes obviously had been made in the areas where the two creek bottom samples were collected during the 1995 Soil Survey (Figure 6a)".

In 1998 LLNL staff visited the location where the two photographs had been taken (Figure 2.5) and measured the slope of the banks in the area where "...improvements to the slopes obviously had been made...". The slope ratio was between 2 and 3 horizontal feet to one vertical foot, steeper than the 5-to-1 ratio specified in the soils report. The slope of the arroyo bank matches the slope of the concrete channel where they meet, so it is highly unlikely that the arroyo bank slopes have changed since the concrete channel was created in 1970. This shows that the slope improvements asserted by the health consultation were not made.

In order to attribute the elevated levels in the park to this pathway, the earth movement would have to have been done prior to the collection of the first sample in 1993. It seems unlikely that clear physical evidence of such activities would survive until 1997 when the evidence was "observed." Indeed, such evidence might be difficult to distinguish from erosion, especially after four or more years. Upon careful inspection, the "cut along toe" shown in the consultation's Figure $6 \mathrm{~b}$ shows a slight undercutting that is typical of erosion, but not characteristic of cuts made by earth moving equipment. This is somewhat difficult to convey in a photograph, but both the consultation's Figure 6b, and the present Figure 2.6 show shadows indicative of slight undercutting. 


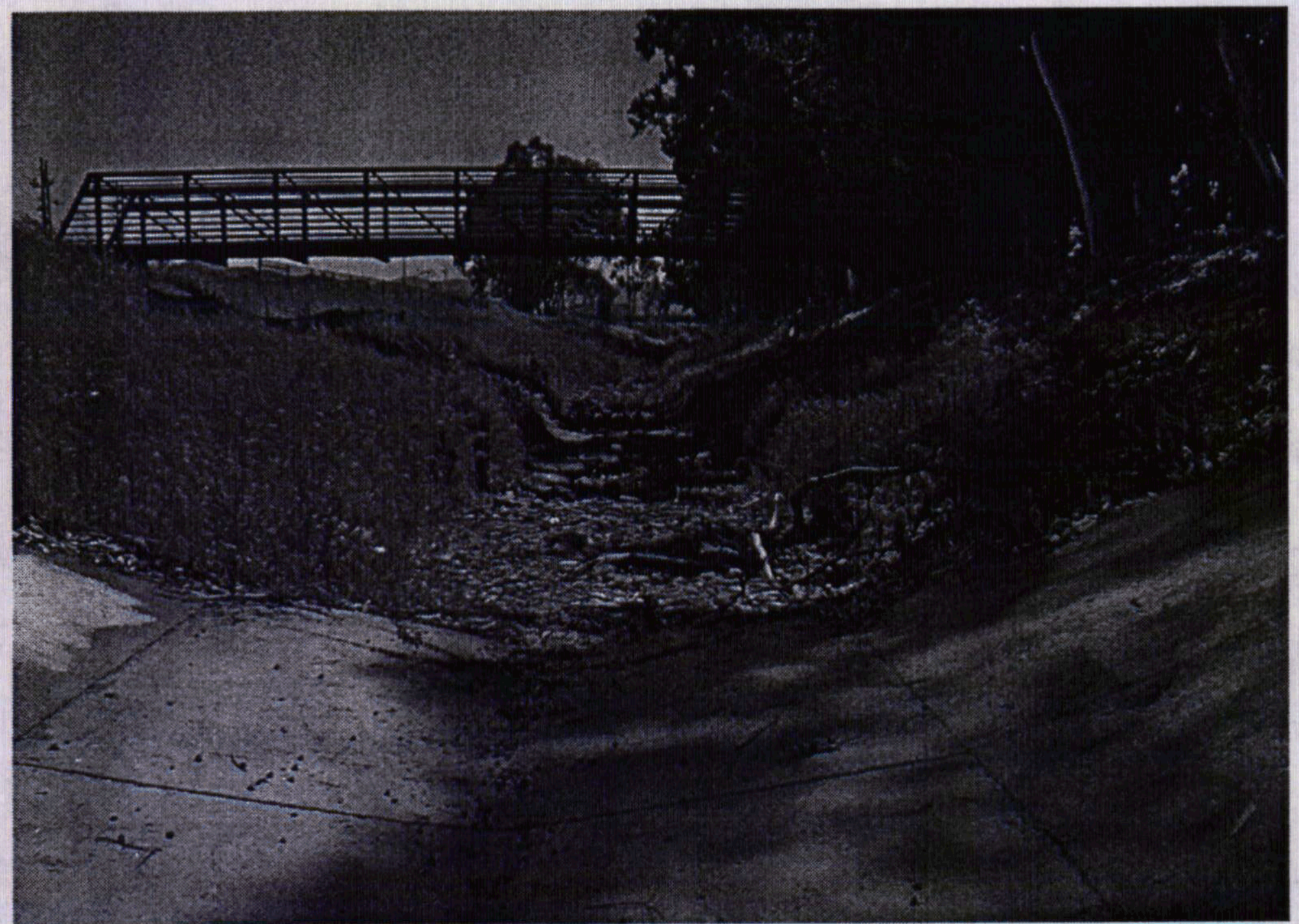

Figure 2.5 Photograph of the Arroyo Seco Channel Slope Walls, taken from the same location as Health Consultation Figure 6a.

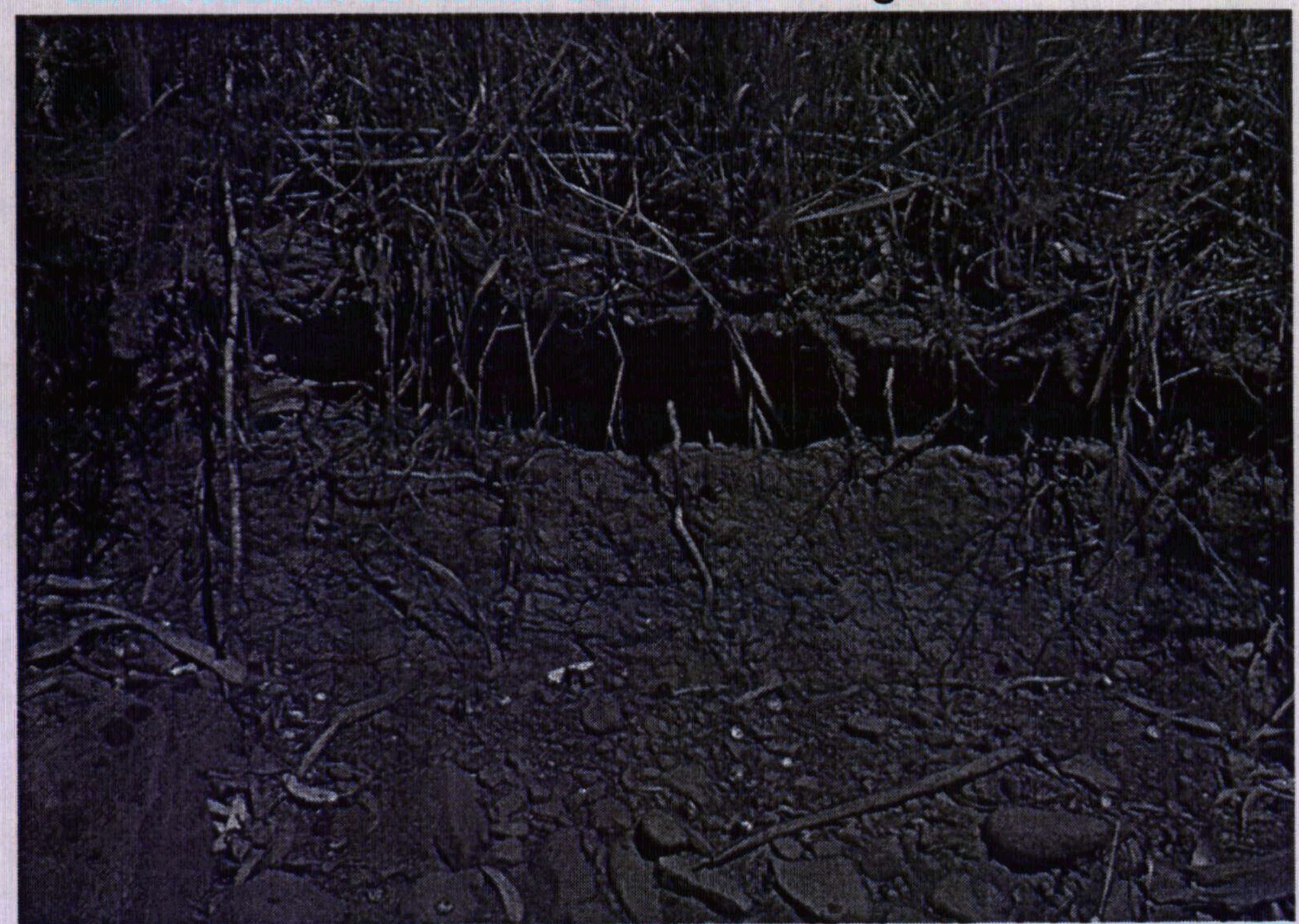

Figure 2.6 Photograph of toe of Arroyo Seco slope similar to Health Consultation Figure $6 \mathrm{~b}$, showing a typical erosion pattern. 


\subsubsection{Sampling for the arroyo-waterborne hypothesis}

Because the Arroyo Seco at Big Trees Park was rechanneled in 1970, samples were collected in both the current arroyo channel and in the former location of the channel (the "Old arroyo channel" in Figure 2.7) as identified from maps. All arroyo samples were analyzed for $\mathrm{Pu}-238$ and $\mathrm{Pu}-239+240$ to determine if this pathway could explain the presence of above-fallout-background plutonium levels along Radial 1.

Three boreholes were drilled into the west end of the old arroyo channel behind the Arroyo Seco School. This part of the arroyo was filled circa 1970 and would therefore be the only place where a historic release of plutonium (if present immediately prior to the filling of the old channel) might not have been washed away during the intervening years. After drilling to the estimated depths the fill/sediment interfaces of the old arroyo channel were identified (see Section 5.4). Samples were collected from the first $0-15 \mathrm{~cm}$ below the respective interfaces, which were found at 305-, 295-, and 285- $\mathrm{cm}$ deep.

The current channel was sampled at seven locations, shown in Figure 2.7. Upstream (east) of Vasco Road, arroyo-bed samples in the current arroyo were collected at the 0-5 cm depth interval, consistent with 1995 sampling and recent LLNL surveillance monitoring (1993-present). At the two locations downstream of Big Trees Park and the two locations near the eastern extension of the park arroyo-bed samples were collected from the $0-25$ $\mathrm{cm}$ depth interval to determine if older plutonium-containing material was present. 


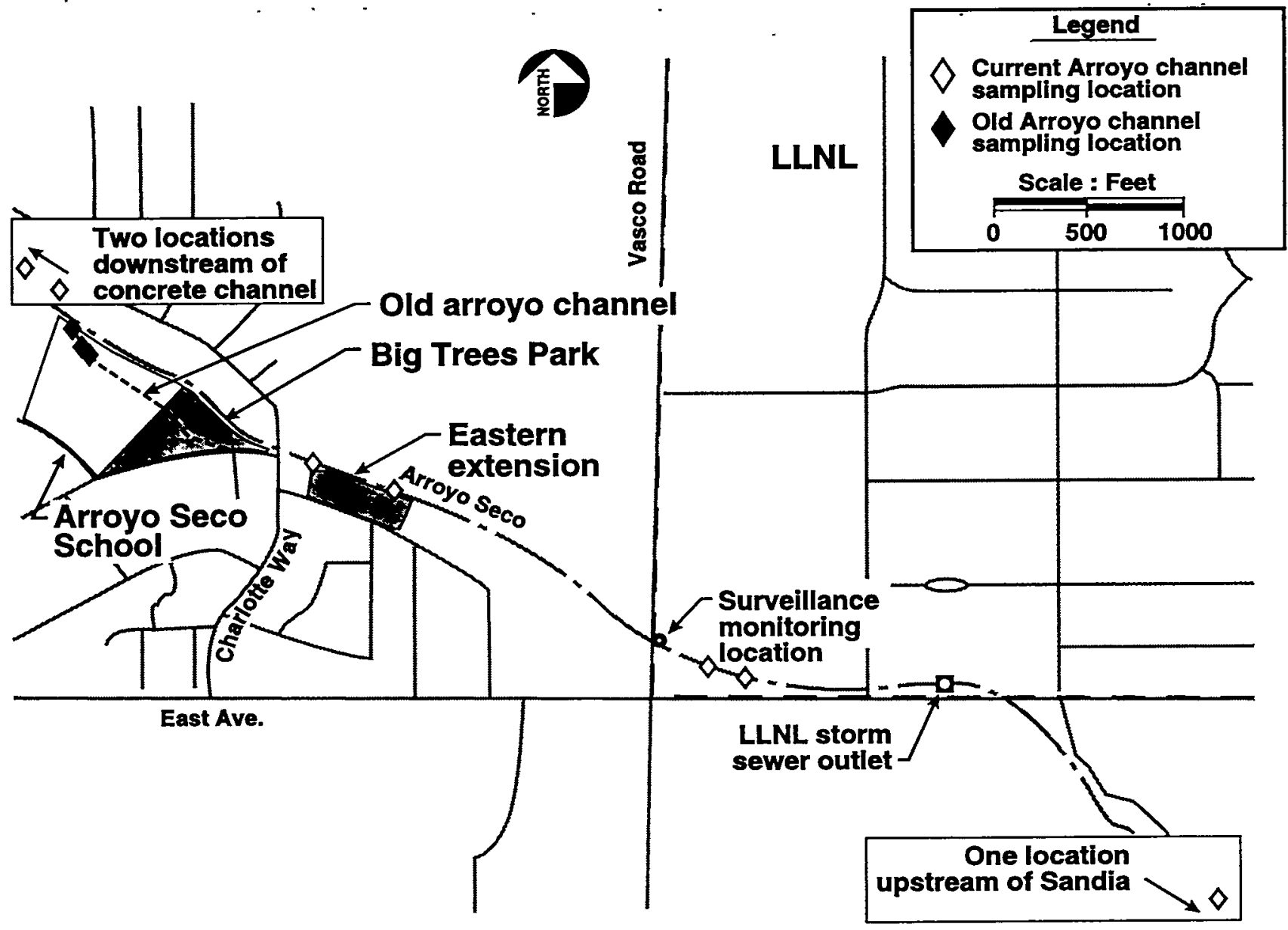

ERD-LSR-98-0150B

Figure 2.7 Arroyo Seco sampling locations, 1998.

\subsubsection{Data Analysis and Interpretation}

With three exceptions plutonium concentrations in the current arroyo samples were non-detections (see Table 2.10).

One field-duplicate and one field-split sample collected at each of the two locations downstream of the concrete channel contained $\mathrm{Pu}-239+240$ at about $0.04 \mathrm{pCi} / \mathrm{g}$. Because the associated samples did not contain detactable levels of $\mathrm{Pu}-239+240$, these results are most likely due to sample heterogeneity.

One sample in the southwest corner of LLNL contained Pu-238 at nearly $0.003 \mathrm{pCi} / \mathrm{g}$ (SSS-AS-102). If this sample was of material similar to that found along Radial 1, it would have been expected that $\mathrm{Pu}-239+240$ would have been detectable at 
approximately $0.03 \mathrm{pCi} / \mathrm{g}$ (see Section 4). However, the $\mathrm{Pu}-239+240$ result was a nondetection.

Table 2.10 Current Arroyo Sampling Results. ${ }^{a}$

\begin{tabular}{llcccc}
\hline Location & Sample ID & Depth & Type & Pu-239+240 & Pu-238 \\
\hline Upstream of Sandia & SSS-AS-101 & $0-5$ & & $-0.000502 \pm 0.00101$ & $0.00237 \pm 0.00239$ \\
\hline SW Corner of LLNL & SSS-AS-102 & $0-5$ & & $-0.0000456 \pm 0.000712$ & $0.00269 \pm 0.00176$ \\
& SSS-AS-103 & $0-5$ & & $-0.000471 \pm 0.000943$ & $-0.000472 \pm 0.000946$ \\
& SSS-AS-103 & $0-5$ & Split & $0.00000808 \pm 0.00062$ & $-0.0000647 \pm 0.000885$ \\
& SSS-AS-103 & $0-5$ & Split & $0.000088 \pm 0.003$ & $-0.00053 \pm 0.003$ \\
\hline Eastern Extension & SSS-AS-104 & $0-25$ & & $-0.000419 \pm 0.00084$ & $0.00149 \pm 0.00173$ \\
& SSS-AS-105 & $0-25$ & & $0.0 \pm 0.00144$ & $0.0 \pm 0.00144$ \\
& SSS-AS-105 & $0-25$ & Split & $-0.000384 \pm 0.000273$ & $-0.000192 \pm 0.000193$ \\
& SSS-AS-105 & $0-25$ & Split & $0.00057 \pm 0.003$ & $0.0014 \pm 0.003$ \\
\hline Downstream of & SSS-AS-106 & $0-25$ & & $0.00191 \pm 0.0022$ & $-0.000637 \pm 0.00174$ \\
concrete channel & SSS-AS-106 & $0-25$ & Split & $0.0388 \pm 0.00887$ & $0.00121 \pm 0.00253$ \\
& SSS-AS-107 & $0-25$ & & $0.0 \pm 0.00129$ & $0.000954 \pm 0.00237$ \\
& SSS-AS-107 & $0-25$ & Duplicate & $0.0432 \pm 0.0097$ & $0.00241 \pm 0.00298$ \\
\hline
\end{tabular}

"Non-detections are shown in italics.

With two exceptions, the samples collected from the former arroyo channel were below detectable levels (Table 2.11). Because both detections were at low levels, and because associated split samples were not detections, these two results are attributed to the sample heterogenity (as discussed in Section 3.2).

Table 2.11 Former Arroyo Seco Sampling Results. ${ }^{a}$

\begin{tabular}{ccccc}
\hline Sample ID & Depth & Type & Pu-239+240 & Pu-238 \\
\hline FAS01 & $305-320$ & & $-0.00162 \pm 0.00186$ & $0.00345 \pm 0.00317$ \\
FAS01 & $305-320$ & Split & $0.000124 \pm 0.000853$ & $0.000181 \pm 0.000847$ \\
FAS01 & $305-320$ & Split & $0.00058 \pm 0.003$ & $-0.00023 \pm 0.003$ \\
\hline FAS02 & $295-310$ & & $-0.000793 \pm 0.00112$ & $0.000535 \pm 0.00275$ \\
FAS02 & $295-310$ & Split & $0.000176 \pm 0.000823$ & $-0.000276 \pm 0.000248$ \\
FAS02 & $295-310$ & Split & $0.002 \pm 0.003$ & $-0.00072 \pm 0.003$ \\
\hline FAS03 & $285-300$ & & $0.000328 \pm 0.00202$ & $-0.0000758 \pm 0.00291$ \\
FAS03 & $285-300$ & Split & $0.00229 \pm 0.00189$ & $0.000764 \pm 0.00109$ \\
\hline
\end{tabular}

\subsubsection{Conclusions Regarding the Arroyo-Waterborne Pathway}

As discussed in the previous sections, the 1998 sampling did not find plutonium in locations that would support the arroyo-waterborne pathway. The historical record of drainage on the LLNL site shows that drainage from LLNL to Arroyo Seco that could have contributed to contamination in Big Trees Park ended well before Big Trees Park was constructed. Anything left behind by such drainage would be very unlikely to remain until the park was constructed. Other evidence presented by CDHS-EHIB to support the arroyo-waterborne pathway has been shown to be erroneous. 


\subsubsection{Sludge Pathway}

This pathway hypothesis suggests that sewage sludge from the Livermore Water Reclamation Plant (LWRP) containing Pu-239+240 was a component of a soil amendment used when ornamental trees were planted in Big Trees Park along the concrete-lined portion of the Arroyo Seco. The source of plutonium in the sludge was permitted releases to the LLNL sanitary sewer, with the largest single release occurring in 1967. During the 1967 investigation of the release it was "anticipated that it will be several years before it [the contaminated sludge] is used in turf building" (Sewell, 1967). Sewell, 1967 also stated, "All of the radioactivity has gone to the sludge lagoons, which have a capacity of approximately 5 years at the present plant volume." These two statements taken together indicate that contaminated sludge was present and available at the time that the park was developed and possibly for somewhat longer.

All LLNL effluent releases of radioactivity to the LWRP, including the 1967 release, were below the applicable regulatory limits of the time.

The sludge pathway was investigated by sampling the wells of 10 trees likely to have been planted when sludge was available as a soil amendment. Radial 1 runs along the line of these trees, including trees at 1995 Location 1. A 1975 aerial photograph shows relatively small trees adjacent to the arroyo and in the vicinity of 1995 Location 1 . The trees were not planted by either the City of Livermore or the LARPD; it is unknown who planted the trees (Ingledue, 1998). The practice of allowing volunteers to plant trees in LARPD parks was and still is followed (Ingledue, 1998).

In sampling tree wells, each tree well location was paired with another location at least 1 meter beyond the irrigation berm surrounding each tree. The second location was chosen far enough away from the tree well to likely not have been affected by soil amendment that might have been introduced to the subsurface during tree planting. See Section 5 for a description of the how the trees were numbered, two photographs showing examples of boreholes inside tree wells, and diagrams of the borehole . locations relative to the tree trunks and berms.

At each location (both inside and outside the tree well), samples were collected at three depths: 0-45 cm, 45-90 cm, and 90-135 cm. The first two intervals were based on estimates of the depths of the holes dug to plant the trees, and were intended to collect material from within the original tree wells. The deepest interval, $90-135 \mathrm{~cm}$ was intended to provide a sample of soil beneath the depth of the tree well.

Samples were analyzed for $\mathrm{Pu}-239+240, \mathrm{Pu}-238, \mathrm{Am}-241$, and five metals commonly present in municipal sewer sludges: chromium, copper, lead, nickel, and zinc. It was 
thought that these metal constituents of sludge might be detectable in the tree wells in quantities greater than the companion samples away from the trees, and that this could confirm or refute the sludge hypothesis.

Additional discussion of the sludge pathway based on the plutonium isotopic ratios of the samples is found in Section 4.

\subsubsection{Grid Results}

The sludge pathway hypothesis predicts that the highest concentrations among the grid samples should be those that are closest to the ornamental trees, i.e., Radial 1. This turned out to be the case (see Section 2.1.1.2). The grid results support the sludge pathway hypothesis.

\subsubsection{Tree Results: Plutonium-239+240}

Soils from beneath all 10 trees that were sampled exhibited detectable quantities of $\mathrm{Pu}-239+240$ inside the tree well at the $0-45 \mathrm{~cm}$ depth interval, and 7 trees had detectable quantities outside the tree well at $0-45 \mathrm{~cm}$ (see Figure 2.3 for a map showing tree locations and Appendix 6 for data).

At the deeper depths, four inside tree-well samples and three outside tree-well samples had detectable quantities of Pu-239+240.

The average $\mathrm{Pu}-239+240$ values for the tree samples are presented in Table 2.12. From these averages, it can be seen that the Pu-239+240 values are substantially higher inside the tree wells at $0-45 \mathrm{~cm}$ than outside the tree wells at $0-45 \mathrm{~cm}$. If a comparison is made of each pair of tree samples, only one tree (number 4) does not exhibit this characteristic.

These results, also shown in Figure 2.8, are statistically significant ( $p \leq 0.00146$; see Table 2.13). 
Table 2.12 Results of sampling inside and outside of ornamental tree wells."

\begin{tabular}{|l|c|c|c|c|c|c|}
\hline $\begin{array}{c}\text { Sample } \\
\text { set }\end{array}$ & $\begin{array}{c}\text { Depths } \\
\text { (cm) }\end{array}$ & $\begin{array}{c}\text { Number } \\
\text { of } \\
\text { locations }\end{array}$ & $\begin{array}{c}\text { Number } \\
\text { of } \\
\text { samples }\end{array}$ & $\begin{array}{c}\text { Number of } \\
\text { Pu-239+240 } \\
\text { detections }\end{array}$ & $\begin{array}{c}\text { Average of } \\
\text { Pu-239+240 } \\
\text { results } \\
\text { (pCi/g) }\end{array}$ & $\begin{array}{c}\text { Average of } \\
\text { Pu-238 } \\
\text { results } \\
\text { (pCi/g) }\end{array}$ \\
\hline Inside tree & $0-45$ & 10 & 10 & 10 & 0.046 & 0.0048 \\
wells & $45-90$ & & 10 & 2 & 0.00063 & 0.00095 \\
& $90-135$ & & 10 & 2 & 0.0016 & 0.00024 \\
\hline Outside tree & $0-45$ & 10 & 10 & 7 & 0.0024 & 0.00066 \\
wells & $45-90$ & & 10 & 1 & 0.00021 & 0.00072 \\
& $90-135$ & & 10 & 2 & 0.00029 & 0.00085 \\
\hline
\end{tabular}

"Non-detections are shown in italics.

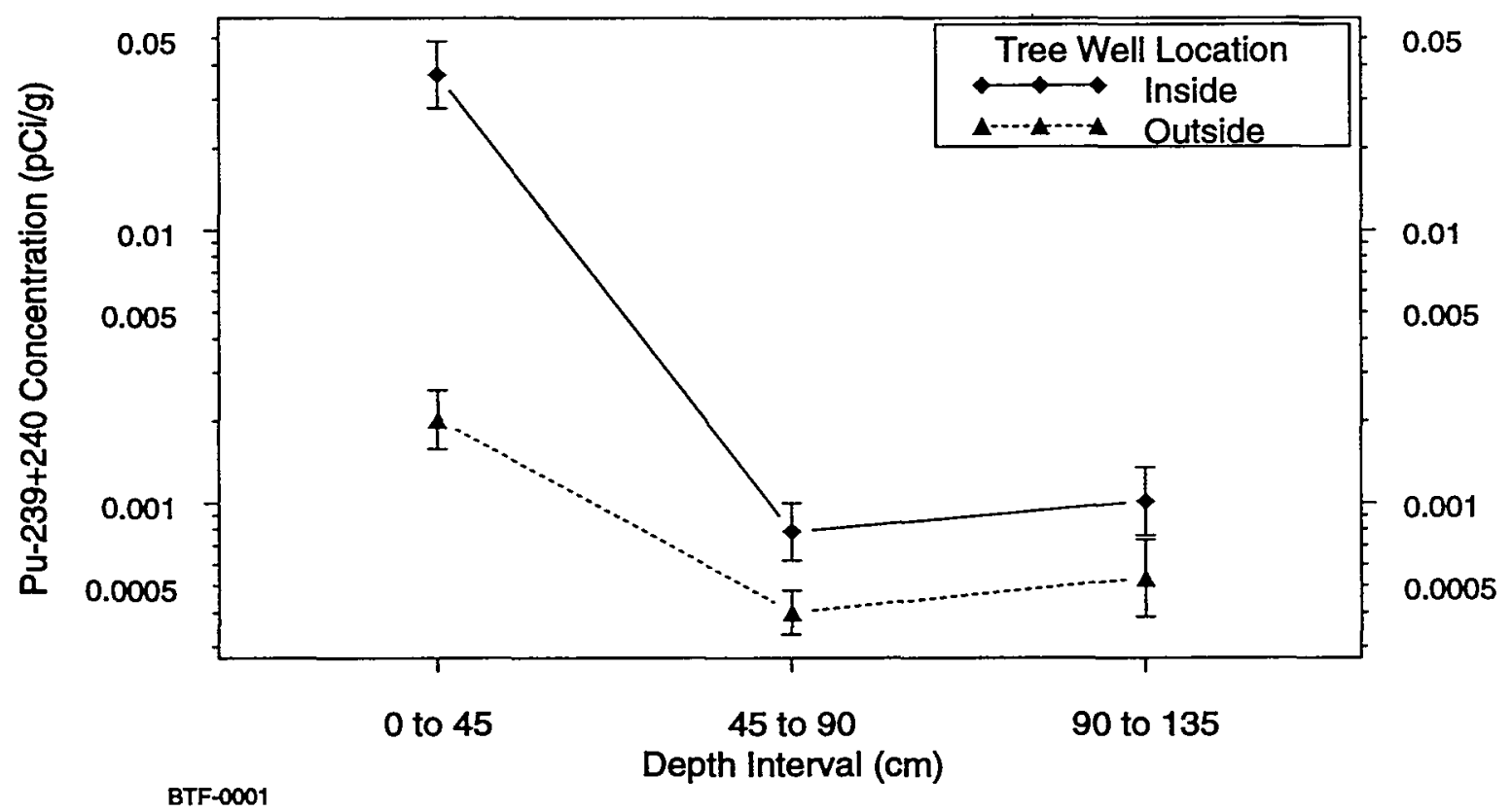

Figure 2.8 Geometric mean concentrations of Pu-239+240 from sampling locations inside and outside tree wells. Error bars are \pm one standard error.

The difference between inside and outside the tree wells at the $45-90 \mathrm{~cm}$ interval is also statistically significant $(p \leq 0.0454)$. However, the average inside the tree wells is not at an intermediate range, as would have been expected if the sludge had been placed at this depth in the tree wells when the trees were planted (and provided that the sample core intersected the entire tree well). Either of two slight revisions to the sludge hypothesis can explain this. The first is that the tree wells in which the trees were planted narrowed as they deepened, so that the sampling boreholes did not intersect the tree wells below 
about $45 \mathrm{~cm}$. The second is that sludge was added as a top-dressing after the trees were planted, instead of in the tree wells when the trees were planted (see Section 2.2.2.7).

Table 2.13 Statistical significance levels of comparisons of radionuclide concentrations inside the tree wells vs. outside the tree wells.

\begin{tabular}{|c|c|c|c|}
\hline Radionuclide & $0-45^{a}$ & $45-90^{a}$ & $90-135$ \\
\hline Pu-239+240 & 0.00146 & 0.0454 & 0.102 \\
\hline Pu-238 & 0.00635 & 0.764 & 0.708 \\
\hline$A m-241^{b}$ & 0.121 & 0.534 & 0.388 \\
\hline Am-241, omitting suspect results ${ }^{b}$ & 0.00195 & 0.678 & 0.264 \\
\hline
\end{tabular}

\subsubsection{Tree Results: Plutonium, Americium, and Metals}

Figure 2.9 shows plots like that of Figure 2.8 for all three radionuclides and for all five metals (chromium, copper, lead, nickel, and zinc). The vertical scales are omitted for clarity, and are not all the same; see Figure 2.10 through Figure 2.17 for figures with vertical scales and Appendix 6 for data tables.

Figure 2.9 shows that all five metals have a similar pattern. Outside the tree wells the average concentration increases with depth. Inside the tree wells, the two deeper intervals are essentially the same as outside, but the top $(0-45 \mathrm{~cm})$ interval is different. It is clear from this pattern that a common factor has affected the $0-45 \mathrm{~cm}$ interval inside the tree wells differently than all the other intervals. A logical explanation for this is the addition of a non-native material such as a fertilizer or soil amendment. Such additions are a normal part of the planting and care of ornamental trees.

The figures also indicate that wherever the metals inside the tree wells are elevated relative to outside the tree wells, the radionuclides, especially $\mathrm{Pu}-239+240$, are also elevated. This is confirmed by the statistically significant results for the $0-45 \mathrm{~cm}$ intervals (Table 2.13 and Table 2.14). The logical conclusion is that the same factor is responsible for all of them. The fact that all eight analytes have this same pattern is strong evidence for the sludge hypothesis. 

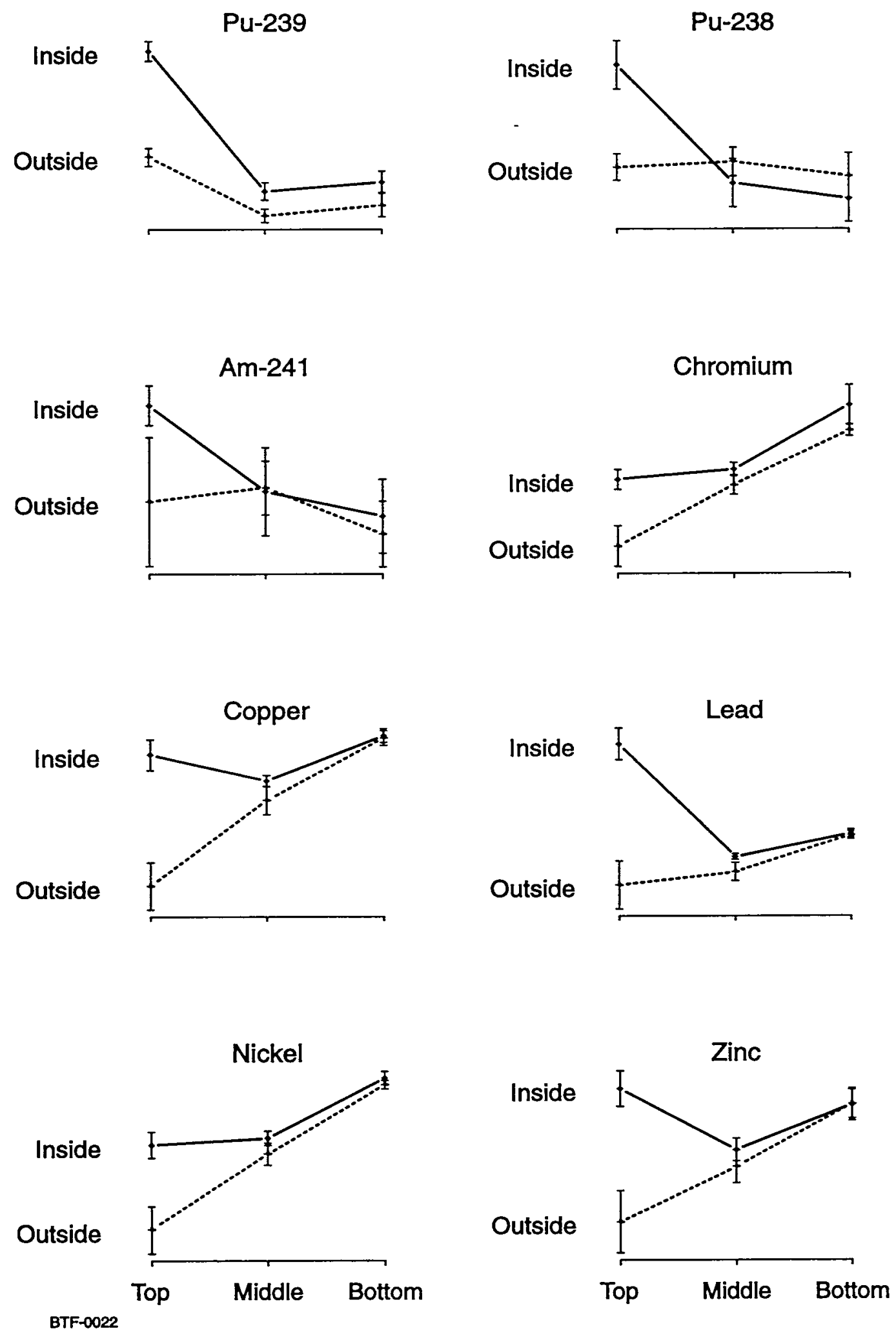

Figure 2.9 Tree well results for all eight analytes 


\subsubsection{Tree Results: Plutonium-238}

Eight of the inside tree-well samples at $0-45 \mathrm{~cm}$ had detectable quantities of Pu-238. In comparison, all other depths, inside or outside the tree well, had at most three detections. The averages for $\mathrm{Pu}-238$ values also show that $\mathrm{Pu}-238$ is substantially higher inside the tree wells at $0-45 \mathrm{~cm}$ than inside the tree wells at deeper depths or outside the tree wells; this difference is statistically significant ( $p \leq 0.00635$, Table 2.13).

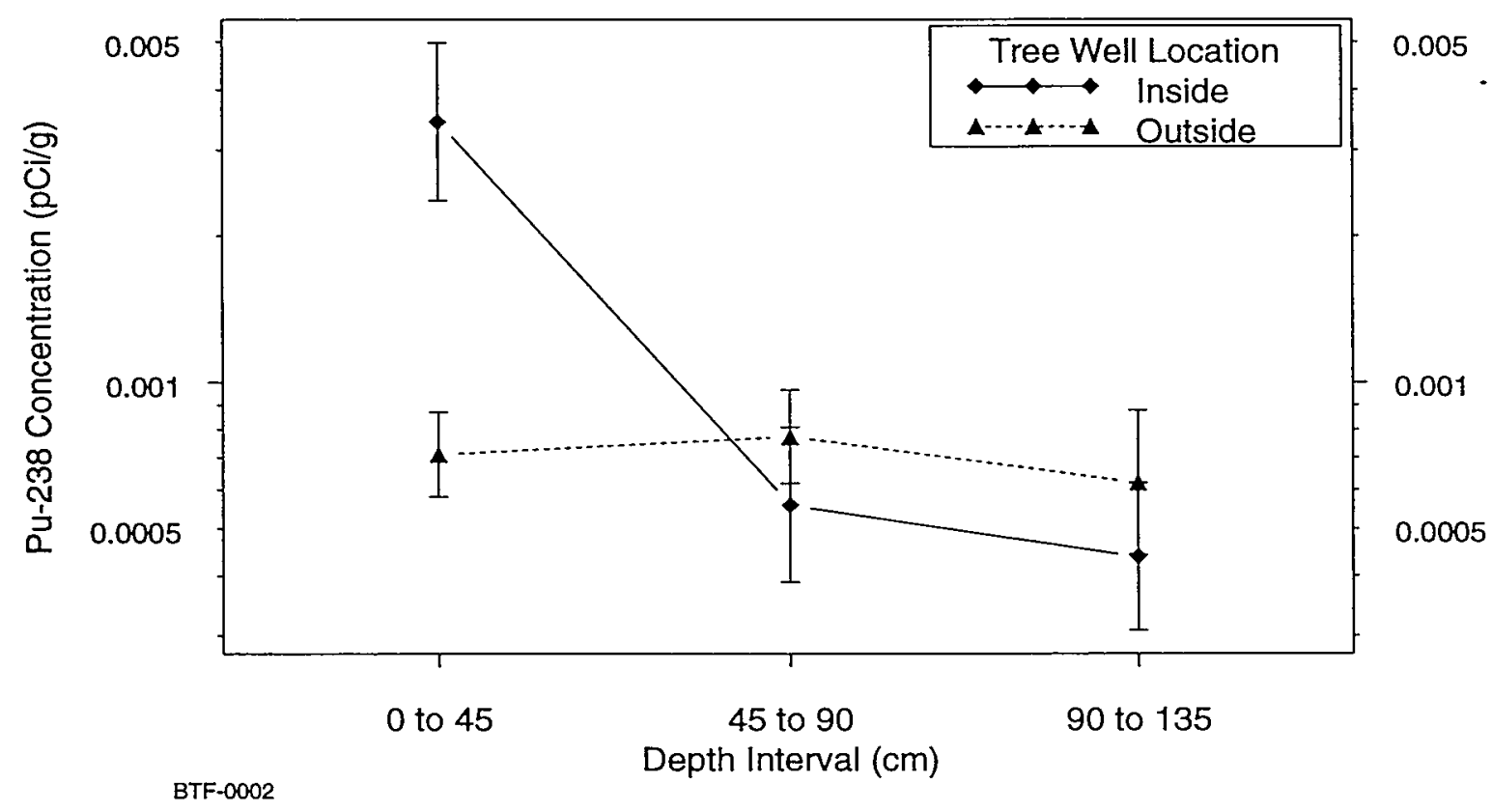

Figure 2.10 Geometric mean concentrations of Pu-238 from sampling locations
inside and outside tree wells. Error bars are \pm one standard error.

It should be noted that the majority of the $\mathrm{Pu}-238$ results are non-detections, all but four of them are below the detection limit specified in the sampling plan, and very few have uncertainties less than 50\% (Appendix 6).

\subsubsection{Tree Results: Americium-241}

The Am-241 data cannot be interpreted as straightforwardly as the plutonium isotope data because of the presence of two outlier values in samples collected outside the tree wells in the top $5 \mathrm{~cm}$. These two results, at trees 3 and 15, have concentrations more than 25 times larger than the only other detection in the top $5 \mathrm{~cm}$ outside the tree wells, at tree 11 (see Appendix 6). With or without the outlier values, the Am-241 data follow the same pattern as the plutonium. That is, the geometric mean of data from the $0-45 \mathrm{~cm}$ interval is greater inside the tree wells than outside the tree wells (see Figure 2.11 and Figure 
2.12). If these values are excluded from the statistical analysis, the difference is statistically significant ( $p \leq 0.00195$, Table 2.13).

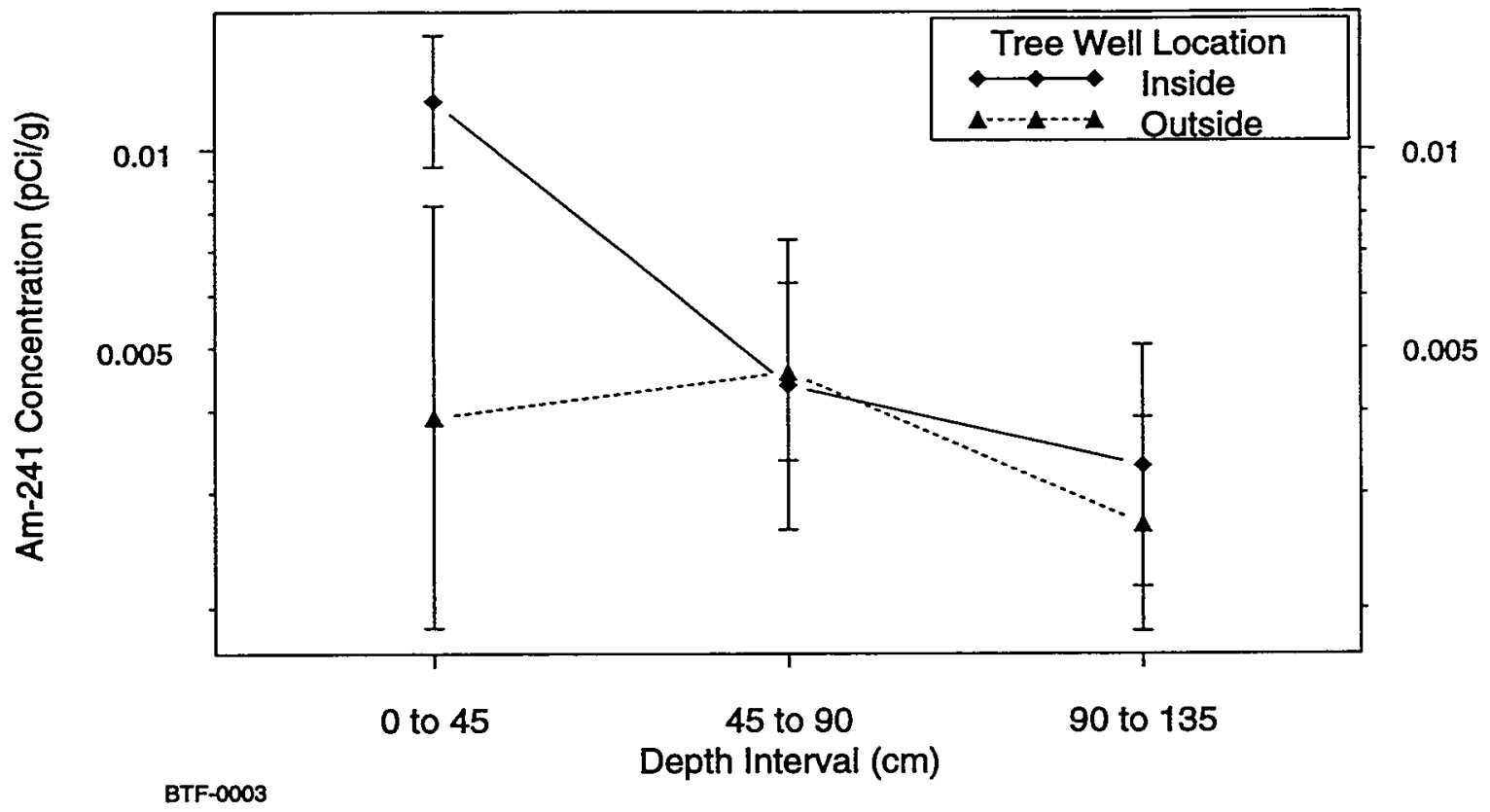

Figure 2.11 Geometric mean concentrations of Am-241 from sampling locations inside and outside tree wells. Error bars are \pm one standard error.

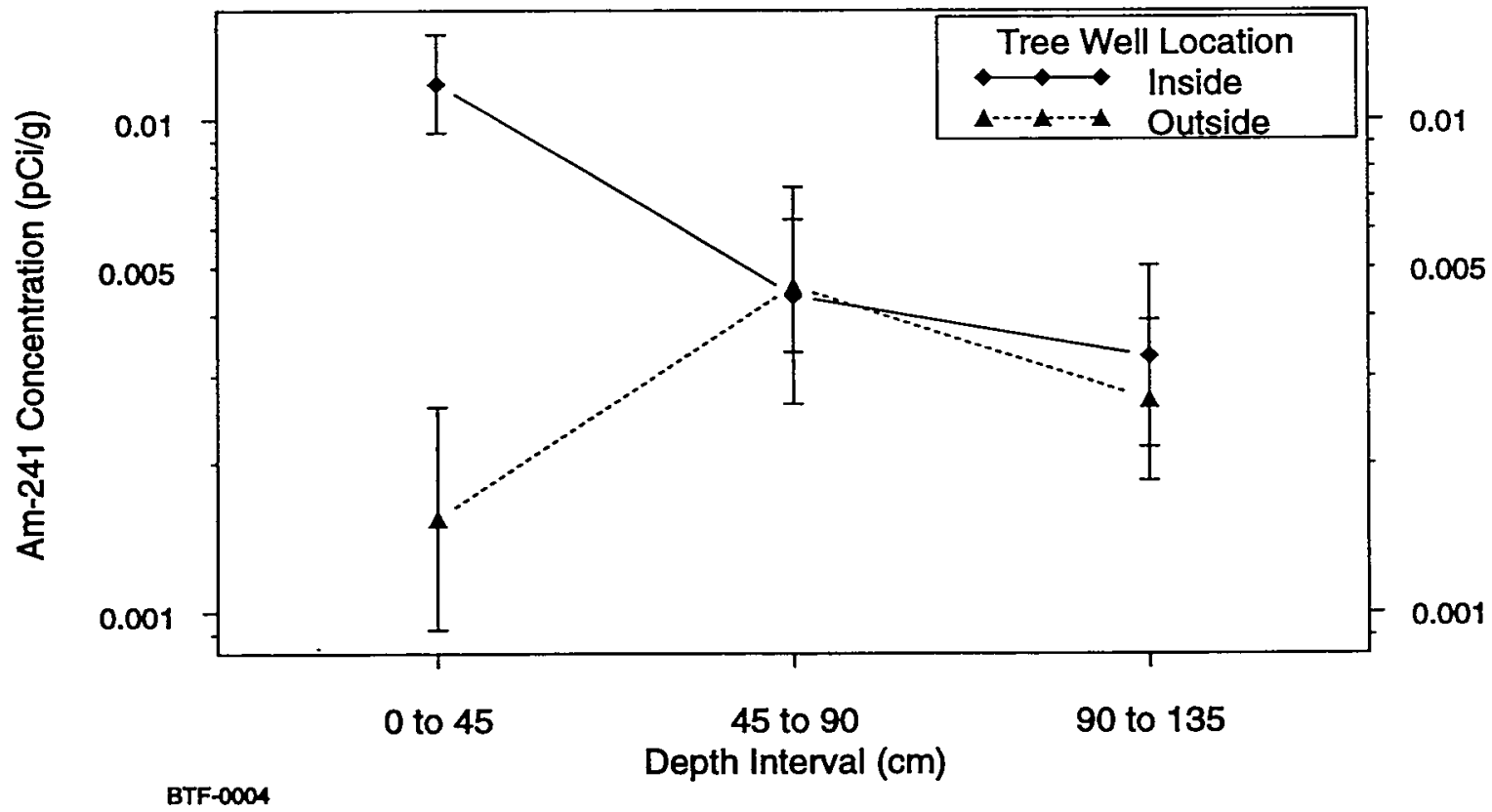

Figure 2.12 Geometric mean concentrations of Am-241 from sampling locations inside and outside tree wells, omitting two suspect results. Error bars are \pm one standard error. 
It should be noted that, like the Pu-238, the majority of the Am-241 results are nondetections, all but three of them are below the detection limit specified in the sampling plan, and very few have uncertainties less than $50 \%$.

\subsubsection{Tree Results: Metals}

The presence of five metals (chromium, copper, lead, nickel, and zinc) was also evaluated inside and outside the tree wells at the three depths. The metals were found at concentrations less than is typical of new sewage sludge, probably due to weathering or leaching over time of these materials after application of the sludge as a soil conditioner. Weathering of metals in sewage sludge applied to soil is a well documented, but not completely understood, phenomenon (McBride et al., 1997).

Statistically significantly higher concentrations of all metals were found inside the tree wells than outside the tree wells at the $0-45 \mathrm{~cm}$ depth (shaded cells in Table 2.14 indicate statistically significant differences, at the $5 \%$ level). Differences between inside and outside at the $45-90 \mathrm{~cm}$ interval were not as large as anticipated (see Section 2.2.2.7).

Table 2.14 Statistical significance levels of comparisons of metal concentrations inside tree wells vs. outside tree wells. ${ }^{b}$

\begin{tabular}{|c|c|c|c|}
\hline Metal & $0-45 \mathrm{~cm}^{2}$ & $45-90 \mathrm{~cm}^{\mathrm{a}}$ & $90-135 \mathrm{~cm}^{\mathrm{a}}$ \\
\hline Chromium & 0.00146 & 0.0854 & 0.0347 \\
\hline Copper & 0.00146 & 0.0786 & 0.344 \\
\hline Lead & 0.00146 & 0.0542 & 0.357 \\
\hline Nickel & 0.00342 & 0.0933 & 0.113 \\
\hline Zinc & 0.00146 & 0.181 & 0.515 \\
\hline Chromium, omitting suspect result & 0.00293 & 0.147 & 0.00488 \\
\hline Copper, omitting suspect result & 0.00293 & 0.157 & 0.216 \\
\hline Lead, omitting suspect result & 0.00293 & 0.108 & 0.194 \\
\hline Nickel, omitting suspect result & 0.00684 & 0.185 & 0.0635 \\
\hline Zinc, omitting suspect result & 0.00293 & 0.36 & 0.542 \\
\hline
\end{tabular}

- Shaded boxes indicate that the average concentration inside the tree well is greater than the average concentration outside the tree well, at the $5 \%$ level or better. 


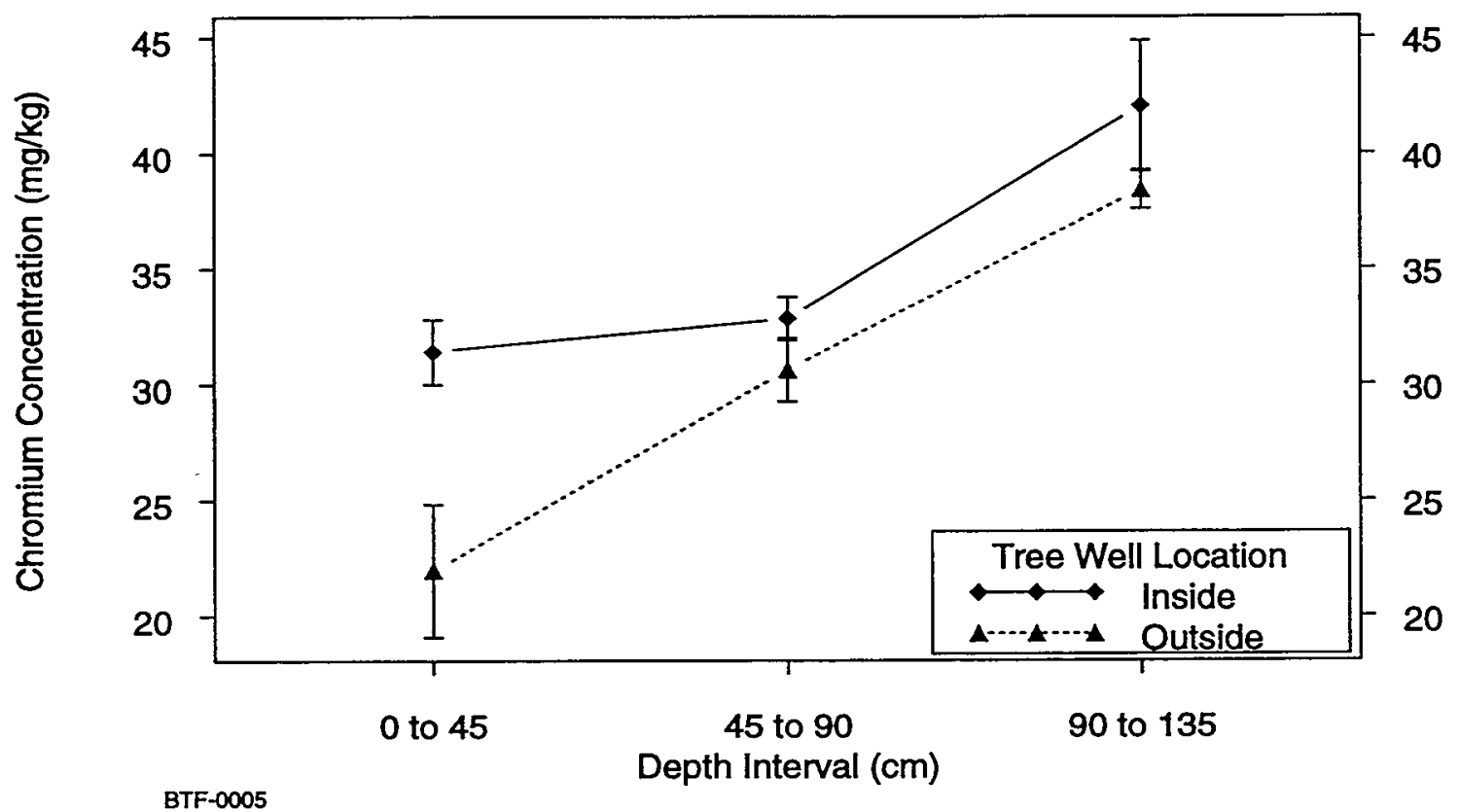

Figure 2.13 Average concentrations of chromium from sampling locations inside and outside of tree wells. Error bars are \pm one standard error.

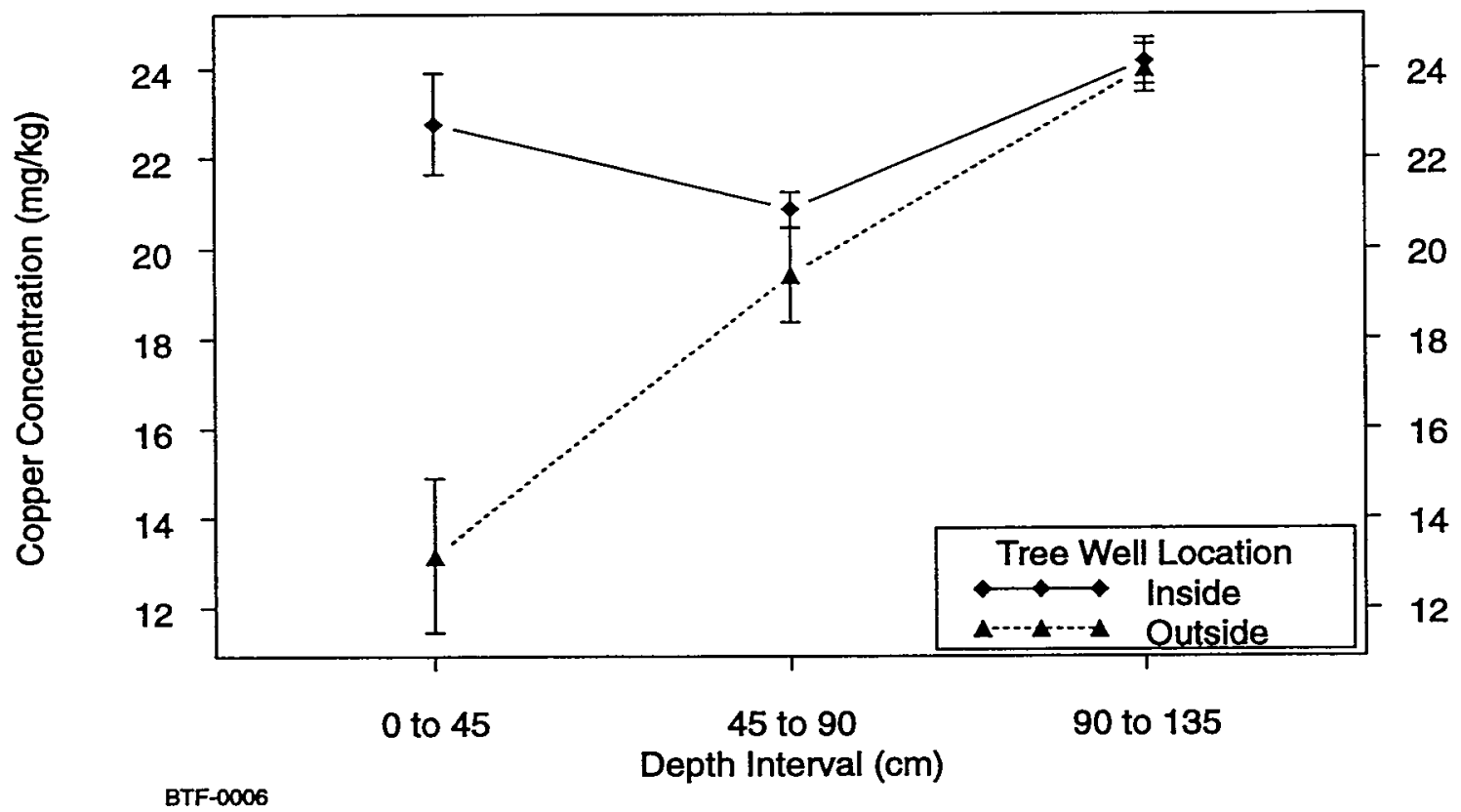

Figure 2.14 Average concentrations of copper from sampling locations inside and outside of tree wells. Error bars are \pm one standard error. 


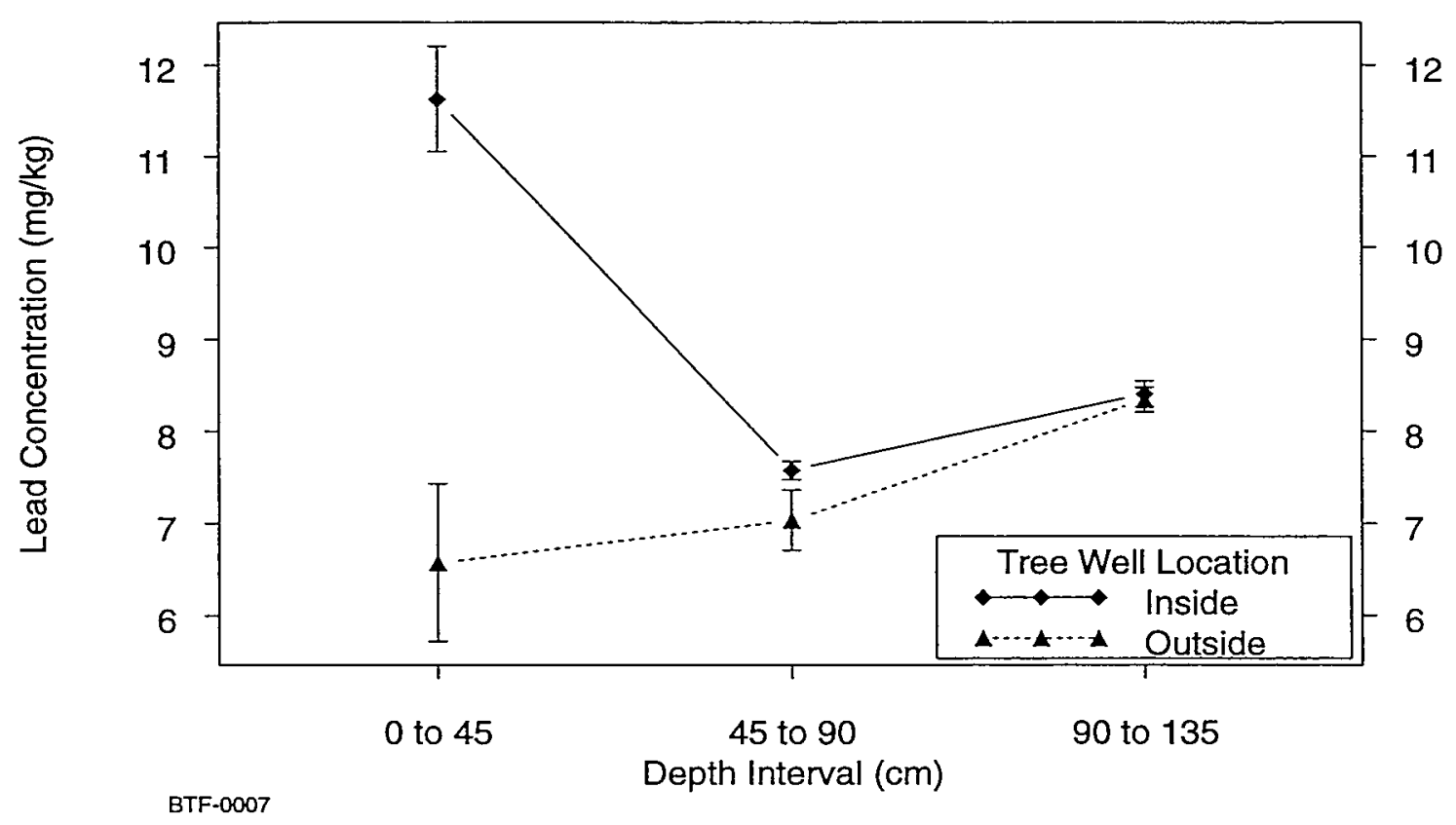

Figure 2.15 Average concentrations of lead from sampling locations inside and outside of tree wells. Error bars are \pm one standard error.

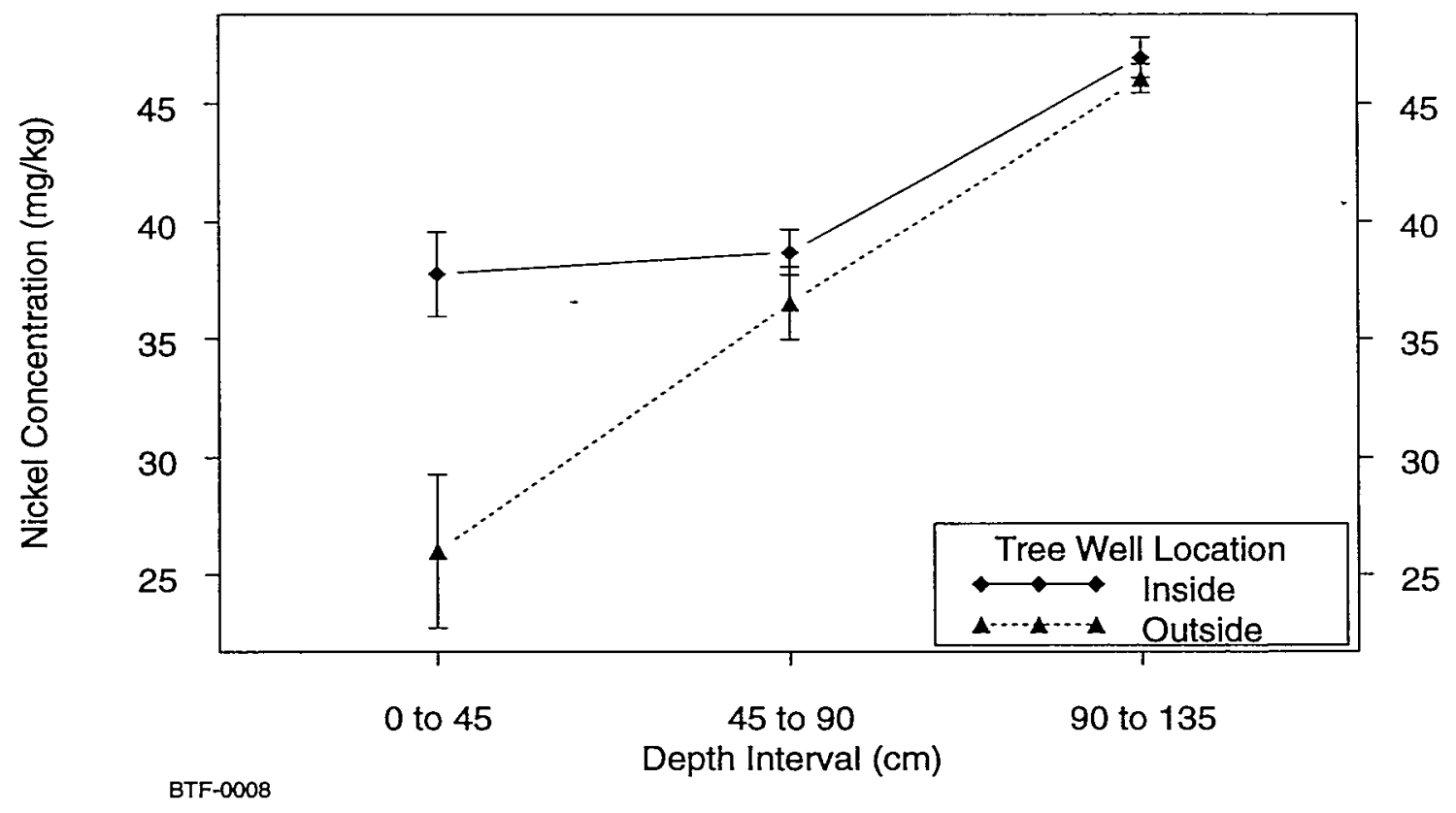

Figure 2.16 Average concentrations of nickel from sampling locations inside and outside of tree wells. Error bars are \pm one standard error. 


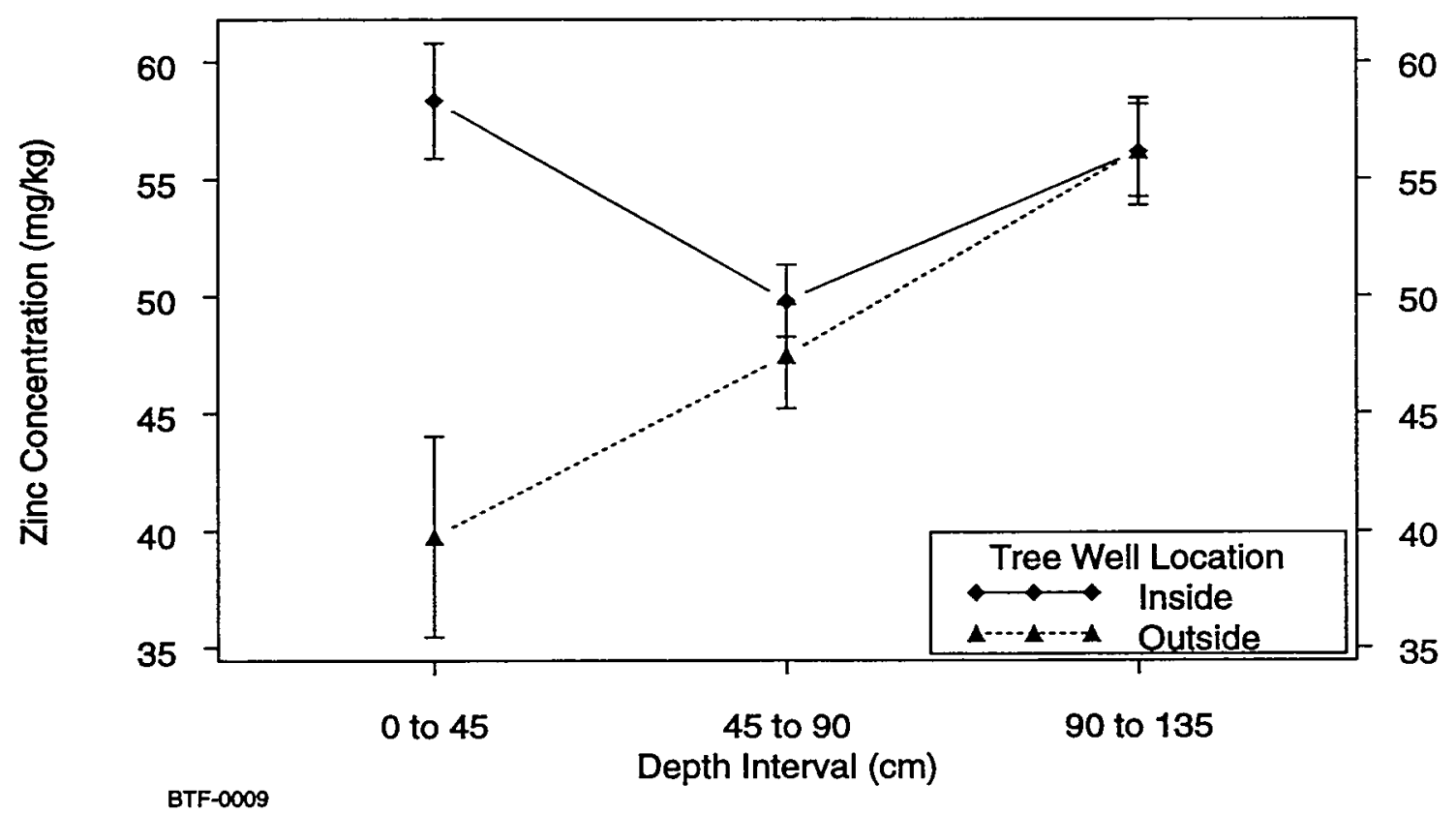

Figure 2.17 Average concentrations of zinc from sampling locations inside and outside of tree wells. Error bars are \pm one standard error.

\subsubsection{Comparison of grid results with tree well results.}

Further support for the top-dressing sludge hypothesis can be found by comparing the $\mathrm{Pu}-239+240$ values in grid samples to values in tree-well samples. If $\mathrm{Pu}-239+240$ values from all depths $(0-5 \mathrm{~cm}, 5-10 \mathrm{~cm}, 10-20 \mathrm{~cm}, 20-30 \mathrm{~cm}$, and $30-40 \mathrm{~cm})$ from the grid samples at each location are averaged and those averages are compared to $0-45 \mathrm{~cm}$ deep tree-well samples, the Radial 1 samples are of the same order of magnitude as the samples collected inside the tree wells (see Figure 2.18), and the other grid samples (Radials 2-4) are of the same order of magnitude as those collected outside the tree wells.

The average Pu-239+240 concentrations of the Radial 1 grid samples (each normalized to an equivalent depth as described in the previous paragraph) and the tree well samples are $0.055 \mathrm{pCi} / g$ and $0.046 \mathrm{pCi} / g$, respectively. These are not statistically different. The geometric means are even closer, $0.030 \mathrm{pCi} / \mathrm{g}$ and $0.037 \mathrm{pCi} / \mathrm{g}$, respectively. 


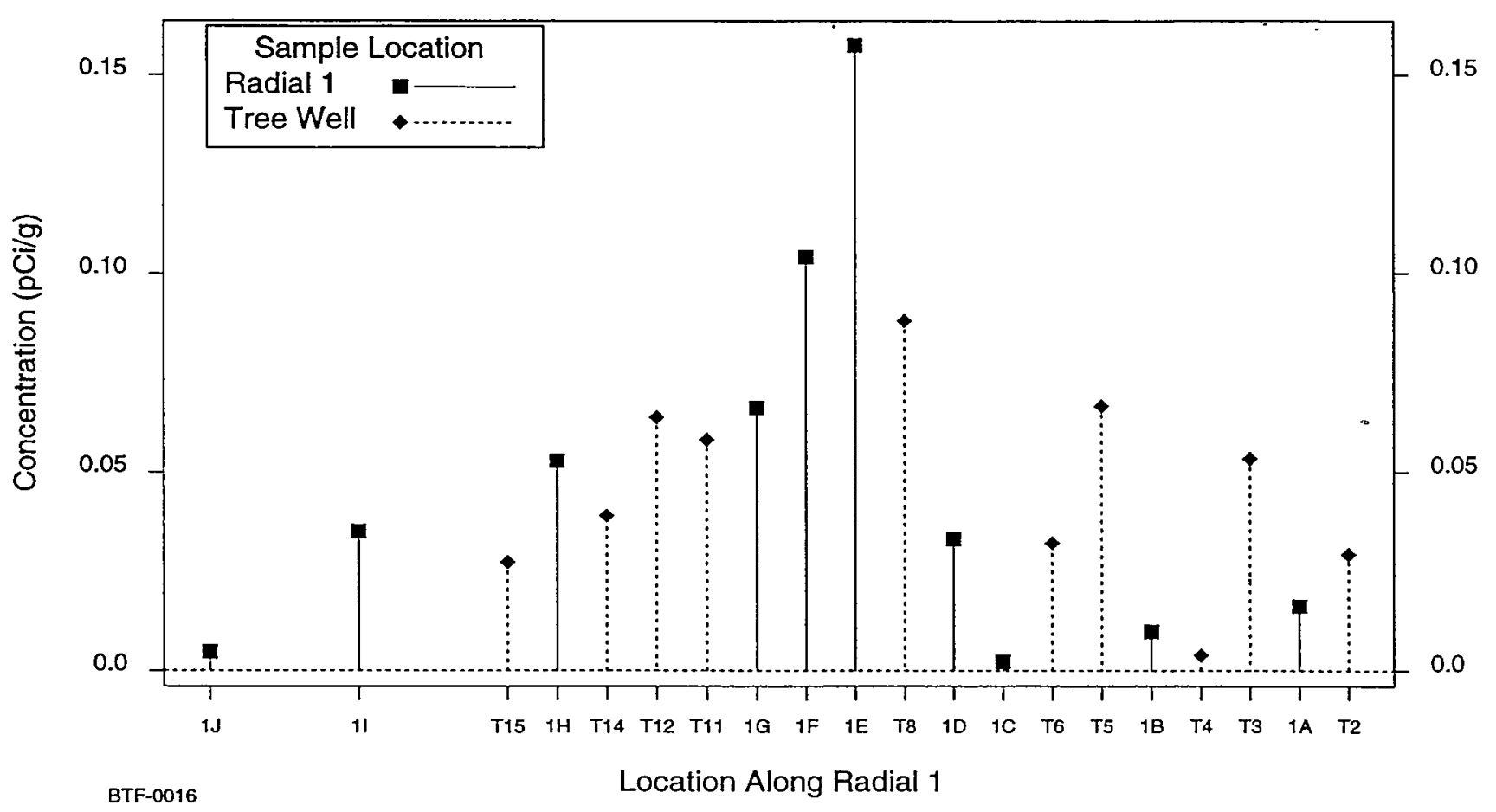

Figure 2.18 Pu-239+240 concentrations measured at grid locations on Radial 1 and in tree wells. Tree samples were collected at 0-45 cm depth intervals and grid samples were normalized to the same depth interval.

\subsubsection{Correlations between tree well ratios}

The discussions of the tree well results in the previous sections focused on average concentrations. That is, at each depth and for each analyte the average of the ten trees' inside-well results was compared with the average of the ten trees' outside-well results.

Another approach is to study the individual ratios. That is, for each tree divide the inside-top sample result by the outside-top sample result, divide the inside-middle sample result by the outside-middle sample result, and so on. The sludge hypothesis suggests that a tree with a large ratio for any one analyte should have large ratios for the other analytes. If the hypothesis is correct, a tree with a larger ratio for any one analyte has a greater proportion of sludge mixed with the soil, and this should increase the concentration for all metals in the sludge. This relationship between different analytes in the same sample is referred to in statistical terms as "having a high correlation" so the data analysis uses graphics and numerical correlation coefficients to find out whether the relationship exists.

Note that: (1) the contaminant must be distributed relatively homogeneously throughout the sludge - otherwise more sludge in the mix does not necessarily imply 
more contaminant in the mix, and (2) the contaminant concentrations must be large enough to be detected and measured so that the ratios can be calculated with good precision.

Of thirty pairs of samples per analyte (10 trees at 3 depths), only seven of the $\mathrm{Pu}$ 239+240 pairs, one Pu-238 pair, and three Am-241 pairs resulted in detections of the analyte both inside and outside the tree well. Only one of the Am-241 pairs had a ratio with less than $100 \%$ uncertainty. The Pu-239+240 results from the inside-top samples had good precision, but the outside top results had low concentrations and therefore large uncertainties. As a result the $\mathrm{Pu}-239+240$ ratios had large uncertainties, ranging from $59 \%$ to $97 \%$, so they do not satisfy the second condition. The $Q C$ results (Section 3.2) indicate that $\mathrm{Pu}-239+240$ is at least somewhat heterogeneously distributed.

In contrast, the analyses for metals satisfy these conditions. Ratios of two pairs of metals are shown in Figure 2.19 (copper and chromium) and Figure 2.20 (nickel and zinc). The other pairs of metals are similar. Correlations for all pairs are shown in Table 2.15.

\section{Table 2.15 Correlation matrix of metal inside:outside tree well ratios}

\begin{tabular}{c|cccc} 
& Chromium & Lead & Nickel & Zinc \\
\hline Copper & 0.979 & 0.995 & 0.985 & 0.990 \\
Chromium & & 0.972 & 0.995 & 0.988 \\
Lead & & & 0.976 & 0.989 \\
Nickel & & & & 0.993
\end{tabular}

These correlations are extremely high. This is in part due to Tree 3, which had an unusually large inside:outside ratio. Even if Tree 3 is excluded, the correlations are still very high, ranging from 0.7 to 0.95 (with seven out of ten correlations above 0.8 ). Because the sewage sludge hypothesis correctly predicts these high correlations, the data support the sludge hypothesis. 


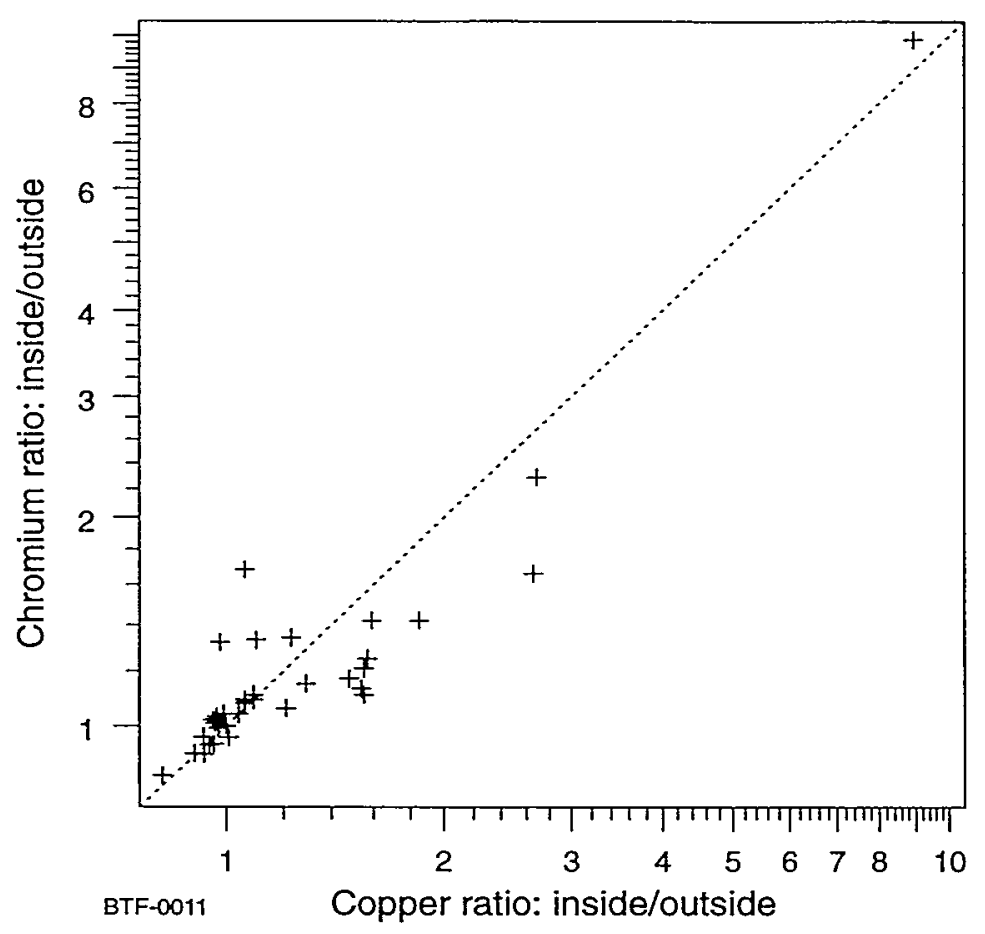

Figure 2.19 Correlation between copper ratios and chromium ratios.

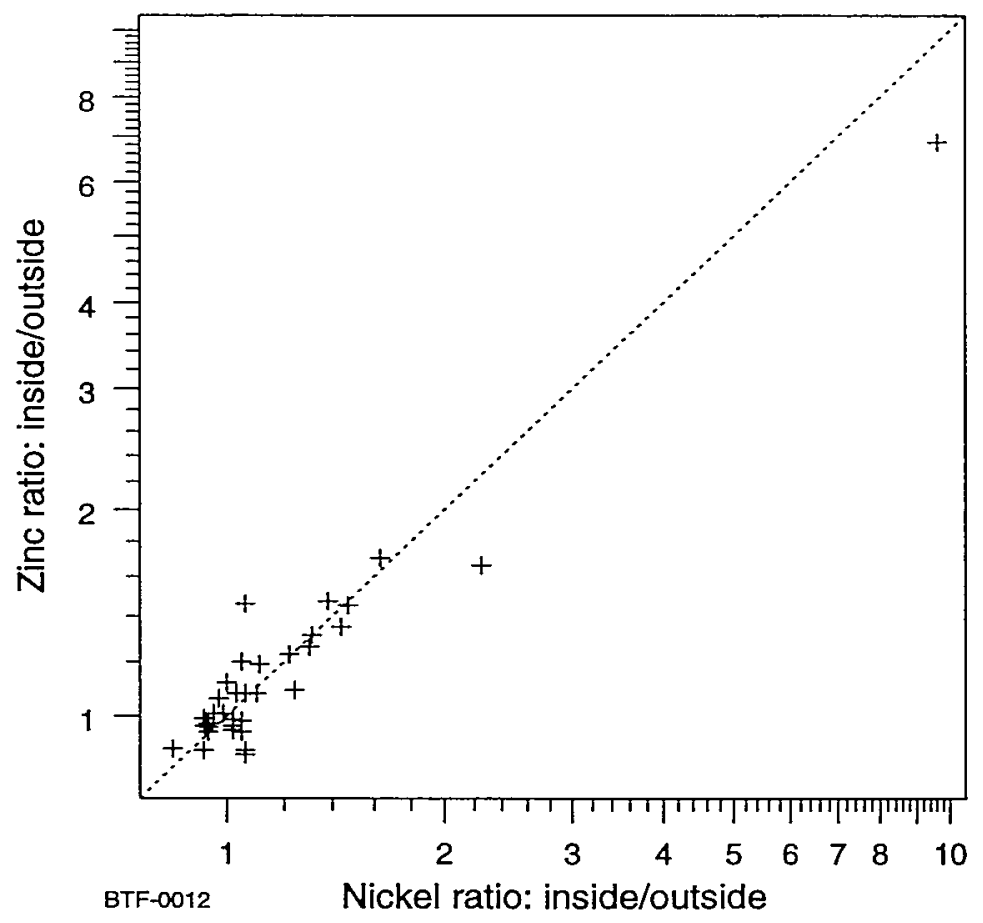

Figure 2.20 Correlation between nickel ratios and zinc ratios. 


\subsubsection{Conclusions Regarding the Sludge Pathway}

Several different ways of looking at the data from the 1998 sampling have shown patterns consistent with the sludge pathway. Foremost among these are the proximity of the highest concentrations of plutonium in surface soil to the ornamental trees, and the presence of metals and plutonium in the tree wells immediately adjacent to the trees.

\subsubsection{Aerial Distribution Pathway}

Another pathway that has been suggested for transmission of plutonium to Big Trees Park is aerial distribution. Although the state and federal agencies that reviewed data from Big Trees Park prior to the 1998 sampling concluded that the plutonium found at 1995 Location 1 was not due to air deposition (EPA 1995; CDHS-EHIB 1998, p. 10), this pathway is further evaluated below using the 1998 data.

The draft version of the health consultation suggested that there was plutonium "throughout the park" due to an aerial release from LLNL (CDHS-EHIB, 1998 pp. 8, 10). This was based on a misinterpretation of the 1995 data (see Section 6), and was removed from the final version. The final version of the health consultation instead hypothesized that the park might be the recipient of "a one time 'puff' release or minute releases over time from LLNL" (CDHS-EHIB, 1999 p. 15). This, too, is evaluated below.

\subsubsection{Grid Results}

The 1998 grid samples show concentrations averaging 10 to 20 times higher along the first grid radial (see Table 2.2) than along the other radials. This pattern of distribution, illustrated in Figure 2.3, is not consistent with aerial distribution because aerial distribution would be expected to show similar averages over the entire area. The subhypothesis that airborne plutonium collected on the leaves of trees and was washed to the ground at Location 1 by rain was rejected by CDHS-EHIB $(1999, \mathrm{p} 15)$ because similarly elevated levels are not found in 1995 around eucalyptus trees away from Location 1. The 1998 data follow a similar pattern and therefore support and strengthen the previous conclusion that plutonium at 1995 Location 1 (which is part of the Radial 1 area) is not due to aerial distribution.

A few of the grid samples of the top $5 \mathrm{~cm}$ away from Radial 1 are above falloutbackground. Other than location $4 \mathrm{H}$ the greatest is $0.037 \mathrm{pCi} / \mathrm{g} \mathrm{Pu}-239+240$, only slightly above fallout-background. These could be explained by one or more factors, including (1) local runoff during rainstorms that would transport material from the 
Radial 1 area to other areas, (2) local re-suspension of dust during the dry season that would transport material to other areas, (3) park maintenance activities such as raking leaves and other debris and transporting them, and (4) spillage of sludge used as soil amendment as it was transported to the ornamental trees.

\subsubsection{Air Surveillance Monitoring}

Data available about air dispersion of plutonium do not support an air route of transport of plutonium to Big Trees Park from LLNL. One potential source could be the Plutonium Facility (Building 332). However; emissions from the facility are filtered with high-efficiency particulate air (HEPA) filters before being released. Sampling systems at the Plutonium Facility consistently show no emissions from that building, except in 1980 when a release occurred (DOE, 1982). This release would be a "one-time puff" of the kind hypothesized by the final health consultation. However, according to records from the LLNL meteorological station that was operating at the time, the wind was not blowing toward the park. Even if the wind had been blowing directly toward the park, air modeling of this release indicates that the amount of plutonium deposited in the soil at the park would be too small to measure (on the order of $0.00000045 \mathrm{pCi} / \mathrm{g}$; see Appendix 2). The plutonium found in Big Trees Park can not be attributed to the 1980 release.

Re-suspension of soil containing plutonium from the southeast quadrant of LLNL is a potential source of "minute releases over time." However, meteorological data show that Big Trees Park is downwind of LLNL only about $5 \%$ of an average year, and that most of the $5 \%$ is during winter and early spring when re-suspension is low due to moistness of the soil.

Figure 2.21 shows concentrations of $\mathrm{Pu}-239+240\left(\mathrm{pCi} / \mathrm{m}^{3}\right)$ in air from air-particulate monitoring location L-B531-AF, located near Building 531 in the southeast quadrant of LLNL $^{1}$. The sampler was in operation from June 1991 through December 1999. Until 1997, the location was surrounded by bare soil. In 1997 a new parking lot covered much of the nearby soil and measured concentrations decreased. In 1999 the remaining soil was covered with tanbark, and the station no longer produced useful information. Therefore the figure shows five complete years of monthly measurements, 1992 through 1996. From this figure, and the following Figure 2.22, it can be seen that Pu-239+240 concentrations in air are highest during the drier parts of the year. This indicates that the primary source of $\mathrm{Pu}-239+240$ in this sampler is soil re-suspension.

\footnotetext{
${ }^{1}$ These data come from LLNL's environmental surveillance monitoring program, results of which are reported each year in the LLNL Site Annual Environmental Report.
} 
Figure 2.21 also shows for each month the proportion of time that wind measured at the LLNL onsite meteorological station was blowing due west, i.e., directly toward Big Trees Park. This figure shows that when Pu-239+240 concentrations are higher, i.e., when re-suspension is higher, the wind usually blows away from Big Trees Park.

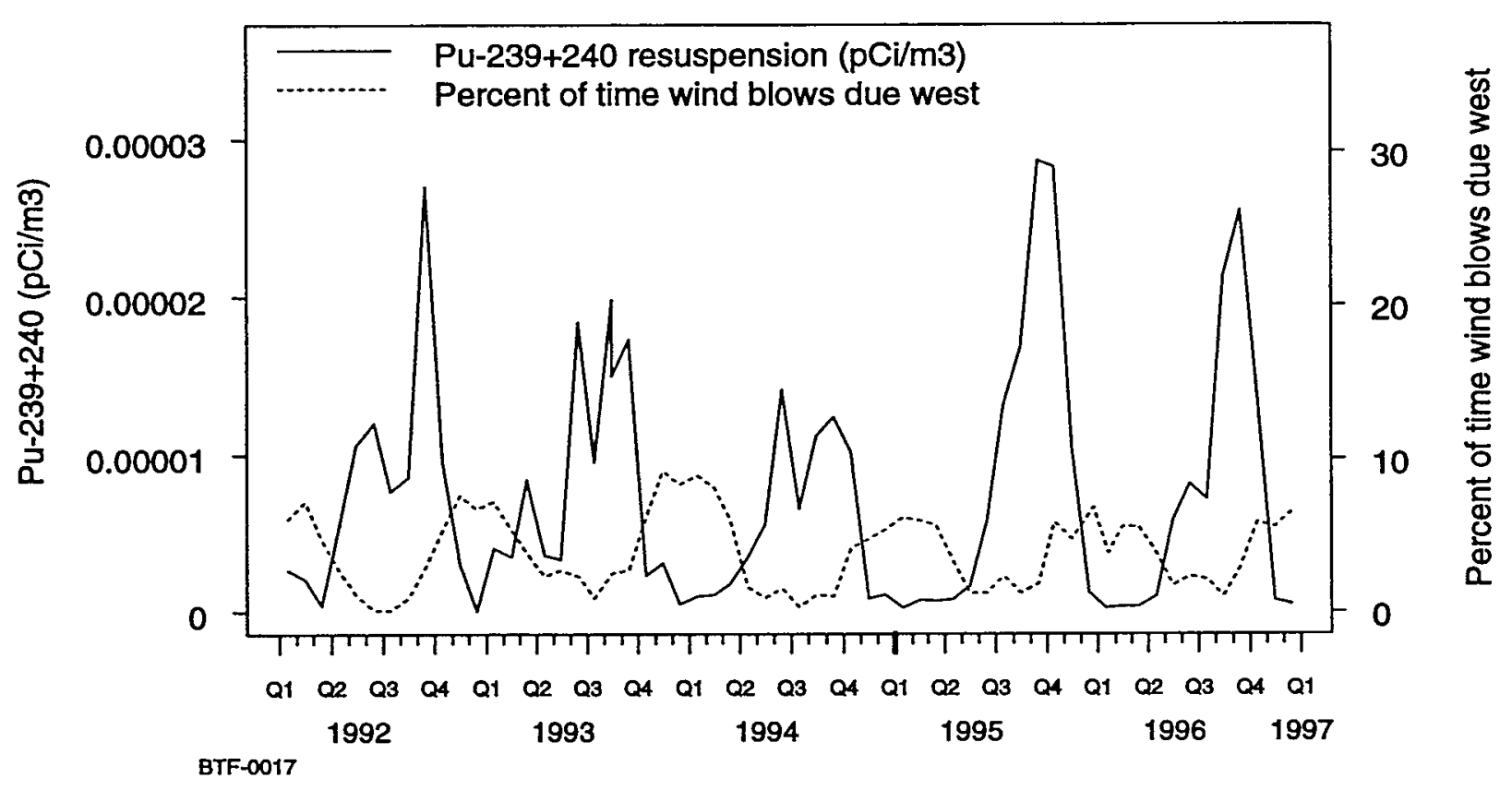

Figure 2.21 Monthly wind direction data and resuspension of Pu-239+240 at sampling location L-B531-AF, 1992 through 1996.

Figure 2.22 shows the same data, averaged over the entire five-year period. From this it is apparent that only in October (on average) is there any overlap between resuspension and winds blowing toward Big Trees Park. Although minute amounts of contaminated soil have probably been carried west, resuspension is clearly not a plausible mechanism for the contamination found in Big Trees Park.

These measurements of $\mathrm{Pu}-239+240$ in air represent extremely low levels. The maximum air concentration in this data set is about $0.14 \%$ of the DOE derived concentration guide for radioactivity in air (DOE 1973) and represents an exposure that is at least 700 times lower than that of natural background radiation from all sources (See Appendix 3). 


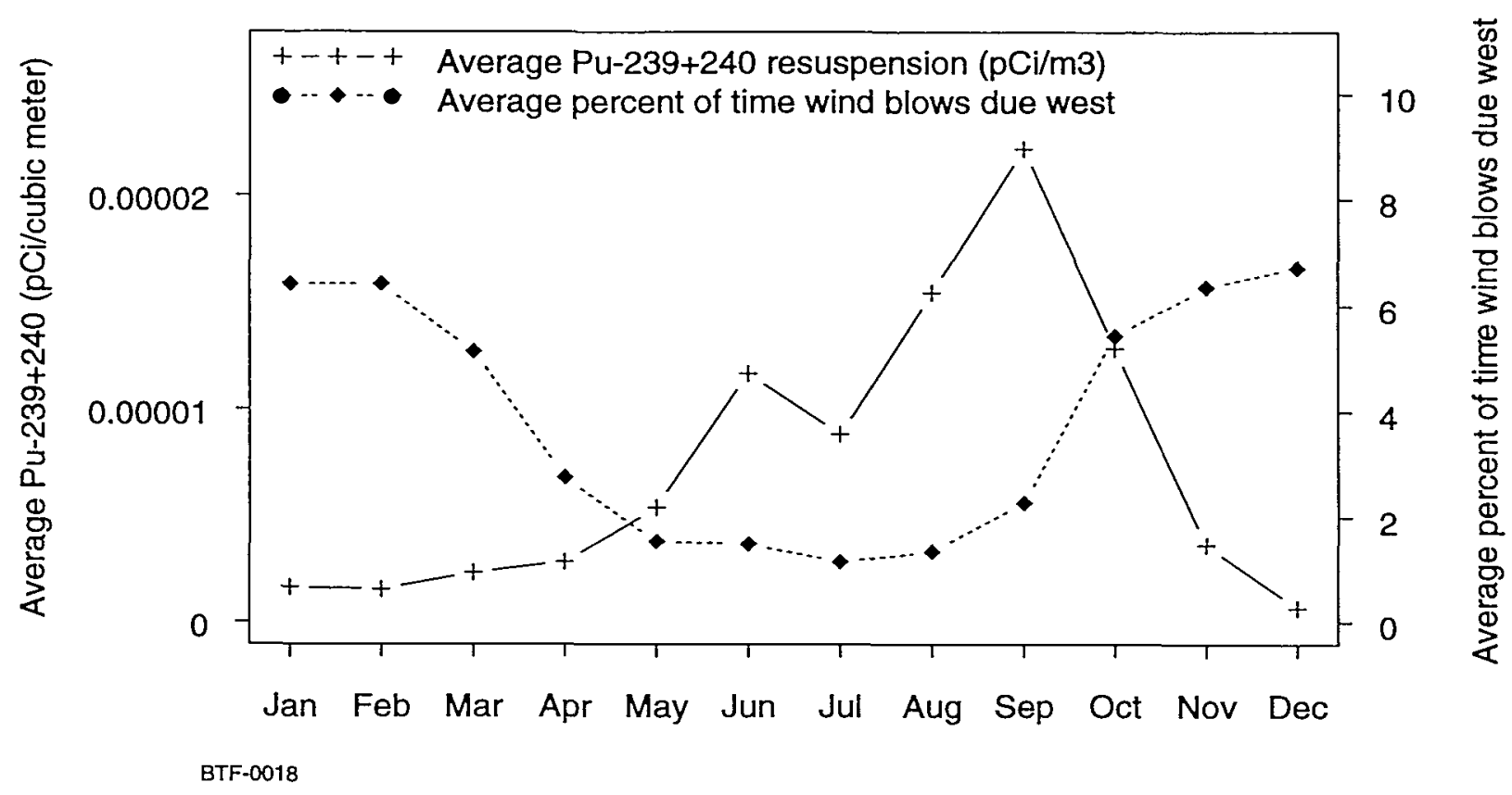

Figure 2.22 Average monthly wind direction data and resuspension of Pu239+240 at sampling location L-B531-AF, 1992 through 1996.

\subsubsection{Soil Surveillance Monitoring}

Soil surveillance sampling location L-MESQ-SO, like Big Trees Park, is located west of LLNL (Figure 2.23). It is located roughly one-half of the distance from the Plutonium Facility (B332) to Big Trees Park. Another location, L-MET-SO, is located near the northwestern corner of LLNL. 


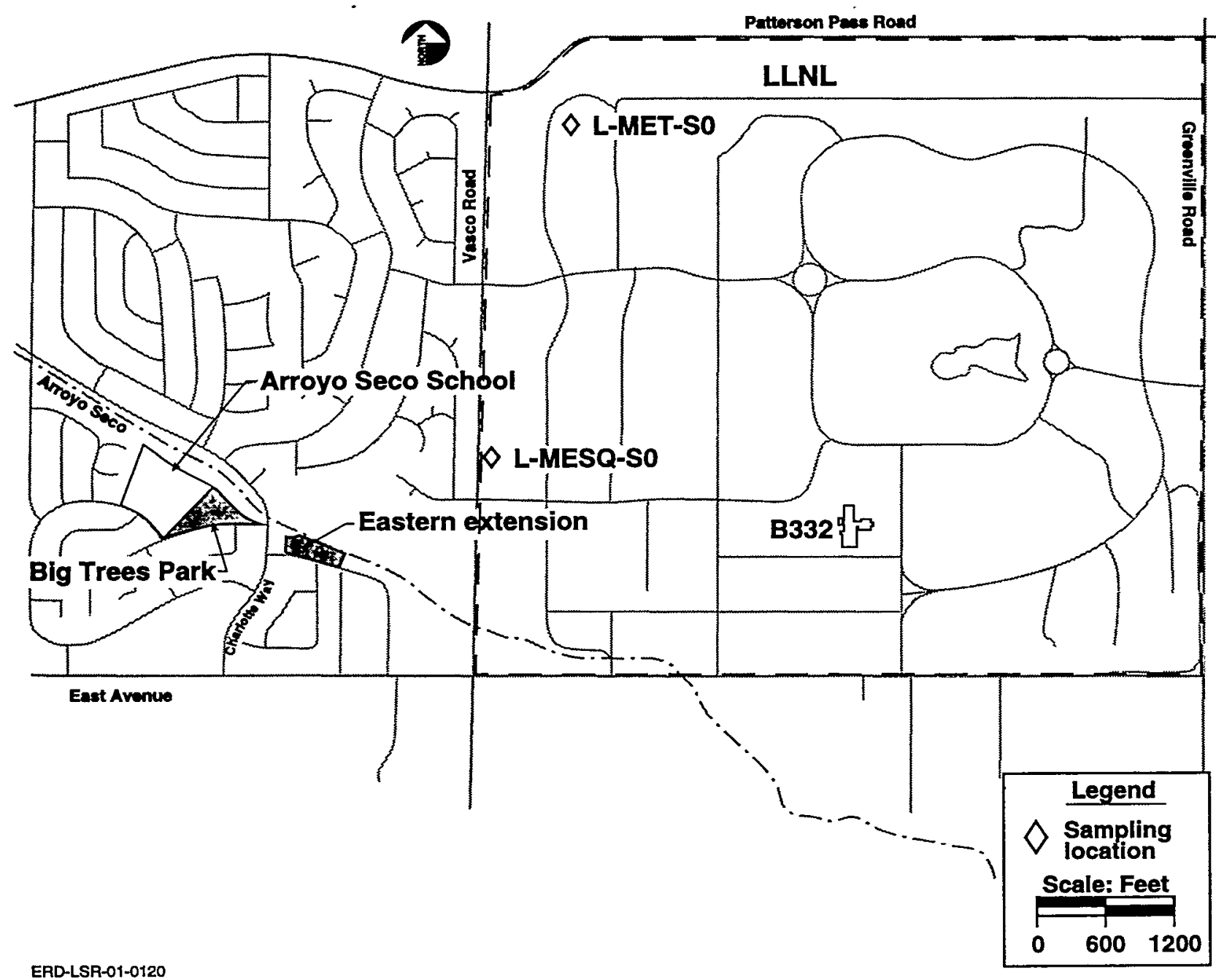

Figure 2.23 Soil surveillance monitoring locations near to and west and northwest of LLNL.

If air dispersion, either short-term or on going, is responsible for the plutonium found in the grid area, then L-MESQ-SO, and possibly L-MET-SO, should have concentrations at least as large as those of the grid. As shown in Figure 2.24 and Table 2.16 through Table 2.18, they do not.

Concentrations at the two soil sampling locations are lower than at Big Trees Park, and the differences are statistically significant. This demonstrates that air dispersion is not responsible for the plutonium in Big Trees Park. 


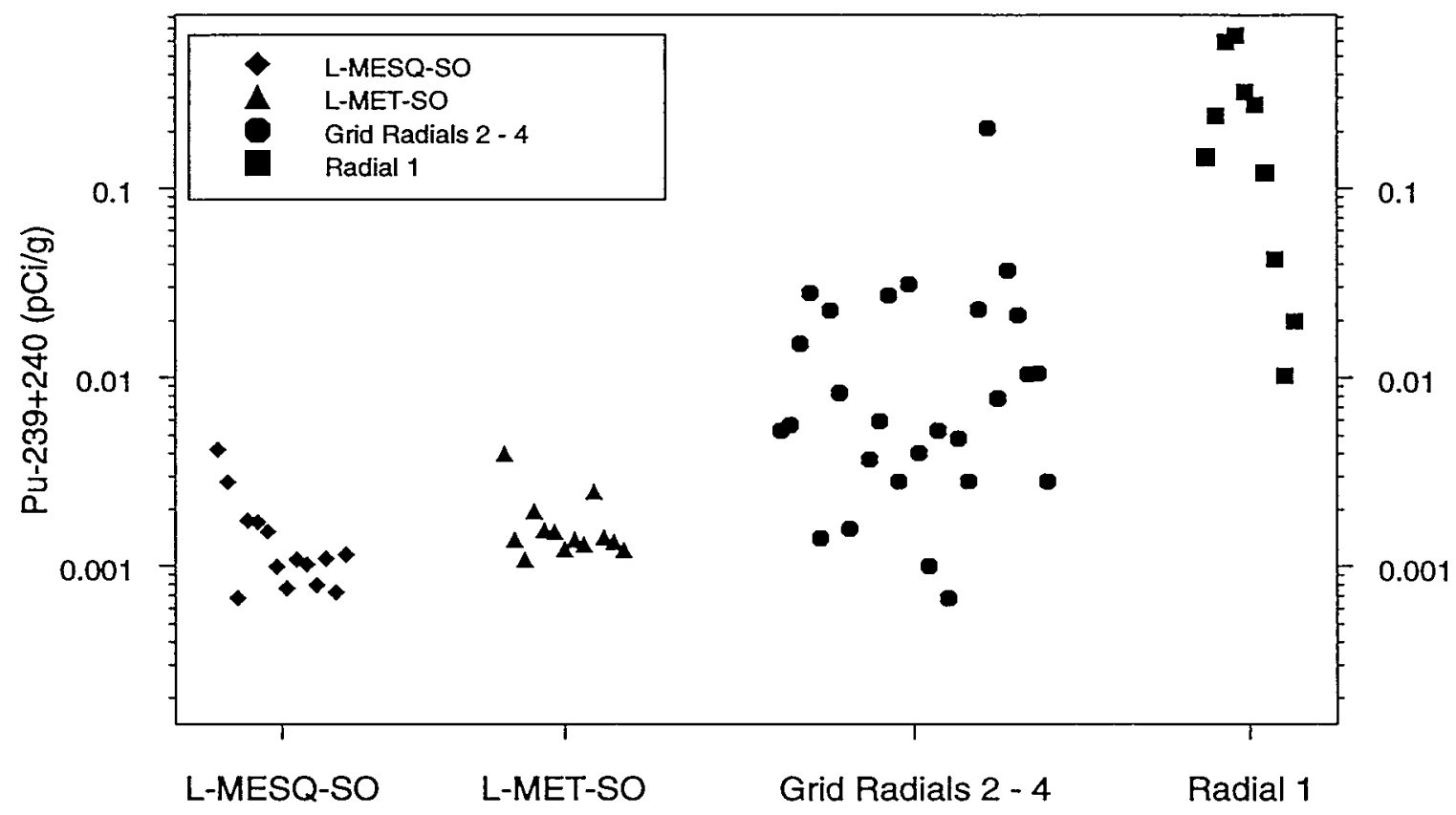

BTF-0015

Figure 2.24 Comparison of surveillance monitoring locations with grid locations, 0-5 cm.

Table 2.16 Average Pu-239+240 concentrations at surveillance monitoring locations and grid locations, 0-5 cm.

\begin{tabular}{clccc}
\hline Location & $\begin{array}{c}\text { Average } \\
\text { (pCi/g) }\end{array}$ & $\begin{array}{c}\text { Standard Deviation } \\
\text { (pCi/g) }\end{array}$ & N & Date Range \\
\hline L-MESQ-SO & 0.00145 & 0.000972 & 14 & $1986-2000$ \\
L-MET-SO & 0.00168 & 0.000788 & 13 & $1988-2000$ \\
Grid Radials 2 - 4 & 0.0178 & 0.0386 & 28 & 1998 \\
Radial 1 & 0.241 & 0.225 & 10 & 1998 \\
\hline
\end{tabular}

Table 2.17 Analysis of variance comparing surveillance monitoring locations and grid locations, $0-5 \mathrm{~cm}^{{ }^{2}}$

\begin{tabular}{cccccc}
\hline Factor & $\begin{array}{c}\text { Degrees of } \\
\text { Freedom }\end{array}$ & $\begin{array}{c}\text { Sum of } \\
\text { Squares }\end{array}$ & $\begin{array}{c}\text { Mean } \\
\text { Squares }\end{array}$ & F Value & $\begin{array}{c}\text { Significance } \\
\text { Level }\end{array}$ \\
\hline Location & 3 & 153 & 50.99 & 46.62 & $1.11 \times 10^{-15}$ \\
Residuals & 60 & 65.63 & 1.094 & & \\
\hline Note: Analysis was performed on the logarithms of the data.
\end{tabular}

Examination with a statistical multiple-comparisons procedure shows that locations on grid Radials 2 through 4 are significantly different than the surveillance locations and 
the two surveillance locations are not different from each other. Also, Radial 1 is significantly different than all of the other locations.

Table 2.18 Simultaneous $95 \%$ confidence intervals for the ratios of surveillance monitoring locations with grid locations, $0-5 \mathrm{~cm}$.

\begin{tabular}{clc}
\hline \multicolumn{1}{c}{ Locations } & Ratio $^{\mathrm{a}}$ & Confidence Interval $^{\mathrm{b}}$ \\
\hline Grid Radials 2 - 4 vs. L-MESQ-SO & 6.05 & $2.43-15$ \\
Grid Radials 2 - 4 vs. L-MET-SO & 4.81 & $1.89-12.2$ \\
Grid Radials 2 - 4 vs. Radial 1 & 0.0589 & $0.0212-0.164$ \\
L-MESQ-SO vs. L-MET-SO & 0.795 & $0.274-2.3$ \\
L-MESQ-SO vs. Radial 1 & 0.00973 & $0.0031-0.0306$ \\
L-MET-SO vs. Radial 1 & -0.0122 & $0.0083-0.0392$ \\
\hline
\end{tabular}

a Ratios shaded gray are statistically significant, as indicated by confidence intervals that exclude the ratio 1.0.

- Confidence intervals were calculated using Tukey's HSD on differences between the average log concentrations, and are presented in the table after back transformation to data units.

\subsubsection{Conclusions Regarding the Aerial Distribution Pathway}

The patterns with which higher concentrations of plutonium were found in the 1998 sampling are not consistent with aerial distribution. In particular, the elevated levels are found in too small an area to be attributable to aerial deposition. Lower levels of plutonium in soil are found closer to LLNL than Big Trees Park, which is the opposite of what would be expected from aerial distribution. In addition, none of the State or Federal agencies that has examined data from Big Trees Park has suggested that the elevated levels along the northeastern border of the park are due to aerial deposition (EPA, 1995; CDHS-EHIB, 1999; ATSDR 2000).

\subsection{Special Sampling}

As a result of public comments and discussions among DOE/LLNL and the regulatory agencies, samples were also collected in 1998 in the disked area, the playing field, the park's eastern extension, and 1995 sampling Locations 1, 7, and 8 (Figure 2.1).

\subsubsection{Disked Area}

The disked area is an open field on the northeast corner of the school property, next to the park. This area has been disked annually for weed abatement and fire control, but otherwise appears not to be maintained. At the suggestion of a nearby resident attending a DOE/LLNL-hosted presentation of the draft sampling plan who reported that children play in this area, LLNL increased the number of samples in this area (MacQueen, 1998). 
Four samples were collected at locations randomly selected within the disked area (see Table 2.19). After several years of disking, it can be reasonably assumed that soil has been thoroughly mixed to depths of at least $15 \mathrm{~cm}$. Because this was the first sampling of this area, the primary question was whether or not there are levels of plutonium above fallout-background in this area. The average $\mathrm{Pu}-239+240$ concentration in the disked area is $0.0018 \mathrm{pCi} / \mathrm{g}$, which is well within the range of fallout-background concentrations.

Table 2.19 Disked Area Results.

\begin{tabular}{lllll}
\hline Sample ID & Depth & Type & Pu-239+240 $(\mathrm{pCi} / \mathrm{g})^{*}$ & ${\text { Pu-238 }(\mathrm{pCi} / \mathrm{g})^{\mathrm{a}}}^{{ }^{*}}$ \\
\hline DISK01 & $0-15$ & & $0.00285 \pm 0.00218$ & $0.0041 \pm 0.00361$ \\
DISK02 & $0-15$ & & $0.00291 \pm 0.00292$ & $0.000808 \pm 0.00265$ \\
DISK03 & $0-15$ & & $0.00049 \pm 0.00213$ & $-0.00064 \pm 0.0025$ \\
& $0-15$ & Split & $0.00036 \pm 0.00119$ & $-0.000845 \pm 0.000442$ \\
& $0-15$ & Split & $-0.00079 \pm 0.003$ & $0.0017 \pm 0.003$ \\
DISK04 & $0-15$ & & $0.00142 \pm 0.00212$ & $0.000236 \pm 0.00236$ \\
\hline
\end{tabular}

- Non-detections are shown in italics.

\subsubsection{Playing Field}

The playing field is an open field behind the school grounds proper. It is now turfed, but was a dirt field at the time of sampling. It is accessible to children as they travel to and from school. Location 12 from 1995 was in this area, and all three 1995 analytical laboratories reported values well within the range of fallout-background concentrations (see Table 2.20).

Two samples were collected in 1998 in this area. All Pu-239+240 results were within the range of fallout-background concentrations (see Table 2.20). 


\section{Table 2.20 Playing Field Results}

\begin{tabular}{|c|c|c|c|c|}
\hline Sample & Depth (cm) & Type & $\mathrm{Pu}-239+240(\mathrm{pCi} / \mathrm{g})^{\mathrm{a}}$ & Pu-238 (pCi/g) = \\
\hline \multirow[t]{10}{*}{1998 No. 1} & $0-5$ & & $0.00493 \pm 0.00318$ & $0.00296 \pm 0.00245$ \\
\hline & $0-5$ & Split & $-0.000192 \pm 0.0014$ & $0.0033 \pm 0.00203$ \\
\hline & $5-10$ & & $0.00105 \pm 0.00122$ & $0.0013 \pm 0.0028$ \\
\hline & $5-10$ & Split & $0.00154 \pm 0.00179$ & $0.000699 \pm 0.00281$ \\
\hline & $10-20$ & & $0.00377 \pm 0.00271$ & $0.00284 \pm 0.00234$ \\
\hline & $10-20$ & Split & $0.0032 \pm 0.00455$ & $0.0016 \pm 0.00322$ \\
\hline & $20-30$ & & $-0.00014 \pm 0.00145$ & $-0.00014 \pm 0.00145$ \\
\hline & $20-30$ & Split & $0.000949 \pm 0.0011$ & $0.00127 \pm 0.00128$ \\
\hline & $30-40$ & & $0.00185 \pm 0.00216$ & $0.000718 \pm 0.00238$ \\
\hline & $30-40$ & Split & $0.00731 \pm 0.00357$ & $0.00178 \pm 0.00265$ \\
\hline \multirow[t]{7}{*}{1998 No. 2} & $0-5$ & & $0.00137 \pm 0.00265$ & $0.00107 \pm 0.00153$ \\
\hline & 0.5 & Split & $0.000894 \pm 0.00129$ & $0.0000102 \pm 0.00078$ \\
\hline & $0-5$ & Split & $0.0017 \pm 0.003$ & $-0.00043 \pm 0.003$ \\
\hline & $5-10$ & & $0.0000157 \pm 0.00238$ & $-0.000644 \pm 0.00166$ \\
\hline & $10-20$ & & $0.000731 \pm 0.000849$ & $0.00122 \pm 0.0011$ \\
\hline & $20-30$ & & $0.00111 \pm 0.00149$ & $0.000705 \pm 0.00285$ \\
\hline & $30-40$ & & $0.0000992 \pm 0.00178$ & $0.00187 \pm 0.00254$ \\
\hline \multirow[t]{3}{*}{1995 No. 12} & 0.5 & & $0.0009 \pm 0.0012$ & $0.00 \pm 0.0012$ \\
\hline & $0-5$ & Split & $0.00483 \pm 0.0134$ & $-0.00846 \pm 0.0226$ \\
\hline & $0-5$ & Split & $0.005 \pm 0.003$ & $-{ }^{b}$ \\
\hline
\end{tabular}

\subsubsection{Special Sampling of the Big Trees Park Eastern Extension}

The eastern extension of Big Trees Park was constructed in about 1986, approximately 15 years after the development of the main grounds of Big Trees Park. It is adjacent to the arroyo, just upstream of where the arroyo enters the concrete channel east of Charlotte Way (Figure 1.1).

Location 13 from the 1995 sampling was in the eastern extension. Two of three laboratories reported results well within the range of fallout. The third laboratory reported a result above fallout-background, but with a high degree of uncertainty (MacQueen, 1995; see also Table 2.21 and Section 6).

Three samples were collected in 1998 within this area, equally spaced along the length of this section of the park. Field duplicates of two samples at Big Trees Park Eastern Extension contained Pu-239+240 at the $0.04 \mathrm{pCi} / \mathrm{g}$ level. If these samples had been of material similar to that found in the first grid radial or the tree wells, $\mathrm{Pu}-238$ would have been measured at approximately $0.004 \mathrm{pCi} / \mathrm{g}$ (see Section 4.2). However, the $\mathrm{Pu}-238$ was well below that level; the $\mathrm{Pu}-238$ values were non-detects, indicating that fallout is the likely source of the material. 
Table 2.21 Eastern Extension Results.

\begin{tabular}{|c|c|c|c|c|}
\hline Sample ID & Depth & Type & $\mathrm{Pu}-239+240(\mathrm{pCi} / \mathrm{g})^{2}$ & $\mathrm{Pu}-238(\mathrm{pCi} / \mathrm{g})=$ \\
\hline \multirow[t]{10}{*}{1998 No. 1} & $0-5$ & & $0.000996 \pm 0.00165$ & $0.000499 \pm 0.00233$ \\
\hline & $0-5$ & Collocated & $0.0399 \pm 0.00958$ & $0.000842 \pm 0.0012$ \\
\hline & $5-10$ & & $0.00219 \pm 0.00183$ & $0.000956 \pm 0.00189$ \\
\hline & $5-10$ & Collocated & $0.000341 \pm 0.000683$ & $0.000683 \pm 0.000969$ \\
\hline & $10-20$ & & $0.0121 \pm 0.00478$ & $0.00252 \pm 0.00299$ \\
\hline & $10-20$ & Collocated & $-0.000469 \pm 0.00094$ & $0.000382 \pm 0.000766$ \\
\hline & $20-30$ & & $0.000574 \pm 0.00251$ & $0.000493 \pm 0.00282$ \\
\hline & $20-30$ & Collocated & $-0.000564 \pm 0.00113$ & $0.000919 \pm 0.00131$ \\
\hline & $30-40$ & & $-0.0000677 \pm 0.00165$ & $0.0011 \pm 0.00156$ \\
\hline & $30-40$ & Collocated & $-0.000645 \pm 0.00196$ & $0.000766 \pm 0.00109$ \\
\hline \multirow[t]{10}{*}{1998 No. 2} & $0-5$ & & $0.00175 \pm 0.00145$ & $0.000938 \pm 0.00218$ \\
\hline & $0-5$ & Collocated & $0.0429 \pm 0.00895$ & $0.000923 \pm 0.00107$ \\
\hline & $5-10$ & & $0.00467 \pm 0.00251$ & $0.0015 \pm 0.00204$ \\
\hline & $5-10$ & Collocated & $0.000308 \pm 0.000617$ & $0.0013 \pm 0.00192$ \\
\hline & $10-20$ & & $0.00395 \pm 0.00259$ & $0.00000000032 \pm 0.00244$ \\
\hline & $10-20$ & Collocated & $0.000655 \pm 0.00124$ & $0.00136 \pm 0.00215$ \\
\hline & $20-30$ & & $0.00492 \pm 0.00253$ & $0.000739 \pm 0.00198$ \\
\hline & $20-30$ & Collocated & $0.000675 \pm 0.000958$ & $0.000873 \pm 0.00278$ \\
\hline & $30-40$ & & $-0.00115 \pm 0.00163$ & $-0.000574 \pm 0.00115$ \\
\hline & $30-40$ & Collocated & $0.000373 \pm 0.000748$ & $-0.00065 \pm 0.0022$ \\
\hline \multirow[t]{7}{*}{1998 No. 3} & 0.5 & & $0.000611 \pm 0.00164$ & $0.000204 \pm 0.00208$ \\
\hline & $5-10$ & & $0.00416 \pm 0.00291$ & $-0.000373 \pm 0.00238$ \\
\hline & $5-10$ & Split & $0.0044 \pm 0.00231$ & $0.0000872 \pm 0.000597$ \\
\hline & $5-10$ & Split & $0.005 \pm 0.003$ & $0.00091 \pm 0.003$ \\
\hline & $10-20$ & & $0.00117 \pm 0.00194$ & $0.000848 \pm 0.00183$ \\
\hline & $20-30$ & & $0.00163 \pm 0.00187$ & $0.00191 \pm 0.00226$ \\
\hline & $30-40$ & & $0.000284 \pm 0.0023$ & $0.0019 \pm 0.00191$ \\
\hline \multirow[t]{3}{*}{1995 No. 13} & $0-5$ & & $0.0012 \pm 0.0021$ & $0.0008 \pm 0.004$ \\
\hline & $0-5$ & Split b & $0.0301 \pm 0.0284$ & $0.0088 \pm 0.038$ \\
\hline & $0-5$ & Split & $0.001 \pm 0.001$ & - $^{c}$ \\
\hline
\end{tabular}

\subsubsection{Special Sampling of 1995 Locations 1,7 , and 8}

The highest concentrations measured in 1995 were at Location $1(0.164-1.02 \mathrm{pCi} / \mathrm{g})$, Location 7 (0.05 pCi/g), and Location $8(0.02 \mathrm{pCi} / \mathrm{g}$ ) (see Figure 2.1). Locations 7 and 8 had results that were intermediate between fallout-background and the highest results at Location 1. It was not possible at that time to determine whether the results at Locations 7 and 8 were due to the same cause as Location 1, or whether they were due to analytical variability or sample heterogeneity. For this reason, samples were collected in 1998 from 1995 Locations 7 and 8.

The 1998 special sampling of 1995 Location 1 consisted of perpendiculars B and C. One of these eight locations (grid location 1C on Radial 1) was actually within 1995 Location 1. Grid location 1B was intended to be within the 1995 Location 1 area but 
overhanging tree branches forced the sample location to be moved away from Radial 1. In addition to the special sampling of Locations 7 and 8 , grid location $1 \mathrm{H}$ was close to 1995 Location 7, and grid location 2I was near 1995 Location 8.

The highest Pu-239+240 concentration of the 1998 Location 1 special sampling on the grid was $0.037 \mathrm{pCi} / \mathrm{g}$ found at location $3 \mathrm{~B}$ (see Table 2.2). All samples collected on Location 1 special grid points had $\mathrm{Pu}-239+240$ results well below the highest value found in 1995 of $1.0 \mathrm{pCi} / \mathrm{g}$.

The 1998 special sampling at Location 7 yielded an average $\mathrm{Pu}-239+240$ value of 0.064 $\mathrm{pCi} / \mathrm{g}$ at $0-5 \mathrm{~cm}$, confirming the previous result (see Table 2.22). Location 7 is about 4 feet away from Radial 1, which runs along the line of the tree wells. The nearest grid sample on Radial 1, at location $1 \mathrm{H}$, had a concentration typical of Radial 1 . Thus, the above-fallout-background values at Location 7 are consistent with the soil amendment hypothesis.

Table 2.22 Results of Sampling at and near 1995 Location 7, 0-5 cm.

\begin{tabular}{|c|c|c|c|}
\hline & Laboratory ${ }^{a}$ & $\mathrm{Pu}-239+240(\mathrm{pCi} / \mathrm{g})$ & $\mathrm{Pu}-238$ (pCi/g) \\
\hline 1995 Location 7 & Lab A & $0.0533 \pm 0.0097$ & $0.0067 \pm 0.0033$ \\
\hline \multirow[t]{2}{*}{ (field splits) } & Lab B & $0.0481 \pm 0.0254$ & $0.031 \pm 0.0267$ \\
\hline & Average & $0.051 \pm 0.0026^{b}$ & \\
\hline 1998 Location 7 & CES & $0.0486 \pm 0.00858$ & $0.00395 \pm 0.00239$ \\
\hline \multirow[t]{3}{*}{ (field splits) } & GEL & $0.0582 \pm 0.0168$ & $0.00846 \pm 0.0062$ \\
\hline & GIT & $0.086 \pm 0.017$ & $0.007 \pm 0.003$ \\
\hline & Average & $0.064 \pm 0.011^{b}$ & \\
\hline 1998 Grid $1 H$ & GEL & $0.275 \pm 0.0393$ & $0.0272 \pm 0.00761$ \\
\hline
\end{tabular}

The 1995 results for Location $8(0-5 \mathrm{~cm})$, as reported in LLNL 1995, were $0.0215 \mathrm{pCi} / \mathrm{g}$ and $0.0251 \mathrm{pCi} / \mathrm{g}$. However, the $0.0251 \mathrm{pCi} / \mathrm{g}$ result was one of two results from the laboratory's internal $Q C$ process (a lab-split sample). The other lab-split result was $0.00877 \mathrm{pCi} / \mathrm{g}$ (NAREL, 1995).

The $19980-5 \mathrm{~cm}$ results for Location 8 ranged from 0.003 to $0.007 \mathrm{pCi} / \mathrm{g}$, with an average $\mathrm{Pu}-239+240$ value of $0.005 \mathrm{pCi} / \mathrm{g}$ at $0-5 \mathrm{~cm}$ and $0.009 \mathrm{pCi} / \mathrm{g}$ at $5-10 \mathrm{~cm}$ (see Table 2.23). Grid sample 2I, collected about nine feet away, was $0.008 \mathrm{pCi} / \mathrm{g}$. Taken as a whole, these 
results show that the 1995 results at approximately $0.02 \mathrm{pCi} / \mathrm{g}$ were due to sample heterogeneity.

The 1998 value for the $10-20 \mathrm{~cm}$ sample at Location 8 was $0.005 \mathrm{pCi} / \mathrm{g}$, and the values for the $20-30-\mathrm{cm}$ and $30-40-\mathrm{cm}$ samples were non-detects. The sample collected at the 40-85 $\mathrm{cm}$ depth had a value of $0.0367 \mathrm{pCi} / \mathrm{g}$. This sample was taken in apparently undisturbed clay. The clay was extremely hard and the field technician experienced unusual difficulty mixing the sample. For these reasons it seems likely that the $40-85 \mathrm{~cm}$ result is due to sample heterogeneity. The results for Location 8 are well below the EPA residential preliminary remediation goal (PRG) of $2.5 \mathrm{pCi} / \mathrm{g}$, and well below any level of health concern.

Table 2.23 Results of sampling at and near 1995 Location $8,0-5 \mathrm{~cm}$.

\begin{tabular}{|c|c|c|c|c|}
\hline \multirow{2}{*}{1995 Location $8,0-5 \mathrm{~cm}$} & \multirow{2}{*}{$\frac{\text { Laboratory }^{a}}{\text { Lab A }}$} & \multirow{2}{*}{$\frac{\mathrm{Pu}-239+240(\mathrm{pCi} / \mathrm{g})^{\mathrm{b}}}{0.0215 \pm 0.0051}$} & \multicolumn{2}{|c|}{$\mathrm{Pu}-238(\mathrm{pCi} / \mathrm{g})^{\mathrm{b}}$} \\
\hline & & & 0.0006 & \pm 0.0012 \\
\hline & Lab B & $0.00877 \pm 0.0133$ & 0.0263 & \pm 0.0286 \\
\hline & Lab B Split c & $0.0251 \pm 0.0133$ & 0.0189 & \pm 0.0286 \\
\hline & Average & $0.019 \pm 0.0050^{d}$ & & \\
\hline \multirow[t]{4}{*}{1998 Location $8,0-5 \mathrm{~cm}$} & CES & $0.00488 \pm 0.00277$ & 0.000675 & \pm 0.00146 \\
\hline & GEL & $0.00304 \pm 0.00233$ & -0.000542 & \pm 0.00163 \\
\hline & GIT & $0.007 \pm 0.003$ & 0.0022 & \pm 0.003 \\
\hline & Average & $0.005 \pm 0.0011^{d}$ & & \\
\hline 1998 Grid 2l, 0-5 cm & GEL & $0.00836 \pm 0.00372$ & 0.00297 & \pm 0.00268 \\
\hline
\end{tabular}

A special feature of the resampling at Locations 1, 7, and 8 was deeper sampling, at a depth of 40 to $85 \mathrm{~cm}$. As shown in Table 2.24 and Table 2.25, all but four results were non-detections. This supports the conclusion that plutonium has not migrated downward to any great extent. The one potential exception, at Location 8 , was discussed above. 


\section{Table 2.24 Pu-239+240 results from special sampling, 40-85 cm depth interval., ${ }^{a, b}$}

\begin{tabular}{ccccc}
\hline Location & Routine & Collocated & Split 1 & Split 2 \\
\hline Grid 1B & $0.00222 \pm 0.00279$ & $-0.000194 \pm 0.00168$ & $0.0018 \pm 0.003$ & $0.00157 \pm 0.00201$ \\
Grid 2B & $0.00286 \pm 0.00269$ & & & \\
Grid 4B & $0.0007 \pm 0.000812$ & & & \\
Grid 1C & $0.000222 \pm 0.00109$ & & & \\
Grid 2C & $0.000099 \pm 0.0014$ & & & \\
Grid 3C & $0.000326 \pm 0.000845$ & & & \\
Grid 4C & $-0.00013 \pm 0.000953$ & $0.00478 \pm 0.00484$ & & \\
Location 7 & $0.000785 \pm 0.00258$ & & & \\
Location 8 & $0.0367 \pm 0.00875$ & & & \\
\hline : Non-detections are shown in italics. & & & \\
b Lack of core integrity prevented a sample from being collected at grid location 3B. &
\end{tabular}

Table 2.25 Pu-238 results from special sampling, 40-85 cm depth interval.a,b

\begin{tabular}{ccccc}
\hline Location & Routine & Collocated & Split 1 & Split 2 \\
\hline Grid 1B & $0.000489 \pm 0.00098$ & $0.00098 \pm 0.00139$ & $0.00088 \pm 0.003$ & $0.00104 \pm 0.00269$ \\
Grid 2B & $0.000215 \pm 0.00137$ & & & \\
Grid 4B & $-0.0000147 \pm 0.00158$ & & & \\
Grid 1C & $0.00117 \pm 0.00118$ & & \\
Grid 2C & $0.000187 \pm 0.00107$ & & \\
Grid 3C & $-0.0000544 \pm 0.00134$ & & \\
Grid 4C & $0.00022 \pm 0.0018$ & $0.0145 \pm 0.00918$ & \\
Location 7 & $0.000884 \pm 0.00207$ & & \\
Location 8 & $0.00978 \pm 0.0043$ & & \\
\hline \\
D Non-detections are shown in italics.
\end{tabular}

\subsubsection{Summary of Results from Special Sampling}

Despite anomalous results at one location, the 1998 special sampling shows that there has been little, if any, migration of plutonium below a depth of $40 \mathrm{~cm}$.

Plutonium was not detected in most of the samples on the school property. Those in which it was detected were within the range of fallout-background.

1995 Location 7, along the northeastern border of the park and near the ornamental trees, was confirmed to be consistent with the sludge hypothesis. 1995 Location 8, away from the northeastern border and the ornamental trees, was confirmed to be consistent with fallout-background.

The Eastern Extension of Big Trees Park was confirmed to be consistent with falloutbackground. 


\subsection{Summary of Distribution Pathways}

The 1998 sampling results are consistent with only one of the three pathways: the sludge pathway. Several supporting arguments not based directly on the 1998 sampling results are also consistent with only the sludge pathway.

The pathways conclusions are summarized individually in Sections 2.2.1.4 (arroyowaterborne), 2.2.2.9 (sludge), and 2.2.3.4 (aerial). 


\section{Quality Control}

The EPA and ATSDR reviewed the $Q C$ results and concluded that the data are useable for their intended purposes (Eidelberg, 1998). The following sections discuss various $Q C$ issues that were evaluated during the $Q C$ phase of the project.

\subsection{Data Quality Objectives}

The sampling plan established data quality objectives (DQOs) for the performance of the analytical laboratories with respect to Pu-239+240 analytical uncertainty (LLNL 1998 Section E-2.4). Table 3.1 compares the primary laboratory's $\mathrm{Pu}-239+240$ performance with the DQO. The analytical uncertainties for Pu-239+240 are slightly greater than the DQO values. The performance is close enough to the objectives to be acceptable.

Pu-238 and Pu-239+240 are analyzed simultaneously, so establishing DQOs for $\mathrm{Pu}-239+240$ effectively establishes the same DQOs for Pu-238. Pu-238 results, shown in Table 3.2, are similar.

Table 3.1 Analytical Data Quality Objectives for Pu-239+240.

\begin{tabular}{|c|c|c|c|c|}
\hline $\begin{array}{c}\text { Concentration } \\
\text { Range (pCi/g) }\end{array}$ & $\begin{array}{c}\text { Sampling Plan } \\
\text { DQO }\end{array}$ & $\begin{array}{c}\text { Average } \\
\text { Uncertainty }\end{array}$ & Range & $\mathbf{N}^{\mathbf{n}}$ \\
\hline $0.001-0.005$ & $100 \%$ or more & 100.1 & $45-273$ & 111 \\
\hline $0.005-0.010$ & $<100 \%$ & 56.6 & $35-117$ & 34 \\
\hline $0.010-0.100$ & Approximately $20 \%$ & 30.1 & $15-62$ & 47 \\
\hline $0.100-0.774$ & Approximately 10\% & 14.5 & $13-16$ & 13 \\
\hline
\end{tabular}

aos not represent all samples in the plan because only results above $0.001 \mathrm{pCi} / \mathrm{g}$ are included.

Table 3.2 Analytical Data Quality Objectives for Pu-238.

\begin{tabular}{|c|c|c|c|c|}
\hline $\begin{array}{c}\text { Concentration } \\
\text { Range }\end{array}$ & $\begin{array}{c}\text { Sampling Plan } \\
\text { DQO for Pu-239+240 }\end{array}$ & $\begin{array}{c}\text { Average } \\
\text { Uncertainty }\end{array}$ & Range & $\mathbf{N}^{\mathbf{*}}$ \\
\hline $0.001-0.005$ & $100 \%$ or more & 119.6 & $47-255$ & 134 \\
\hline $0.005-0.010$ & $<100 \%$ & 52.5 & $36-79$ & 17 \\
\hline $0.010-0.100$ & Approximately $20 \%$ & 34.1 & $20-63$ & 16 \\
\hline
\end{tabular}

- Does not represent all samples in the plan because only results above $0.001 \mathrm{pCi} / \mathrm{g}$ are included.

Twelve $\mathrm{Pu}-239+240$ analyses had an associated minimum detectable concentration (MDC) greater than the reporting limit of $0.005 \mathrm{pCi} / \mathrm{g}$ specified in the sampling plan. Of these, nine were between 0.005 and $0.006 \mathrm{pCi} / \mathrm{g}$ and the largest was $0.00879 \mathrm{pCi} / \mathrm{g}$. Based on their concentrations and associated uncertainties, none of these slightly elevated MDCs had a detrimental impact on risk evaluation or pathway analysis. Most 
MDCs were in fact below $0.005 \mathrm{pCi} / \mathrm{g}$, and there are a number of results below 0.005 $\mathrm{pCi} / \mathrm{g}$ that are considered detections.

\subsection{Reproducibility}

Reproducibility was measured in this sampling effort by four kinds of quality control samples. These were:

- Laboratory control (lab-split) samples, created when a laboratory splits a sample and separately analyzes both parts. These samples are part of the laboratory's internal quality control process.

- Intra-laboratory split (field-split) samples, in which a sample is split before delivery to a laboratory, and both parts are sent to the same laboratory.

- Collocated samples, in which two separate samples are collected close to each other and sent to the same laboratory.

- Inter-laboratory split (field-split) samples, in which a sample is split before delivery to a laboratory, and the parts are sent to different laboratories.

Field-split samples were sent to three laboratories: (1), the General Engineering Laboratory, Inc. (GEL) in Charleston, South Carolina , (2) the Environmental Resources Center laboratory at the Georgia Institute of Technology (GIT), and (3) the Chemistry and Environmental Services laboratory at LLNL (CES). GEL was the project contract laboratory and analyzed all samples. GIT was contracted by ATSDR to analyze interlaboratory field-split samples for the EPA, and CES analyzed inter-laboratory field-split samples for LLNL.

Some of the split samples of all types showed large differences that are evidence of the particulate nature of radionuclides in soil. This is normal for analyses of soil using small aliquots (Gilbert and Doctor, 1985; Lamé and Deflze, 1993). Such pairs are considered outliers for this analysis and are excluded from the summary statistics in Table 3.3 and Table 3.4. Laboratory control samples, especially, illustrate within-sample heterogeneity because within the same laboratory both parts of a split sample are analyzed using a procedure that is the same in every detail. (For example, all laboratories used a total dissolution procedure, but one of the laboratories used a microwave-assisted dissolution while the other laboratories used a strictly chemical dissolution.) Small aliquot sizes (3-5 gram) were used due to the regulatory agencies' request that the laboratories use a total dissolution method rather than a leaching method. 
Additional variability may be introduced when samples are split in the field because it is very difficult, if not impossible, to homogenize a soil sample in the field (EPA 1992, p. 3-7, 5-13; Myers, 1997 p. 216; Pitard 1993 p. 241). Instead, the purpose of mixing the sample in the field before splitting is to randomize the distribution of the soil and contaminant particles among the splits. A method known as alternate shoveling (EPA, 1992; Myers, 1997 p. 219) was used.

Collocated sample results are expected to be more variable, because they include smallscale (short distance) spatial variability in addition to within-sample variability.

Variability of paired results (either split or collocated) is measured by the relative error ratio (RER), defined as $R E R=\frac{R_{1}-R_{2}}{\sqrt{\sigma_{1}^{2}+\sigma_{2}^{2}}}$, where $R_{1}$ and $R_{2}$ are the two results, and $\sigma_{1}$ and $\sigma_{2}$ are the one-sigma analytical uncertainties reported by the laboratory. The analytical uncertainties reported by the laboratory result primarily from the random nature of radioactive decay (i.e., counting uncertainty), and to a lesser degree from other steps in the analysis such as chemical preparation of the sample and instrument calibration. Therefore, the RER does not include variability due to sample heterogeneity.

A set of several paired samples is summarized by the standard deviation of their relative error ratios. If the only source of variability is counting uncertainty, then the standard deviation should be close to one. A larger standard deviation indicates additional sources of variability, such as within-sample variability (soil heterogeneity) or spatial variability.

Table 3.3 Intra-laboratory relative error ratio (RER) results for $\mathrm{Pu}-\mathbf{2 3 9 + 2 4 0}$ for the primary laboratory, outliers removed.

\begin{tabular}{ccccc}
\hline Type of Sample & N & Mean & $\begin{array}{c}\text { Standard } \\
\text { Deviation }\end{array}$ & $\begin{array}{c}\text { Number of } \\
\text { Outliers }\end{array}$ \\
\hline Laboratory Split & 19 & -0.07 & 1.45 & 0 \\
Field Split (sent to same lab) & 32 & 0.13 & 2.28 & 2 \\
Collocated (sent to same lab) & 35 & 0.64 & 2.58 & 3 \\
\hline
\end{tabular}

\subsubsection{Within-laboratory Reproducibility}

The laboratory control sample (lab-split) results show good reproducibility within the laboratory. The variation is somewhat larger (RER standard deviation $=1.45$ ) than can be attributed to counting uncertainty alone (RER standard deviation $=1$ ). This is normal, because sample splitting at the laboratory introduces variability due to sample heterogeneity. 


\subsubsection{Intra-laboratory Field-Split Reproducibility}

The intra-laboratory field split samples show greater variability (RER standard deviation $=2.28$ ) than the laboratory $Q C$ duplicates. This is normal, because field splitting introduces additional variability.

\subsubsection{Small Scale Spatial Reproducibility}

Collocated samples have additional variability due to being collected at slightly different locations (standard deviation $=2.58$ ).

\subsubsection{Inter-laboratory Field-Split Reproducibility}

Evaluation of the samples that were split into three parts in the field and sent to each of the three laboratories indicates that there were two samples where the GEL result was a low outlier relative to the two other laboratories, and one sample where CES was a high outlier relative to the other two laboratories. With these outliers removed, the variability between laboratories was as comparable to the GEL within-lab variability.

Table 3.4 Inter-laboratory relative error ratio (RER) results for Pu-239+240, outliers removed.

\begin{tabular}{ccccc}
\hline Laboratories & N & Mean & $\begin{array}{c}\text { Standard } \\
\text { Deviation }\end{array}$ & $\begin{array}{c}\text { Number of } \\
\text { Outliers }\end{array}$ \\
\hline GEL with GIT & 26 & -0.46 & 1.69 & 2 \\
GEL with CES & 25 & 0.00 & 1.57 & 3 \\
CES with GIT & 27 & -0.64 & 1.27 & 1 \\
\hline
\end{tabular}

\subsubsection{Sources of Variability}

This section describes an analysis of sources of variability in the analytical results requested by EPA Region 9 . Good discussions of this issue are found in references Gilbert and Doctor, 1985 and EPA, 1990. In particular, Gilbert and Doctor show that up to 100 grams or more of soil must be analyzed in order to obtain low variability.

The sources of variability are analytical, laboratory, field, and small-scale spatial. Analytical variability is measured by the counting uncertainty reported by the laboratory (variability due to the random nature of radioactive decay). Laboratory variability is measured by comparing laboratory control sample (lab-split) results; this is a measure of how well the result reported by the lab represents the entire sample sent to the lab. Field variability is measured by splitting samples in the field, and then sending the splits to the same laboratory (intra-laboratory splits); this is a measure of sample heterogeneity and sample-collection variability. Small scale spatial variability 
measures how much concentrations vary over very short distances, in this case, about one to three feet (collocated samples).

The samples to be split were chosen at random, as is appropriate for the other quality control purposes in this sampling effort. In contrast, an experiment specifically designed to study sources of variability would select samples in a different manner that would be more appropriate for the sources-of-variability calculations (see Appendix 1, EPA 1984, p. 37, EPA 1990, and Gilbert and Doctor, 1985).

Because the samples to be split were chosen at random, it was not possible to control the concentration ranges for which split results were available. Most of the samples had low concentrations so there were sufficient pairs to complete the analysis in only two concentration ranges: less than $0.005 \mathrm{pCi} / \mathrm{g}$, and between 0.005 and $0.05 \mathrm{pCi} / \mathrm{g}$.

The analysis, shown in Table 3.5, indicates that at these low levels there is considerable variability on a percentage basis from all sources. Considering that the lowest range is below the analytical detection limit, this result is not surprising. The analytical and sample heterogeneity variabilities are due primarily to the small aliquot size; a different methodology would be necessary to provide more reproducible results. The small scale spatial variability indicates that even if there were no other sources of variability, samples within a few feet of each other would still have concentrations that vary by approximately $\pm 70 \%$ of each other (at these low levels). See Appendix 1 for additional details.

On an absolute basis the variabilities are quite small.

Table 3.5 Two-sigma relative uncertainty (\%Unc) for various concentration ranges and sources of variability."

\begin{tabular}{|c|c|c|c|c|c|}
\hline $\begin{array}{c}\text { Concentration range } \\
\text { pCi/g }\end{array}$ & $\begin{array}{c}\text { Analytical } \\
\text { uncertainty } \\
\% \text { Unc (n) }\end{array}$ & $\begin{array}{c}\text { Laboratory } \\
\text { heterogeneity } \\
\text { \%Unc (n) }\end{array}$ & $\begin{array}{c}\text { Field } \\
\text { heterogeneity } \\
\% \text { Unc (n) }\end{array}$ & $\begin{array}{c}\text { Small scale } \\
\text { spatial variability } \\
\% \text { Unc (n) }\end{array}$ & $\begin{array}{c}\text { Total } \\
\% \text { Unc }\end{array}$ \\
\hline$<0.005$ & $80.0(710)$ & $84.4(33)$ & $55.6(56)$ & $75.6(60)$ & 150 \\
\hline 0.005 to 0.05 & $20.6(120)$ & $40.4(8)$ & $81.8(8)$ & $69.5(16)$ & 116 \\
\hline 0.05 to 0.5 & $9.4(32)$ & $-{ }^{\mathrm{b}}(0)$ & $--^{\mathrm{b}}(2)$ & $-^{\mathrm{b}}(0)$ & $-^{\mathrm{b}}$ \\
\hline 0.5 to 1 & $11.4(6)$ & $-^{\mathrm{b}}(0)$ & $--^{\mathrm{b}}(0)$ & $-^{\mathrm{b}}(0)$ & $-^{\mathrm{b}}$ \\
\hline
\end{tabular}

- Relative to the mid-point of the concentration range.

b Too few samples in this concentration range to calculate variability.

Gilbert and Doctor (1985) studied measurement variability as a function of aliquot size. A large volume of soil was collected from the Nevada Test Site and dried, ground, and sieved. Aliquots ranging from 1 to 100 grams were then withdrawn in a random order and analyzed for Am-241 by gamma spectroscopy. Counting uncertainty was held to less than $10 \%$. One-gram aliquots were nearly 10 times more variable than 100 gram 
aliquots (two-sigma relative uncertainties of $158 \%$ and $18 \%$ respectively). The twosigma relative uncertainty of 5 gram aliquots, estimated from their results, would be about $80 \%$. Because the soil was ground and sieved before the aliquots were removed, the variability measured in their study corresponds most closely to the laboratory heterogeneity component of Table 3.5. The laboratory heterogeneity variabilities reported in Table $3.5,84.4 \%$ and $40.4 \%$ are as good as and better than the $80 \%$ expected based on Gilbert and Doctor.

Although Gilbert and Doctor measured americium, the same causes of variability are present for any contaminant with a particulate nature, including plutonium. It should also be noted that the average concentration in Gilbert and Doctor study was slightly less than 2 nanocuries per gram, on the order of 40,000 times greater than the upper end of the range reported in Table $3.5(0.05 \mathrm{pCi} / \mathrm{g})$. Variability is expected to be greater at lower concentrations because there are fewer contaminant particles in the soil.

\subsection{Other Issues}

\subsubsection{Ion-exchange columns}

Two of the laboratories, GIT and GEL, used a single ion-exchange column for radionuclide elution. The third laboratory, CES, used a sequence of two ion-exchange columns. The ion-exchange column removes naturally occurring radionuclides that, if present, may cause decay-chain interference in the counting of $\mathrm{Pu}-238$. Such interference would tend to cause over-estimates of the $\mathrm{Pu}-238$ concentrations.

Figure 3.1 compares CES Pu-238 results (horizontal axis) with GEL and GIT Pu-238 results for all of the field-split samples. Except for three outliers, the data cluster fairly evenly around a ratio of 1:1 (shown as a diagonal dotted line), suggesting that such over-estimation did not occur. 




Figure 3.1 Comparison of CES with GEL and GIT Pu-238 field-split results.

As discussed in Section 3.2, there is evidence of sample heterogeneity. This is indicated in Figure 3.1 by outliers (two or three points in Figure 3.1 that are further from the line than the bulk of the pairs), especially, and also by the increased scatter at the lower below-the-detection-limit concentrations (below $0.005 \mathrm{pCi} / \mathrm{g}$ ). Differences between split results due to heterogeneity are not relevant to, and will tend to mask, differences due to the number of columns used. It is not possible to directly eliminate heterogeneity effects from the comparison between laboratories. However, heterogeneity tends to have the most effect at lower levels, so this section restricts statistical analysis to the subset of samples for which all three laboratories reported a Pu-238 detection (i.e., twosigma uncertainty less than $100 \%$ ).

Because there are three laboratories to be compared, these data can be analyzed with a randomized-complete-blocks analysis of variance, with samples providing the blocking factor. This method is better at detecting differences between laboratories than 
comparing the averages of the three laboratories (Montgomery, 1991, Section 5.1). Because differences between laboratories are necessarily smaller when the true sample concentrations are smaller, and the concentrations cover a large range of values, analysis was performed on the logarithms of the concentrations. The laboratories are not significantly different ( $p \leq 0.15 ;$ Table 3.6). If the analysis is instead performed on a larger subset in which at least one laboratory detected $\mathrm{Pu}-238$, the conclusion is the same.

Table 3.6 Analysis of Variance of Pu-238 results from field-split samples. ${ }^{\mathrm{a}}$

\begin{tabular}{cccccc}
\hline Factor & $\begin{array}{c}\text { Degrees of } \\
\text { Freedom }\end{array}$ & $\begin{array}{c}\text { Sum of } \\
\text { Squares }\end{array}$ & $\begin{array}{c}\text { Mean } \\
\text { Squares }\end{array}$ & F Value & $\begin{array}{c}\text { Significance } \\
\text { Level }\end{array}$ \\
\hline Laboratory & 2 & 0.1956 & 0.09781 & 2.396 & 0.15 \\
Sample & 4 & 18.63 & 4.659 & 114.1 & $4.3 \times 10^{-7}$ \\
Residuals & 8 & 0.3265 & 0.04081 & & \\
\hline Note: Analysis was performed on the logarithms of the data. &
\end{tabular}

Note that there are statistically significant differences between samples. This is as it should be because the samples were collected from a variety of areas with different concentrations. Indeed, this is precisely why the randomized-blocks method is appropriate: so that differences between locations do not mask differences between laboratories.

\subsubsection{Performance evaluation samples}

In addition to quality control samples derived from the field samples, each laboratory analyzed some standardized performance evaluation samples having wellcharacterized concentrations. These samples were obtained by LLNL from the DOE Environmental Measurements Laboratory (EML QAP XLI [9409]) and the National Institute of Standards and Technology (NIST SRM 4357, prepared from ocean sediment). The EPA obtained a different EML performance evaluation sample for analysis by GIT.

As can be seen from Table 3.7 and Table 3.8, GEL had excellent Pu-239+240 results for the EML sample and CES had excellent results for the NIST sample. GIT had very good results for their EML sample.

Table 3.7 Results for the EML performance evaluation samples (pCi/g).

\begin{tabular}{lcccc}
\hline & $\begin{array}{c}\text { EML Reference } \\
\text { Value for GEL }\end{array}$ & GEL Result & $\begin{array}{c}\text { EML Reference } \\
\text { Value for GIT }\end{array}$ & GIT Result \\
\hline $\mathrm{Pu}-238$ & 0.00837 & $0.00585 \pm 0.0036$ & 0.012 & $0.015 \pm 0.005$ \\
$\mathrm{Pu}-239+240$ & 0.21 & $0.211 \pm 0.0337$ & 0.274 & $0.30 \pm 0.06$ \\
\hline
\end{tabular}




\section{Table 3.8 Results for the NIST performance evaluation sample."}

\begin{tabular}{lccc}
\hline & $\begin{array}{c}\text { NIST Value } \\
\text { (pCi/g) }\end{array}$ & GEL Result & $\begin{array}{c}\text { CES Result } \\
\text { (pCi/g) }\end{array}$ \\
\hline Pu-238 & 0.06183 & See Table 3.9 & $0.0565 \pm 0.0119$ \\
Pu-239+240 & 0.2808 & See Table 3.9 & $0.279 \pm 0.0437$
\end{tabular}

- The EPA diluted this sample with site soil in a 3:1 ratio before sending it to GIT. As a result, the reference value is not applicable and the GIT result is not reported.

GEL had varied results for the NIST sample (see Table 3.9). The reasons for this are unknown, but may be due to the fact that aliquot sizes were necessarily small. Rather than the more usual process of analyzing a performance evaluation sample once, one of the regulatory agencies requested that GEL analyze a portion of the sample with each batch of field samples. This resulted in the laboratory using 5 gram aliquots, rather than the minimum of ten grams recommended by NIST. The sample information sheet supplied by NIST for this material states that plutonium heterogeneity exists at 10 gram aliquot sizes. The effects of heterogeneity would be even greater with 5 gram aliquots.

Table 3.9 GEL NIST performance evaluation results.

\begin{tabular}{|c|c|c|}
\hline & \multicolumn{2}{|c|}{ GEL Results (pCi/g) } \\
\hline & Pu-239+240 & Pu-238 \\
\hline & $0.229 \pm 0.0469$ & $0.0469 \pm 0.00931$ \\
\hline & $0.271 \pm 0.0563$ & $0.0563 \pm 0.0102$ \\
\hline & $0.248 \pm 0.0526$ & $0.0526 \pm 0.00832$ \\
\hline & $0.265 \pm 0.0529$ & $0.0529 \pm 0.00952$ \\
\hline & $0.277 \pm 0.05$ & $0.05 \pm 0.0107$ \\
\hline & $0.237 \pm 0.0793$ & $0.0793 \pm 0.0266$ \\
\hline & $0.279 \pm 0.044$ & $0.047 \pm 0.00838$ \\
\hline & $0.247 \pm 0.0574$ & $0.0574 \pm 0.0271$ \\
\hline & $0.236 \pm 0.0478$ & $0.0478 \pm 0.00979$ \\
\hline & $0.233 \pm 0.0434$ & $0.0434 \pm 0.00855$ \\
\hline & $0.243 \pm 0.0423$ & $0.0423 \pm 0.00935$ \\
\hline & $0.307 \pm 0.0529$ & $0.0529 \pm 0.0119$ \\
\hline & $0.263 \pm 0.0469$ & $0.0469 \pm 0.0298$ \\
\hline & $0.231 \pm 0.0396$ & $0.0396 \pm 0.00884$ \\
\hline & $0.278 \pm 0.0555$ & $0.0555 \pm 0.0101$ \\
\hline & $0.238 \pm 0.0523$ & $0.0523 \pm 0.00931$ \\
\hline & $0.191 \pm 0.0562$ & $0.0562 \pm 0.00428$ \\
\hline & $0.24 \pm 0.0463$ & $0.0463 \pm 0.0115$ \\
\hline $\begin{array}{l}\text { NIST reference } \\
\text { value }(\mathrm{pCi} / \mathrm{g})\end{array}$ & 0.2808 & 0.06183 \\
\hline
\end{tabular}


Although the GEL NIST performance evaluation results are generally lower than the reference value, statistical tests comparing the three labs on the field-split samples do not find a significant difference ( $p \leq 0.12$ for Pu-239+240 in Table 3.10, and $p \leq 0.15$ for $\mathrm{Pu}-238$ in Table 3.6).

Table 3.10 Analysis of Variance of Pu-239+240 results from field-split samples. ${ }^{a}$

\begin{tabular}{cccccc}
\hline Factor & $\begin{array}{c}\text { Degrees of } \\
\text { Freedom }\end{array}$ & $\begin{array}{c}\text { Sum of } \\
\text { Squares }\end{array}$ & $\begin{array}{c}\text { Mean } \\
\text { Squares }\end{array}$ & F Value & $\begin{array}{c}\text { Significance } \\
\text { Level }\end{array}$ \\
\hline Laboratory & 2 & 2.02 & 1.01 & 2.316 & 0.12 \\
Sample & 10 & 82.34 & 8.234 & 18.89 & $4.5 \mathrm{e}-08$ \\
Residuals & 20 & 8.72 & 0.436 & & \\
\hline
\end{tabular}

- Note: Analysis was performed on the logarithms of the data.

\subsubsection{Sample preparation}

GIT analyzed every sample for Am-241 by gamma spectroscopy, and a subset by alpha spectroscopy. These can be used to compare the different sample preparation methods used by the laboratories.

All of the GIT samples received gamma analyses for Am-241 prior to sieving. With three exceptions these were on 175 gram portions. One sample (grid 1F) was analyzed by gamma spectroscopy after sieving. This permits a direct before-vs.-after examination of sieving without any other complicating factors. This sample and three others were also analyzed for Am-241 by alpha spectroscopy on 3 gram aliquots after sieving. This permits a before-after comparison of the effects of sieving, but with additional complicating factors present. These factors include aliquot size (the alpha analysis uses only a small portion of the sample), and chemical processing (alpha analysis requires chemical preparation of the sample, gamma does not). Am-241 results for all four of these samples are shown in Table 3.11. 
Table 3.11 Comparison of sample preparation methods *

\begin{tabular}{|c|c|c|c|c|c|c|}
\hline Location & $\begin{array}{c}\text { Depth } \\
\text { (cm) }\end{array}$ & $\begin{array}{c}\text { GIT } \\
\text { gamma } \\
\text { not sieved } \\
(p C i / g)\end{array}$ & $\begin{array}{c}\text { GIT } \\
\text { gamma } \\
\text { sieved }^{b} \\
(p C i / g)\end{array}$ & $\begin{array}{c}\text { GIT } \\
\text { alpha } \\
\text { sieved } \\
\text { (pCi/g) }\end{array}$ & $\begin{array}{c}\text { GEL } \\
\text { alpha } \\
\text { (pCi/g) }\end{array}$ & $\begin{array}{l}\text { Portion } \\
\text { remaining } \\
\text { after sieve }\end{array}$ \\
\hline \multicolumn{7}{|c|}{ Americium-241 } \\
\hline Grid 1F & $0-5$ & 0.27 & 0.23 & $0.21 \pm 0.05$ & $0.205 \pm 0.0661$ & $21.2 \%$ \\
\hline Grid 3G & $5-10$ & $<0.04$ & & $0.005 \pm 0.004$ & Not analyzed for & $17.7 \%$ \\
\hline Loc. 7 Special & $0-5$ & 0.02 & & $0.02 \pm 0.01$ & $0.031 \pm 0.0163$ & $34.3 \%$ \\
\hline Grid 1D & $0-5$ & 0.18 & & $0.14 \pm 0.03$ & $0.0612 \pm 0.0334$ & $21.1 \%$ \\
\hline \multicolumn{7}{|c|}{ Plutonium-238 } \\
\hline Grid 1F & $0-5$ & & & $0.0777 \pm 0.0128$ & $0.0666 \pm 0.013$ & $21.2 \%$ \\
\hline Grid 3G & $5-10$ & & & $0.00067 \pm 0.003$ & $0.00127 \pm 0.00256$ & $17.7 \%$ \\
\hline Loc. 7 Special & $0-5$ & & & $0.007 \pm 0.003$ & $0.00846 \pm 0.0062$ & $34.3 \%$ \\
\hline Grid 1D & $0-5$ & & & $0.046 \pm 0.01$ & $0.000463 \pm 0.00145$ & $21.1 \%$ \\
\hline \multicolumn{7}{|c|}{ Plutonium-239+240 } \\
\hline Grid 1F & $0-5$ & & & $0.671 \pm 0.0677$ & $0.575 \pm 0.076$ & $21.2 \%$ \\
\hline Grid 3G & $5-10$ & & & $0.02 \pm 0.003$ & $0.01 \pm 0.00621$ & $17.7 \%$ \\
\hline Loc. 7 Special & $0-5$ & & & $0.086 \pm 0.017$ & $0.0582 \pm 0.0168$ & $34.3 \%$ \\
\hline Grid 1D & $0-5$ & & & $0.51 \pm 0.091$ & $0.0275 \pm 0.00767$ & $21.1 \%$ \\
\hline
\end{tabular}

The GIT gamma results on the grid 1F sample before and after sieving, $0.27 \mathrm{pCi} / \mathrm{g}$ and $0.23 \mathrm{pCi} / \mathrm{g}$, were reported by the laboratory as agreeing within the uncertainty of measurement. For the other three samples, the GIT Am-241 gamma (before sieving) and GIT Am-241 alpha (after sieving) results are also in good agreement (note that a nondetection of $<0.04$ is considered consistent with an estimated concentration of 0.005 , even though a direct comparison of two measured values is not possible). These four pairs of results indicate that sieving did not have a systematic effect on measured concentrations.

The GIT and GEL alpha spectroscopy results for the grid location 1F sample are in agreement with each other, and within the uncertainty range of the gamma analyses. Thus one GEL and three GIT results are in agreement, indicating that for this sample, sample preparation (for alpha analyses, GIT sieved first and then ground whereas GEL ground first and then sieved) did not introduce a bias.

The GEL and GIT Am-241 results from the Location 7 Special sample are in good agreement. Gamma analyses on the grid below $5 \mathrm{~cm}$ were not part of the sampling plan so there is no GEL result for Am-241 at grid location 3G. The plutonium results for grid 
locations $1 F, 3 G$, and Location 7 show good agreement between the labs and therefore good agreement between sample preparation methods.

GEL had much lower results than GIT at grid location 1D. This has previously been described as most likely being due to sample heterogeneity (Section 3.2). This conclusion is supported by a set of results from GIT for grid location $1 \mathrm{~A}(0-5 \mathrm{~cm})$. Initially, GIT reported about $0.3 \mathrm{pCi} / \mathrm{g}$ for $\mathrm{Pu}-239+240$ in this sample. The other two laboratories reported results of about $0.03 \mathrm{pCi} / \mathrm{g}$. GIT recounted their original aliquot and obtained the same result of about $0.3 \mathrm{pCi} / \mathrm{g}$. They then reanalyzed a new aliquot and obtained a result of about $0.03 \mathrm{pCi} / \mathrm{g}$, consistent with the other two labs (Kahn, 1999). This is a very clear indication of sample heterogeneity: a single laboratory obtained results an order of magnitude different on different aliquots of the same sample. For this reason, it is reasonable to attribute this difference in grid location 1D results to sample heterogeneity.

If the GIT results for grid location 1D are adjusted to reflect the sample mass removed by sieving, the results do not account for the differences in concentration. For example, the $0.51 \mathrm{pCi} / \mathrm{g}$ result for $\mathrm{Pu}-239+240$ at location $1 \mathrm{D}$ would become $0.51 \times 21.1 \%=0.11$ $\mathrm{pCi} / \mathrm{g}$, which still is not close to the $0.0275 \mathrm{pCi} / \mathrm{g}$ reported by GEL. Such corrections applied to the other pairs would cause them to have much poorer agreement than they do now. (The adjustment assumes the portion removed has no contamination, which is appropriate, because most of the removed material consists of pebbles and stones whose interiors can have no contamination.)

Regardless of the reason for infrequent large differences such as the one at grid 1D, the results shown in this section indicate that there is not a systematic effect due to differences in sample preparation. 


\section{Isotopic Composition}

The isotopic composition of plutonium in soil, as measured by the activity ratio Pu-238 : Pu-239+240, can be a useful tool in determining the source of the plutonium. However, both the $\mathrm{Pu}-238$ and the $\mathrm{Pu}-239+240$ must be measured with high precision in order for the ratio to be calculated with sufficient precision to be meaningful. The analytical method requested by the regulatory agencies for the Big Trees Park sampling, total dissolution, caused the analytical laboratories to use only 3 to 5 grams of soil per analysis; this does not provide sufficient precision at low levels (Gilbert and Doctor, 1985). Therefore, this analysis of Big Trees Park isotopic ratios is limited to samples in which (1) the Pu-239+240 result was above $0.012 \mathrm{pCi} / \mathrm{g}$, (2) both the Pu-238 and the $\mathrm{Pu}-239+240$ reported activities were positive, and (3) the two-sigma propagated uncertainty of the calculated ratio was less than the calculated ratio. The only samples that fit this criteria were from the inside-top $(0-45 \mathrm{~cm})$ tree well samples, the grid Radial 1 $0-5 \mathrm{~cm}$ samples, and a few other grid samples. All ratios in this section are decaycorrected to September, 1998.

\subsection{Isotopic Composition of Fallout-background}

The $\mathrm{Pu}-238: \mathrm{Pu}-239+240$ activity ratio in fallout nation-wide ranges from about 0.03 to 0.06 (EPRI, 1981). These data (found in EPRI, 1981) are labeled “National Background 0-1 $\mathrm{cm}^{\prime \prime}$ in Table 4.1 and Figure 4.1. LLNL upwind surveillance monitoring samples collected from the same depth interval, $0-1 \mathrm{~cm}$, have the same range, which confirms the fact that the LLNL upwind samples represent fallout-background. LLNL upwind surveillance monitoring samples collected from other depth intervals have a larger range (see Figure 4.1). The three sets of data shown in Table 4.1 have almost identical geometric means. Therefore, the LLNL upwind samples from all depths are combined into a single group for the remainder of the analyses in this section.

Table 4.1 Pu-238 : Pu-239+240 isotopic ratios of fallout-background."

\begin{tabular}{lccc}
\hline \multicolumn{1}{c}{ Data Set } & $\begin{array}{c}\text { Geometric } \\
\text { Mean }\end{array}$ & $\begin{array}{c}\text { Geometric } \\
\text { Standard } \\
\text { Deviation }\end{array}$ & $\begin{array}{c}\text { Number of } \\
\text { Samples }\end{array}$ \\
\hline National Background 0-1 cm & 0.0422 & 1.16 & 60 \\
LLNL Upwind Background 0-1 cm & 0.0456 & 1.28 & 6 \\
LLNL Upwind Background Other Depths & 0.0430 & 1.75 & 64 \\
\hline
\end{tabular}

- Decay corrected to September 1998. 


\subsection{Isotopic Composition of Big Trees Park Samples}

In contrast to fallout-background, samples collected in Big Trees Park have distinctly different isotopic ratios, averaging about 0.09 to 0.11 (see Table 4.2 and Figure 4.1).

Table 4.2 Geometric means of Pu-238: Pu-239+240 ratios of background and Big Trees Park data sets.

\begin{tabular}{lccc}
\hline \multicolumn{1}{c}{ Data Set } & $\begin{array}{c}\text { Geometric } \\
\text { Mean }\end{array}$ & $\begin{array}{c}\text { Geometric } \\
\text { Standard } \\
\text { Deviation }\end{array}$ & $\begin{array}{c}\text { Number of } \\
\text { Samples }\end{array}$ \\
\hline National Background $^{\mathrm{a}}$ & 0.0422 & 1.16 & 60 \\
Valley Upwind Background $^{\mathrm{a}}$ & 0.0432 & 1.71 & 70 \\
\hline Inside Tree Well 0-45 cm & 0.109 & 1.17 & 13 \\
Radial 1 0-5 cm & 0.104 & 1.16 & 14 \\
Radial 1 5-10 cm & 0.0956 & 1.81 & 6 \\
Other Grid $^{\text {Residences }}{ }^{\mathrm{a}}$ & 0.0862 & 1.31 & 5 \\
\hline \multicolumn{1}{c}{ Decay corrected to September 1998. } & 0.0744 & 1.42 & 6 \\
\hline
\end{tabular}

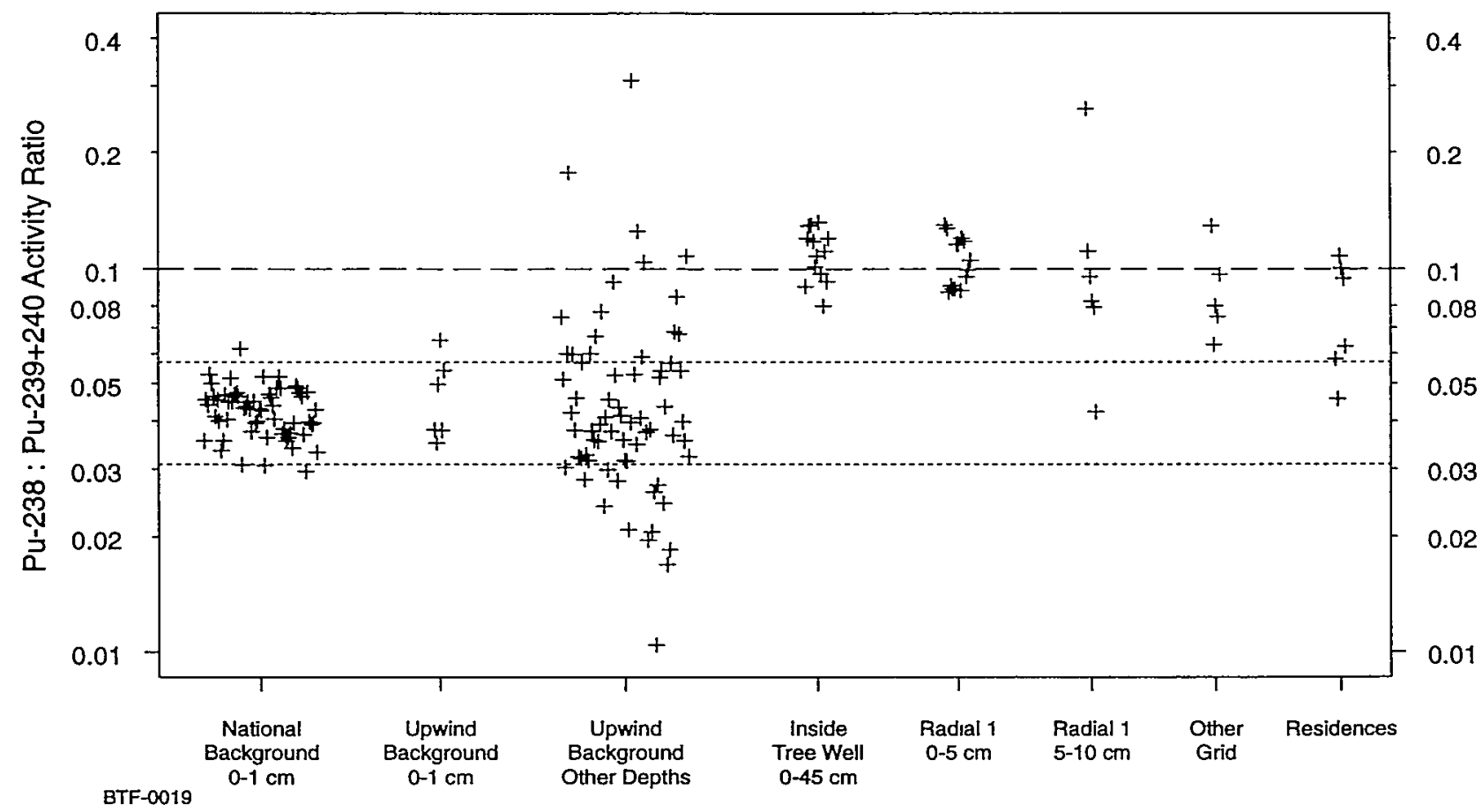

Figure 4.1 Pu-238: Pu-239+240 ratios of Big Trees Park, fallout-background, and residence samples, decay corrected to September 1998. 
While preparing for the 1998 sampling, LLNL found some previously unpublished data that provided measurements for $0-1 \mathrm{~cm}$ and $1-25 \mathrm{~cm}$ deep samples collected 25 years earlier. The source described samples taken at three residences in the Livermore Valley where the homeowners had applied post-1967-release LWRP sewage sludge as a soil amendment (see Table 4.3). For further discussion of these results see ATSDR 2000 (p. 16), which noted that no further action is needed because the highest concentration was below the EPA Region 9 PRG (2.5 pCi/g), and below the $51 \mathrm{pCi} / \mathrm{g}$ level at which the National Commision on Radiation Protection and Measurements recommends additional action (NCRP, 1999).

Table 4.3 1973 Results from LLNL Employee Residences."

\begin{tabular}{cccccc}
\hline Date & Description & $\begin{array}{c}\text { Pu-239+240 } \\
(\% \text { uncertainty }) \\
\text { pCi/g }\end{array}$ & $\begin{array}{c}\text { Pu-238 } \\
\text { (\% uncertainty } \\
\text { pCi/g }\end{array}$ & $\begin{array}{c}\text { Decay- } \\
\text { Activity } \\
\text { Ratio }\end{array}$ & $\begin{array}{c}\text { Derrected } \\
\text { cortivity Ratio }\end{array}$ \\
\hline Mar-73 Site 1, $0-1 \mathrm{~cm}$ & $0.324(9.8)$ & $0.0233(10)$ & 0.072 & 0.058 \\
Mar-73 Site 1, $1-25 \mathrm{~cm}$ & $0.00412(7.4)$ & $0.00023(11.6)$ & 0.056 & 0.046 \\
Mar-73 Site 2, $0-1 \mathrm{~cm}$ & $1.840(13)$ & $0.243(13)$ & 0.132 & 0.108 \\
Mar-73 Site 2, $1-25 \mathrm{~cm}$ & $0.784(9)$ & $0.0964(9.1)$ & 0.123 & 0.101 \\
Mar-73 Site 3, $0-1 \mathrm{~cm}$ & $0.00797(8.8)$ & $0.000923(19)$ & 0.116 & 0.094 \\
Mar-73 Site 3, $1-25 \mathrm{~cm}$ & $0.00168(15)$ & $0.00013(46)$ & 0.077 & 0.063 \\
\hline
\end{tabular}

"These data have also been published by the ATSDR on page 16 of their Health Consultation for Big Trees Park 1998 Sampling, Lawrence Livermore Laboratory (USDOE), Livermore, Alameda County, California, CERCLIS NO. CA2890012584, dated January 10, 2000.

${ }^{b}$ One-sigma uncertainty as a percent of the measured concentration.

Three of the six samples have ratios very close to the average of the ornamental tree and Radial 1 samples from Big Trees Park, including the two with the greatest Pu concentrations. This strongly suggests that these residence samples and the Big Trees Park samples have plutonium from the same source. The geometric mean activity ratio of these six samples is greater than that of fallout, and the difference is statistically significant (see Table 4.5). Since the samples come from residences where it is known that sewage sludge was applied, this supports the conclusion that the source of contamination in Big Trees Park is sewage sludge used as soil amendment.

Statistical analysis comparing the geometric means of the activity ratios of the seven data sets identified in Table 4.2 shows that these sets have different ratios $\left(p<10^{-15}\right.$, Table 4.4). 
Table 4.4 Analysis of Variance of Plutonium Isotopic Ratio Data Sets. ${ }^{a}$

\begin{tabular}{|c|c|c|c|c|c|}
\hline Factor & $\begin{array}{c}\text { Degrees of } \\
\text { Freedom }\end{array}$ & $\begin{array}{c}\text { Sum of } \\
\text { Squares }\end{array}$ & $\begin{array}{c}\text { Mean } \\
\text { Squares }\end{array}$ & F Value & $\begin{array}{c}\text { Significance } \\
\text { Level }\end{array}$ \\
\hline Data Sets & 6 & 22.98 & 3.829 & 26.1 & $<10^{-15}$ \\
\hline Residuals & 167 & 24.5 & 0.1467 & & \\
\hline
\end{tabular}

Analysis performed on the logarithms of the activity ratios.

Figure 4.1 suggests that fallout-background ratios (the "National Background" and "Upwind Background" sets in Figure 4.1) are lower than the ratios from Big Trees Park and the residences (the other five sets in Figure 4.1). Examination of these seven data sets with a statistical multiple comparisons procedure (Table 4.5) confirms that: (1) the two background sets are not significantly different from each other; (2) the other five sets are not statistically different from each other; and (3) each of the fallout-background data sets data sets has a significantly lower average ratio than each of the five nonbackground data sets.

\section{Table 4.5 Simultaneous $95 \%$ confidence intervals comparing isotopic ratio data sets.}

\begin{tabular}{lcc}
\hline \multicolumn{1}{c}{ Data Sets } & Ratio & $\begin{array}{c}\text { Confidence } \\
\text { Interval }^{\mathrm{b}}\end{array}$ \\
\hline National Background vs. Upwind Background & 0.976 & $0.798-1.19$ \\
\hline National Background vs. Other Grid & 0.49 & $0.288-0.834$ \\
National Background vs. Radial 1 & 0.407 & $0.29-0.571$ \\
National Background vs. Radial 1 Other Depths & 0.442 & $0.271-0.72$ \\
National Background vs. Trees & 0.388 & $0.274-0.551$ \\
National Background vs. Residences & 0.567 & $0.348-0.926$ \\
Upwind Background vs. Other Grid & 0.502 & $0.296-0.852$ \\
Upwind Background vs. Radial 1 & 0.417 & $0.298-0.582$ \\
Upwind Background vs. Radial 1 Other Depths & 0.452 & $0.278-0.735$ \\
Upwind Background vs. Trees & 0.398 & $0.282-0.562$ \\
Upwind Background vs. Residences & 0.581 & $0.357-0.945$ \\
\hline Other Grid vs. Radial 1 & 0.83 & $0.458-1.51$ \\
Other Grid vs. Radial 1 Other Depths & 0.901 & $0.451-1.8$ \\
Other Grid vs. Trees & 0.793 & $0.434-1.45$ \\
Other Grid vs. Residences & 1.16 & $0.58-2.31$ \\
\hline Radial 1 vs. Radial 1 Other Depths & 1.09 & $0.621-1.9$ \\
Radial 1 vs. Trees & 0.955 & $0.615-1.48$ \\
Radial 1 vs. Residences & 1.39 & $0.798-2.44$ \\
Radial 1 Other Depths vs. Trees & 0.88 & $0.5-1.55$ \\
Radial 1 Other Depths vs. Residences & 1.29 & $0.664-2.49$ \\
\hline Trees vs. Residences & 1.46 & $0.831-2.57$ \\
\hline a Ratios shaded gray are statistically significant, as indicated by confidence intervals that exclude the ratio & 1.0. \\
b Gonfidence intervals were calculated using Tukey's HSD on the logarithms of the activity ratios, and are presented in the
\end{tabular}


table after back transformation to ratios.

\subsection{Summary of Isotopic Composition Results}

Among the Big Trees Park samples with the highest Pu-239+240 concentrations, the $\mathrm{Pu}-238$ activity values are approximately $10 \%$ of those for Pu-239+240. Other than those, the $\mathrm{Pu}-238$ results are mostly non-detections or too low for a meaningful isotopic ratio. Since the $\mathrm{Pu}-238$ : $\mathrm{Pu}-239+240$ activity ratio for fallout plutonium is approximately $3 \%$ to $6 \%$, this $10 \%$ activity ratio indicates that neither fallout nor weapons-grade plutonium alone is responsible for the elevated plutonium levels present at Big Trees Park. The unusual Pu-238: $\mathrm{Pu}-239+240$ activity ratio suggests that the source of plutonium is not related to one particular operation, but is more likely a mixture of sources. In addition, mass spectrometric analysis of several samples from Big Trees Park yielded excess and variable Pu-242 compared to weapons-grade plutonium compositions; these results also strongly indicate that the elevated plutonium levels are from several sources or waste streams (Lougheed and Moody, 1999; Velsko, 1995; Kelly, 1995). The permitted liquid waste stream that leaves LLNL for the LWRP is a mixture of multiple sources. 


\section{Sample Collection}

\subsection{Tree sample locations}

The ornamental trees along the northeast edge of the park next to the concrete arroyo channel were numbered, starting with the tree nearest the intersection of Charlotte Way and Kathy Way, which was designated tree number 1.

A primary requirement of the tree well sampling was that the inside-tree-well samples should intersect the original tree well. In order to have the best chance of intersecting the tree well, the drill rig used to extract the samples from the tree wells was placed as close as possible to each tree, constrained by the height of the drill rig, the shape of the tree, and locations of its limbs.

The trees were numbered starting with the first tree in the southeast corner of the park, closest to the intersection of Charlotte Way and Kathy Way. Ten of the first 15 trees (numbers 2, 3, 4, 5, 6, 8, 11, 12, 14, and 15) were selected for sampling, based on accessibility to the inside of the tree well by the drill rig.

Approximate distances from the center of each ornamental tree trunk to the ornamental tree samples (both inside the tree wells and outside the tree wells) are shown in Table 5.1.

Table 5.1 Approximate distances from ornamental trees (center of trunk) to ornamental tree sample locations.

\begin{tabular}{lcc}
\hline Tree & $\begin{array}{c}\text { Approximate Distance to } \\
\text { Inside Tree Well Sample (feet) }\end{array}$ & $\begin{array}{c}\text { Approximate Distance to } \\
\text { Outside Tree Well Sample (feet) }\end{array}$ \\
\hline Tree 2 & 1.7 & 8.2 \\
Tree 3 & 0.7 & 10.7 \\
Tree 4 & 1.5 & 9.8 \\
Tree 5 & 1.3 & 6.9 \\
Tree 6 & 1.0 & 7.2 \\
Tree 8 & 1.4 & 9.4 \\
Tree 11 & 1.2 & 9.1 \\
Tree 12 & 2.3 & 9.4 \\
Tree 14 & 1.6 & 9.4 \\
Tree 15 & 3.2 & 9.4 \\
\hline
\end{tabular}


Note that with two exceptions, the inside-well samples are all less than about 20 inches (1.7 feet) from the trees. None of the outside-well samples are less than about 80 inches (6.9 feet).

The figures on the following pages show schematic diagrams indicating how close each borehole was to its tree. Following the diagrams are photographs of two boreholes that were particularly close to the trees. 

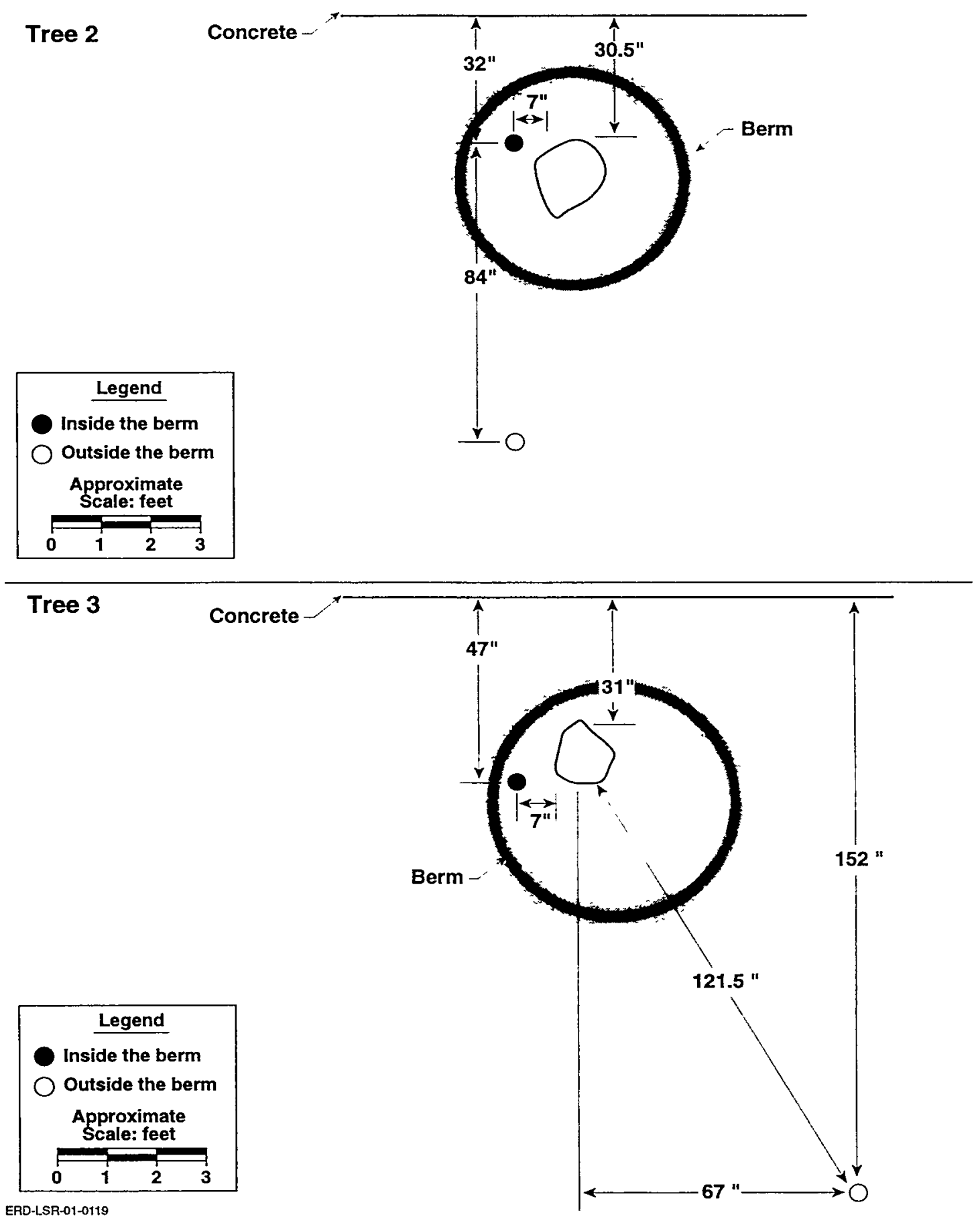

Figure 5.1 Schematic diagram of borehole locations at Trees 2 and 3 


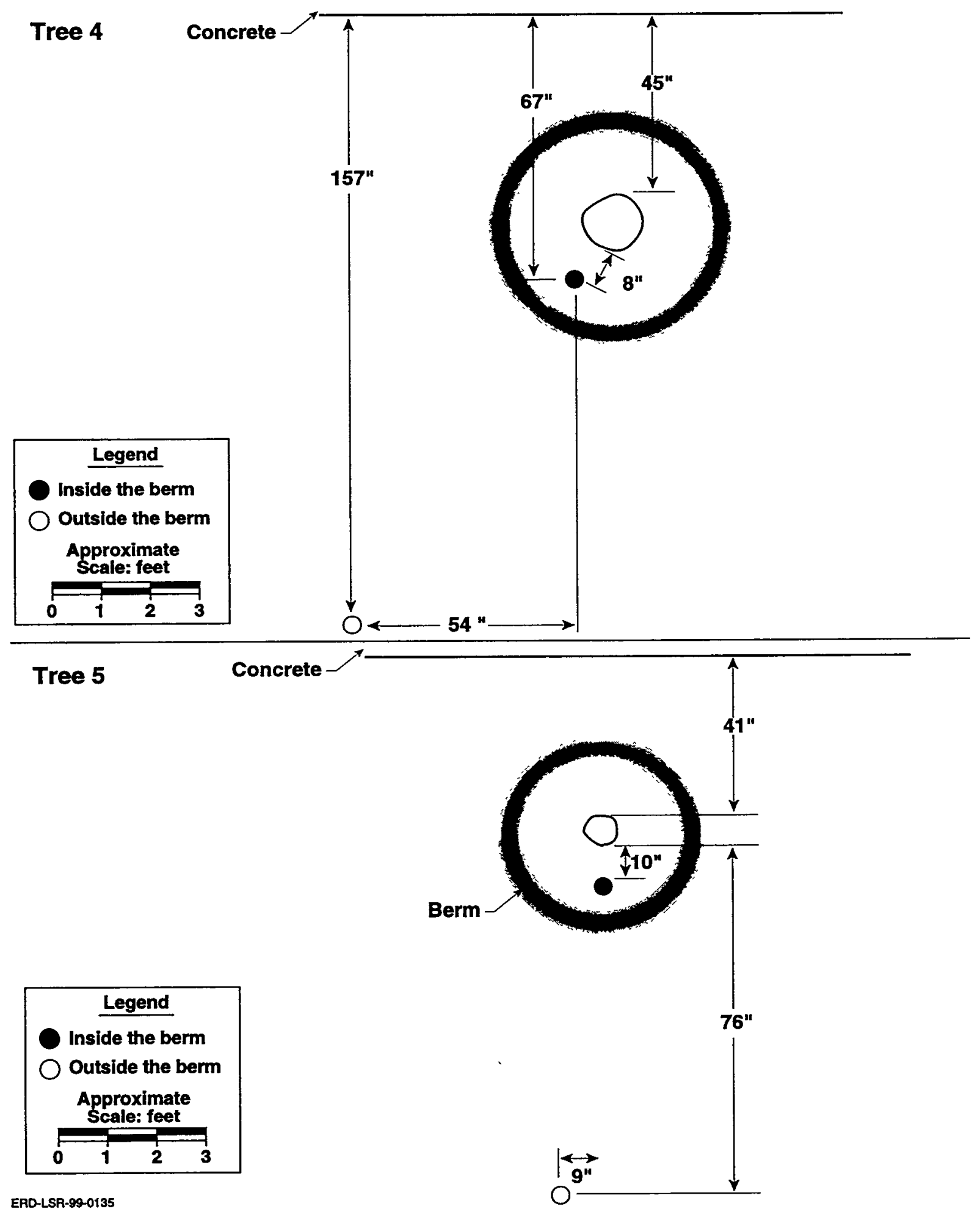

Figure 5.2 Schematic diagram of borehole locations at Trees 4 and 5 

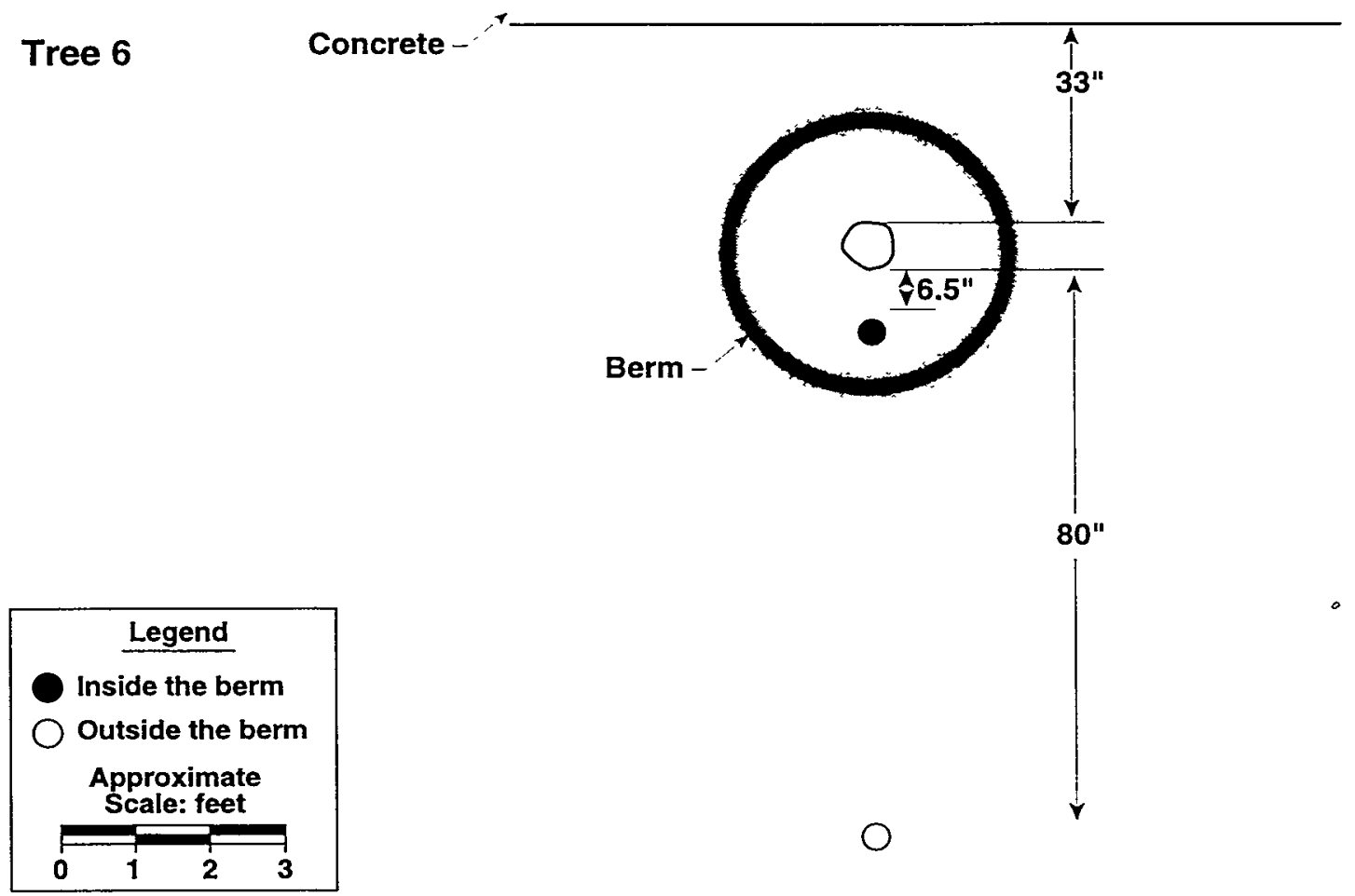

Tree 8

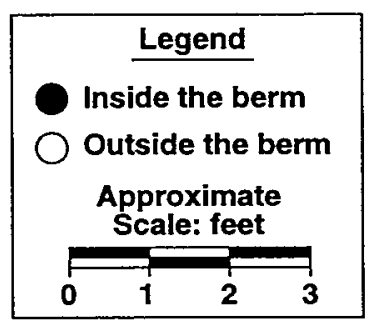

ERD-LSR-99-0136
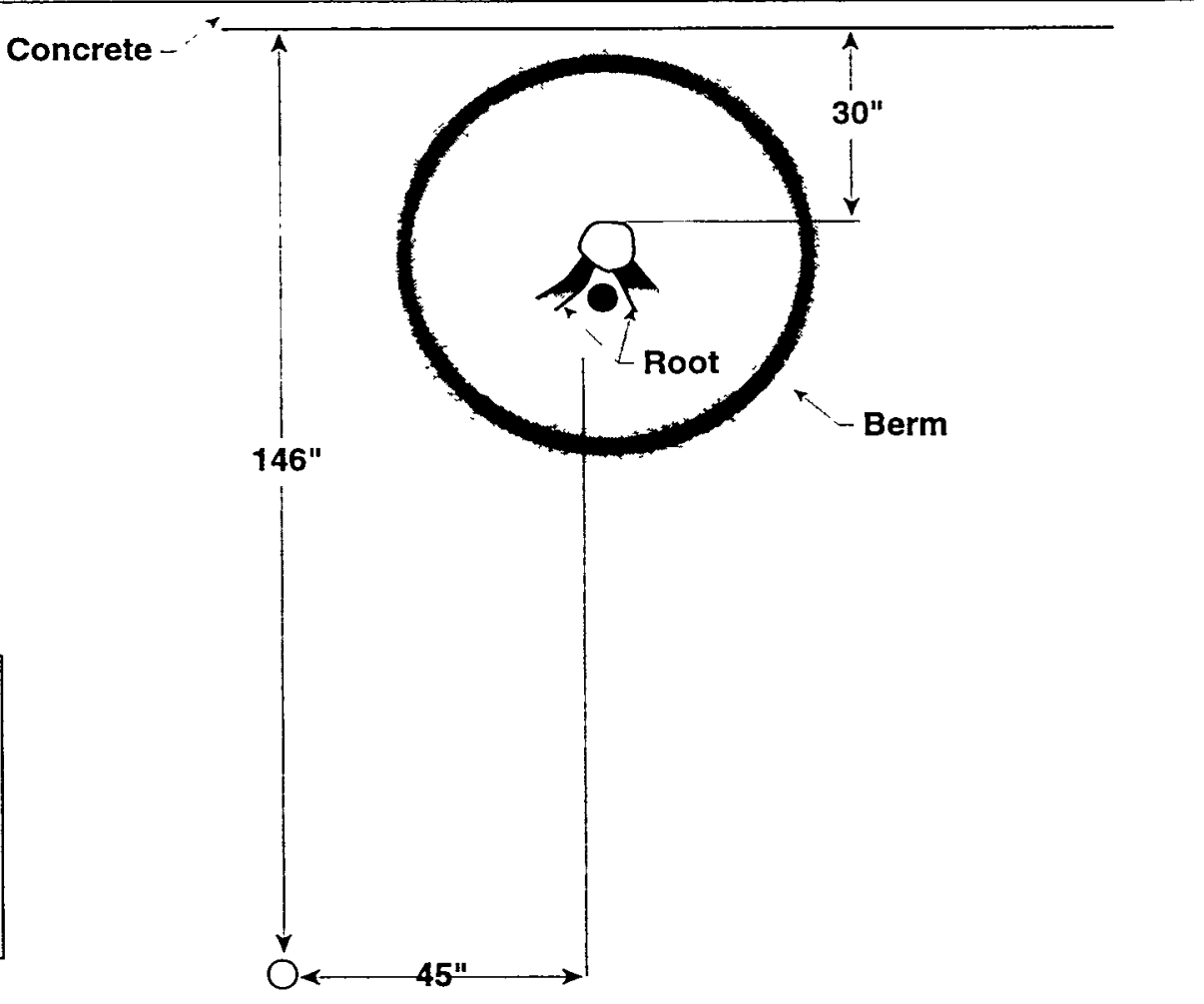

Figure 5.3 Schematic diagram of borehole locations at Trees 6 and 8 
Tree 11
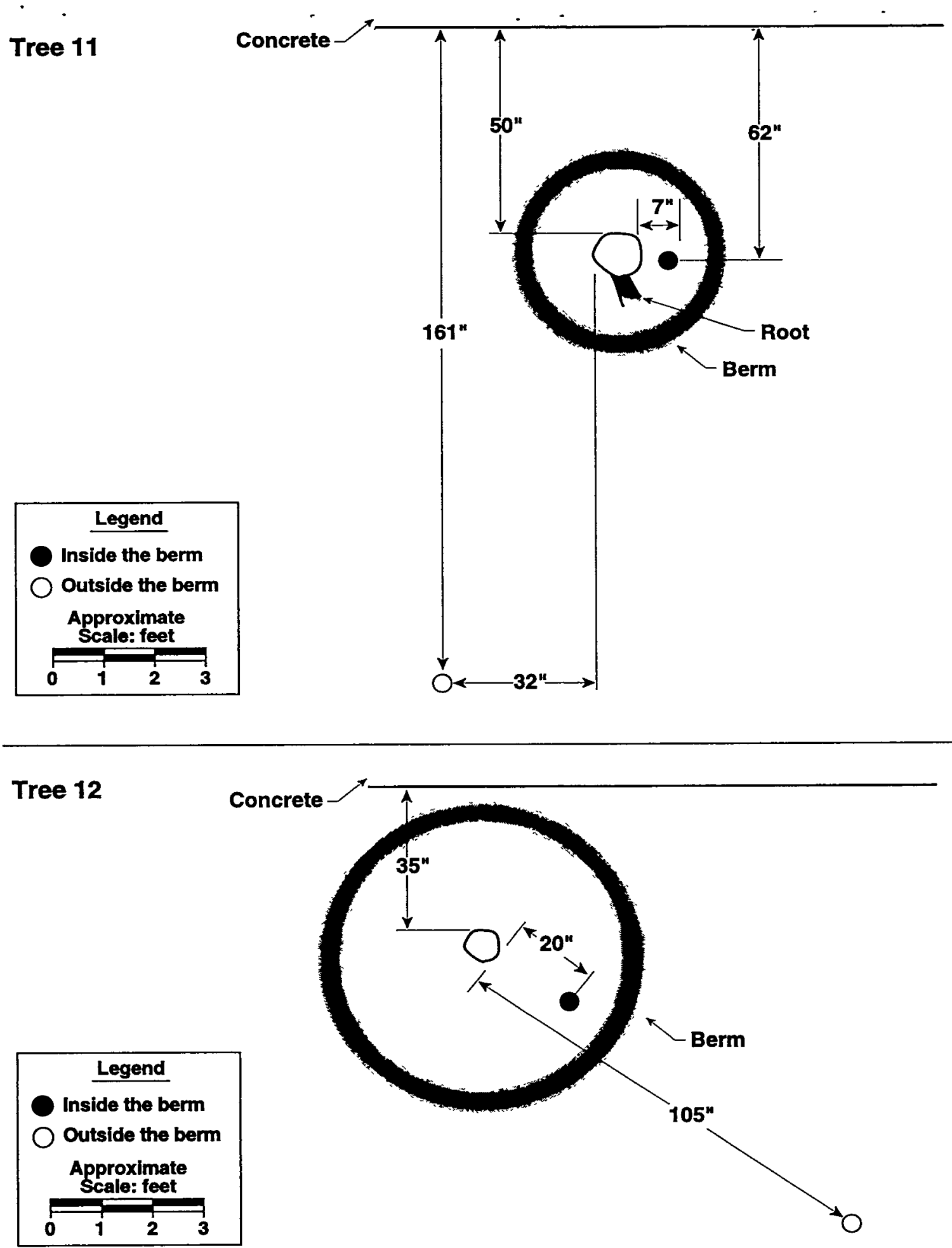

ERD-LSR-99-0138

Figure 5.4 Schematic diagram of borehole locations at Trees 11 and 12 
Tree 14

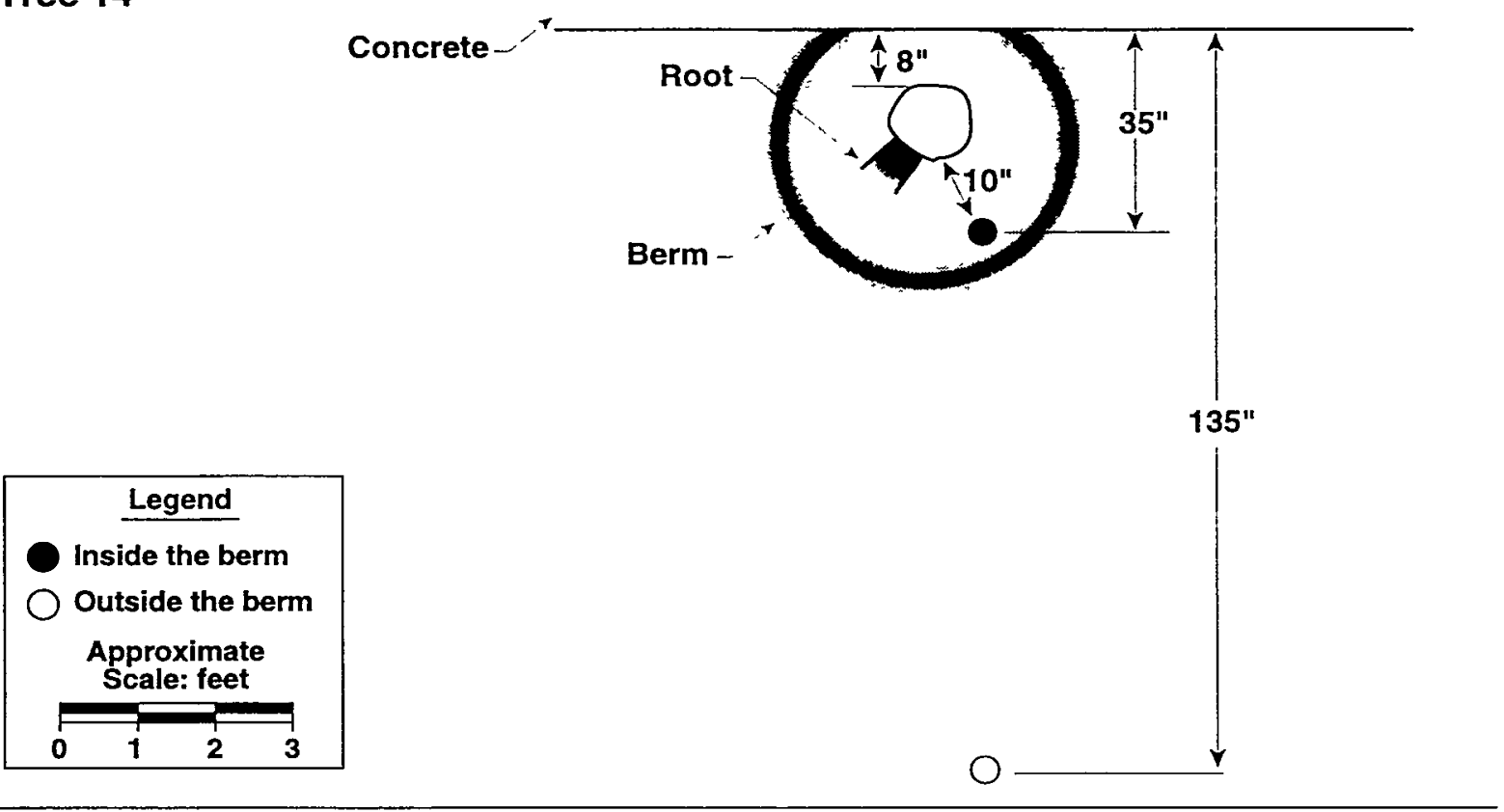

Tree 15

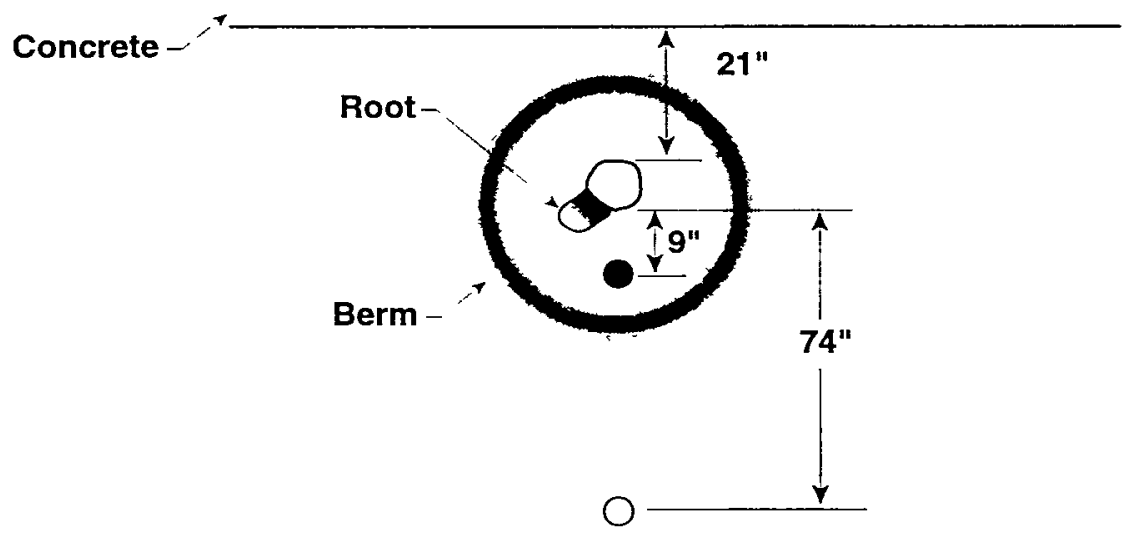

ERD-LSR-99-0137

Figure 5.5 Schematic diagram of borehole locations at Trees 14 and 15 


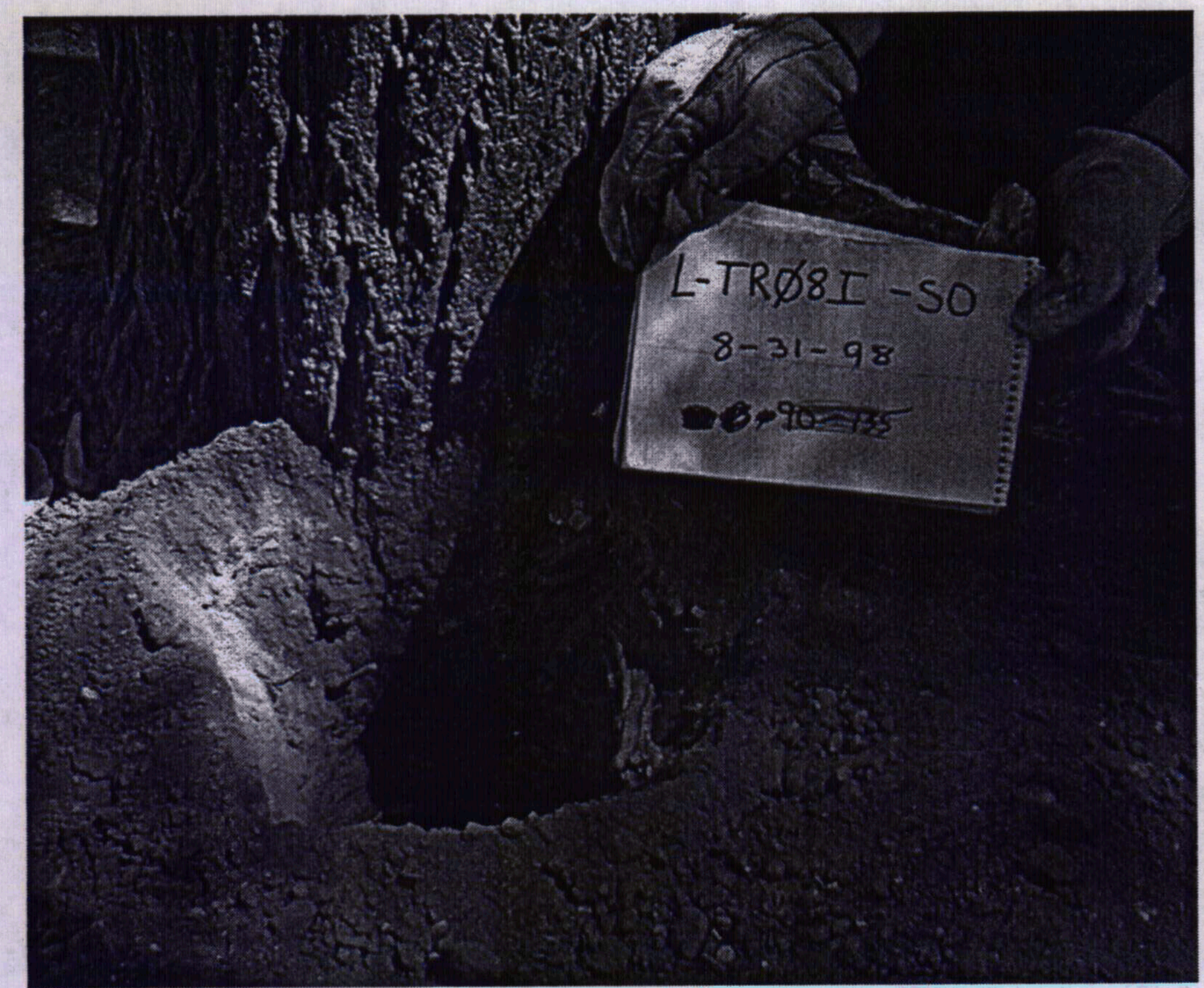

Figure 5.6 Photograph of borehole inside the tree well at Tree 8 


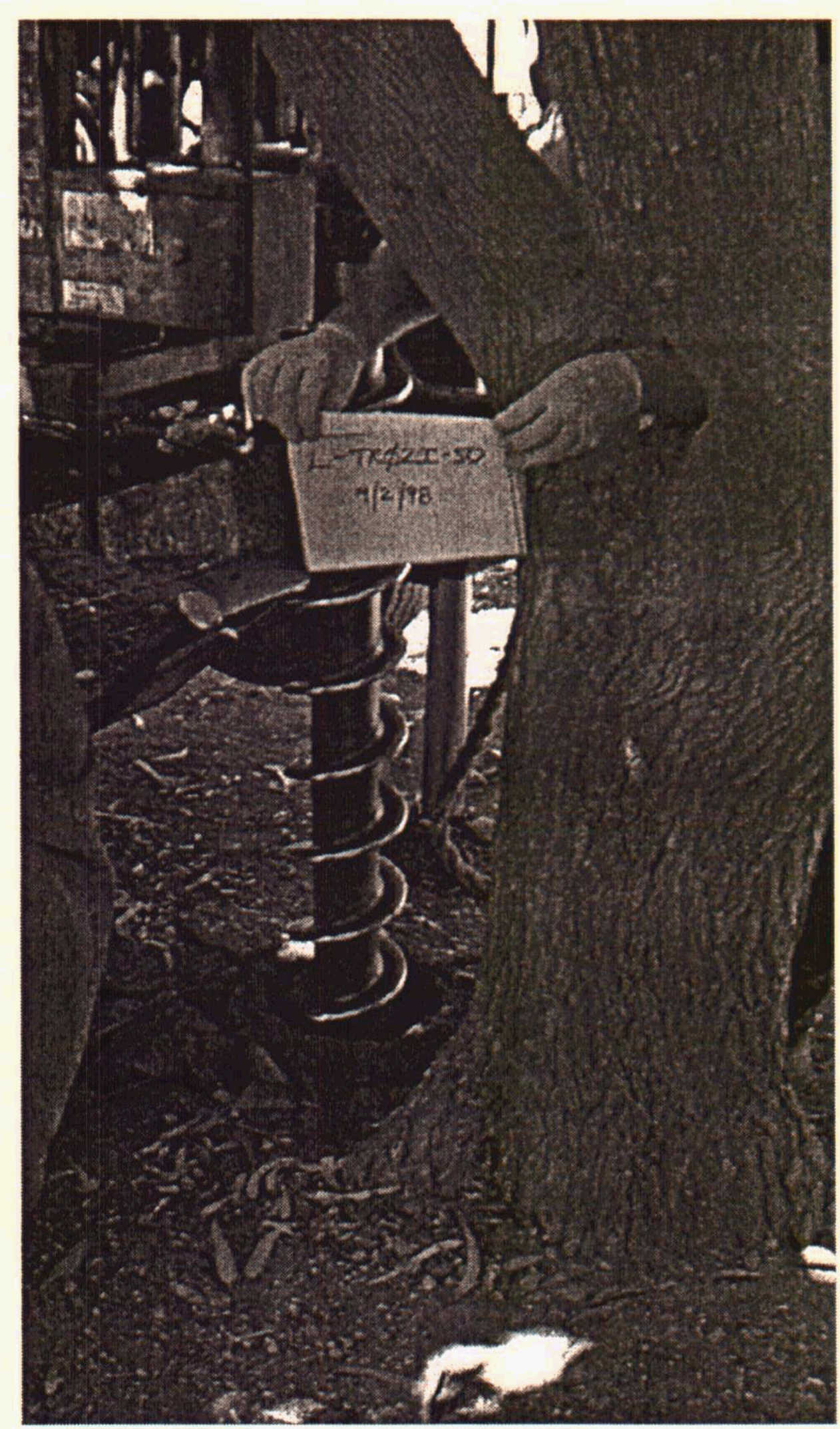

Figure 5.7 Photograph of borehole being drilled inide the tree well at Tree 2.

\subsection{Grid sample locations}

Grid location 1B was moved from its planned location because overhanging tree branches prevented the drill rig from reaching the planned location. The intersection of grid radial 4 and grid perpendicular $\mathrm{F}$ was inside the sandbox, so this sample was collected from a position on perpendicular $\mathrm{F}$ just outside the sandbox.

At several grid locations the first attempt to collect a sample was unsuccessful because the soil was too loose to be extracted by the drill rig. The drill rig was moved a short distance (approximately 1 to 2 feet) and a sample was then successfully collected. 


\subsection{Completeness}

All samples except one were collected as specified in the sampling plan. The $0-45 \mathrm{~cm}$ sample inside the well at tree 3 was collected by hand from within the borehole, instead of from a core contained in a split spoon sampler, because a tree root was encountered.

In addition to the 309 samples indicated in Table 2.1, 38 collocated QC samples and 36 field-split $Q C$ samples were planned, for a total of 383 planned samples. After three attempts, samples from the $20-30 \mathrm{~cm}$ and $30-40 \mathrm{~cm}$ depths at grid location $3 \mathrm{~B}$ were not collected due to insufficient sample recovery (the soil was too loose to be extracted by the drill rig). Field-split samples planned for locations L-DISK01-SO and SSS-AS-104 were not collected. Thus 379 out of 383 planned samples were collected, for a $99 \%$ recovery rate.

Distances from the grid Radial 1 locations to the nearest ornamental tree are shown in Table 5.2.

Table 5.2 Distances from ornamental trees to grid locations.

\begin{tabular}{ccc}
\hline Tree & $\begin{array}{c}\text { Grid } \\
\text { Location }\end{array}$ & $\begin{array}{c}\text { Approximate } \\
\text { Distance (feet) }\end{array}$ \\
\hline Tree 3 & 1A & 4.8 \\
Tree 4 & 1B & 9.1 \\
Tree 6 & 1C & 5.0 \\
Tree 8 & 1D & 11.7 \\
Tree 9 & 1E & 10.0 \\
Tree 9 & 1F & 13.0 \\
Tree 11 & 1G & 6.9 \\
Tree 15 & 1H & 4.8 \\
\hline
\end{tabular}

\subsection{Former arroyo sampling}

Prior to the sampling of the old arroyo channel behind the Arroyo Seco School (the portion of the channel that was filled when the arroyo was re-channeled in about 1970), the depth of the channel was estimated from surveyor's maps (R. M. Galloway and Associates, 1970). During drilling, as each segment of core was removed from the ground, it was inspected by two geologists, one from LLNL and one representing the EPA. These geologists examined the soil for evidence of the interface between the fill and the original arroyo bottom. When the interface was identified, a $15 \mathrm{~cm}$ increment of the core from immediately below the interface was removed and used as the samples. The samples were collected from 305-320, 295-310, and 285-300 cm (results are shown in Table 2.11). 


\section{Review of 1995 Results}

In 1995, as in 1998, samples were split in the field for quality control purposes. Seven of the samples were split into three portions for LLNL, the EPA (Region 9), and the CDHSRHB. The remaining twelve were split into two portions for LLNL and the EPA. Each organization sent their samples to their respective laboratories (designated A, B, and C in this section).

The four samples with the highest concentrations (roughly $0.2 \mathrm{pCi} / \mathrm{g}$ to $1 \mathrm{pCi} / \mathrm{g}$, from Location 1) were in very good agreement among all three laboratories. Among the samples with lower concentrations, laboratory B reported results that appeared to be inconsistent with the other two laboratories (Figure 6.1). The dotted horizontal reference line in Figure 6.1, at $0.01 \mathrm{pCi} / \mathrm{g}$, is the value used in CDHS-EHIB $(1998,1999)$ for comparisons with fallout-background.

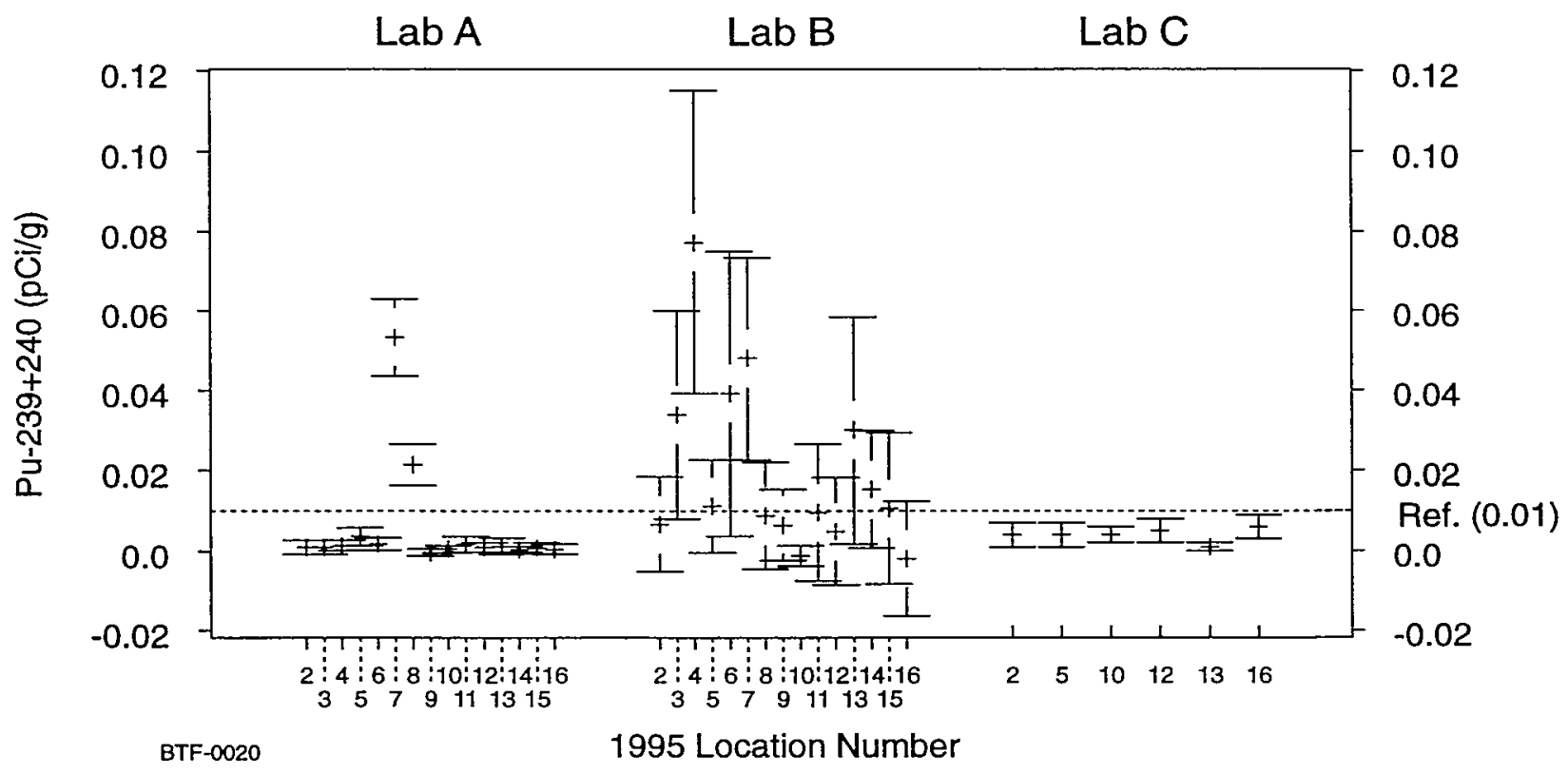

Figure 6.1 1995 Pu-239+240 Split Sample Results.

LLNL's report on the 1995 sampling (MacQueen, 1995) took into account results from both laboratories $\mathrm{A}$ and $\mathrm{B}$ by using the error-weighted average of the their results. Interpretations and conclusions were based on the error-weighted average. 


\subsection{CDHS-EHIB Interpretation of a Subset of the 1995 Data}

The Public Comment Release version of the CDHS-EHIB health consultation (the only version available prior to the 1998 sampling [CDHS-EHIB, 1998]) based interpretations, conclusions, and recommendations on only a selected subset of the data, the results from laboratory B. For example, it stated, "Sixty eight percent of the split samples analyzed by [laboratory B] in the 1995 survey contained Pu-239 concentrations above the upper end of the range $(0.001$ to $0.01 \mathrm{pCi} / \mathrm{g}$...) considered to be attributed to global fallout. This indicates that there is an additional burden of Pu-239 throughout Big Trees Park which cannot be attributed to global fallout." The draft consultation later introduced aerial dispersion as "a plausible explanation for the above 'background" levels of Pu-239 found throughout Big Trees Park, with the exception of location \#1."

\subsection{Interpretation of 1995 Results, Using All of the 1995 Data}

Note that the starting point of the CDHS-EHIB interpretation was that there were plutonium levels above fallout-background "throughout the park." However, only 2 of 12 results from laboratory A outside of Location 1 were above $0.01 \mathrm{pCi} / \mathrm{g}$ (the value used in the health consultation to represent the upper range of fallout-background). Using laboratory A's results, one can not conclude there are above fallout levels "throughout the park."

Thus, Laboratory A's data directly contradicts one of the conclusions of CDHS-EHIB 1998. That conclusion was reached by using only Laboratory B's data, a subset of the available data. Results from Laboratory $C$ match those of Laboratory $A$, not Laboratory B. No explanation for CDHS-EHIB use of only a subset of the data was offered in the draft health consultation.

Although the health consultation was a "draft" document, it was also the "Public Comment Release" version of the document. It was distributed to the public and the news media and had considerable influence on subsequent events. The final version of the health consultation did not claim that there were levels above fallout throughout the park.

\subsection{Data Quality Objectives}

Neither LLNL's 1995 report, nor the draft health consultation, nor the final health consultation offered an explanation for apparent inconsistencies between laboratories $\mathrm{A}$ and B. In fact, there is a simple explanation: LLNL and the EPA specified different data quality objectives to their respective laboratories. 
- The EPA instructed its laboratory to determine whether the sample concentrations were above or below the EPA Region 9 preliminary remediation goal (PRG) of $2.5 \mathrm{pCi} / \mathrm{g}$. In order to satisfy this instruction, the laboratory analyzed in such a way that detection limits would not exceed about $0.25 \mathrm{pCi} / \mathrm{g}$, (Dean, 1998).

- LLNL instructed its laboratory to analyze the samples with a detection limit of $0.005 \mathrm{pCi} / \mathrm{g}$, below the upper limit of fallout-background used in NAREL 1994.

These are very different data quality objectives.

In response, Laboratory $\mathrm{A}$ analyzed samples using 5 gram aliquots and a 24 hour counting time.

Laboratory B analyzed samples using 0.5 gram aliquots $(1 / 10$ the quantity used by laboratory A) and a 162/3 hour counting time.

It is well established that variability increases as aliquot size decreases (Gilbert and Doctor, 1985; Lamé and Deflze, 1993).

Given the different data quality objectives, particularly the aliquot size, the results are not inconsistent.

In addition, the counting time and aliquot size used by laboratory $B$, are such that it is possible that laboratory B could count blanks (i.e., operate a counting instrument with no sample in it) and still report results above $0.01 \mathrm{pCi} / \mathrm{g}$ as much as $20 \%$ of the time (see Appendix 5).

When the EPA established the Data Quality Objectives process for environmental investigations (EPA, 1994a), one of the stated objectives was to ensure that data would be of sufficient quality to support the uses to which it would be put. Laboratory A's results can be used to assess whether sample concentrations are above or below $0.01 \mathrm{pCi} / \mathrm{g}$ because their detection limit of $0.005 \mathrm{pCi} / \mathrm{g}$ is less than $0.01 \mathrm{pCi} / \mathrm{g}$.

As a result of their smaller aliquot size and shorter counting time, Laboratory B's results are highly variable below about $0.1 \mathrm{pCi} / \mathrm{g}$. Such variability has no effect on decisions relative to the PRG of $2.5 \mathrm{pCi} / \mathrm{g}$, so these data are appropriate for their intended purpose (i.e., comparison with the PRG). However, due to the increased variability, Laboratory B's results do not have sufficient quality to be used for decisions relative to $0.01 \mathrm{pCi} / \mathrm{g}$, as was done in the draft health consultation. 


\subsection{Data Quality Objectives}

In 1998, LLNL proposed and the regulatory agencies agreed that all laboratories would use the same analytical data quality objective, a detection limit for plutonium of 0.005 $\mathrm{pCi} / \mathrm{g}$.

Figure 6.2 shows that in the concentration range crucial to decisions relative to falloutbackground (similar to the concentration range of Figure 6.1), none of the 1998 laboratories stood out as distinctly different from the others.

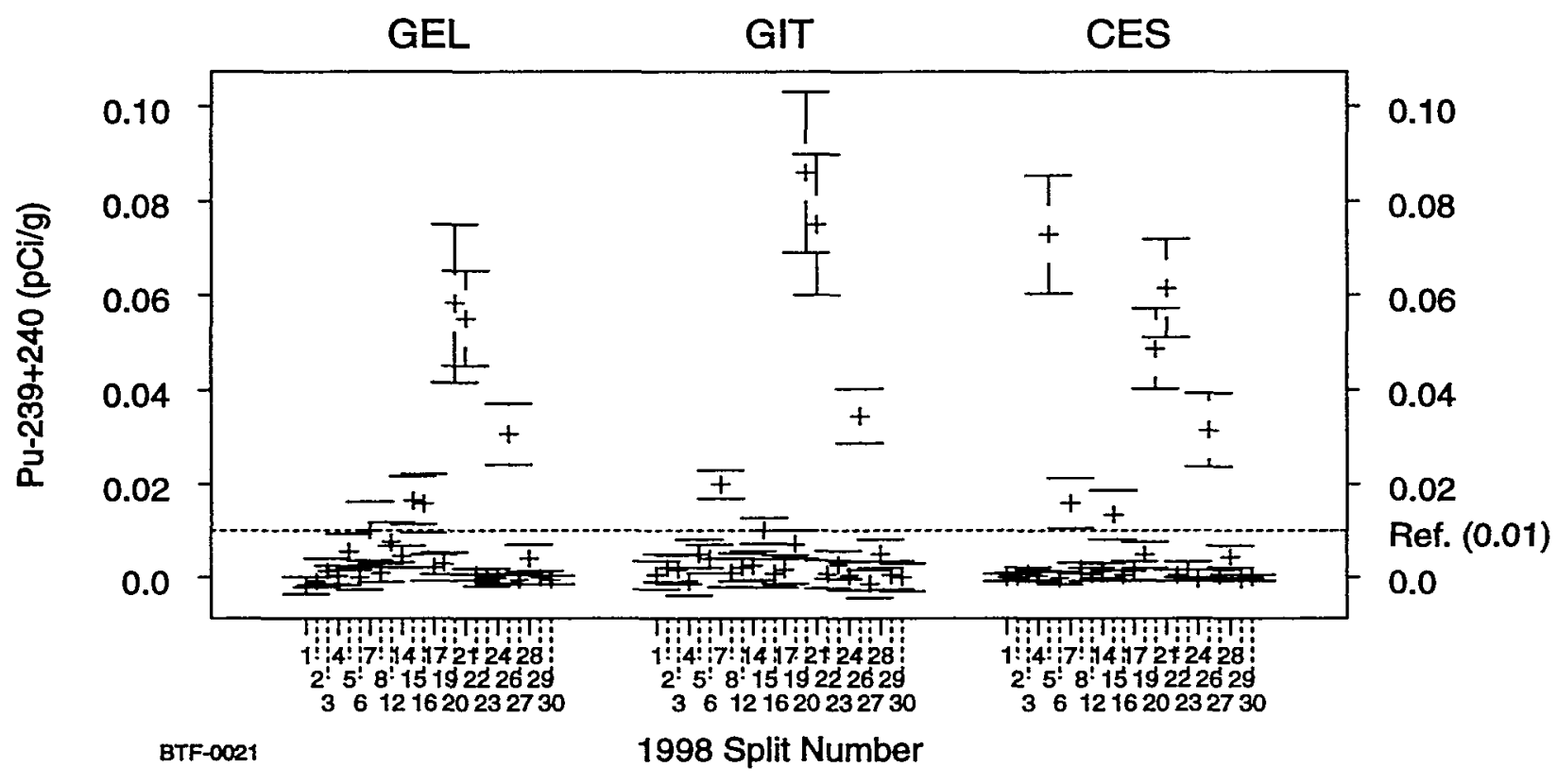

Figure 6.2 1998 Pu-239+240 Split Sample Results.

Figure 6.1 and Figure 6.2 illustrate the fact that split samples must be analyzed with comparable data quality objectives.

The use of different DQOs in 1995 is reflected in the greater variation of Laboratory B's results seen in Figure 6.1, whereas the similarity of results among the three laboratories in Figure 6.2 is a direct result of having similar DQOs in 1998.

It must be emphasized that the issues discussed in this section are irrelevant to the question of health risk. Health risk assessments in the draft health consultation and elsewhere have been based on the highest measured value in the 1995 sampling (CDHSEHIB, 1999; EPA, 1995), and the laboratories reported almost identical values for this. 


\section{Review of 1993 Samples}

In addition to Big Trees Park, samples were also collected in 1993 from two other offsite locations, "Sycamore Grove Park" and "Neighborhood Park on Sunflower Street" (NAREL, 1994). Two samples were collected at each park, one having a depth of 0-1 cm, and another having a depth of 0-5 cm. Each sample was analyzed for both Pu-238 and $\mathrm{Pu}-239+240$. Results for these locations from NAREL (1994), are reproduced in Table 7.1. The $0-1 \mathrm{~cm}$ and $0-5 \mathrm{~cm}$ samples were collected within three feet of each other.

Six of the twelve measurements at all three parks are non-detections (shown in italics in Table 7.1).

Only two of the twelve measurements, both from Big Trees Park, can be said to be definitely above background (these are shaded in Table 7.1).

Table 7.1 Results from 1993 NAREL Park Samples.

\begin{tabular}{|l|c|c|c|c|}
\hline \multirow{2}{*}{$\begin{array}{c}\text { Soil concentrations in pCi/g } \\
\text { (ttwo sigma percent uncertainty) }\end{array}$} & \multicolumn{2}{|c|}{$\mathbf{~ c m}$} & \multicolumn{2}{c|}{$5 \mathrm{~cm}$} \\
\cline { 2 - 5 } & Pu-238 & Pu-239+240 & Pu-238 & Pu-239+240 \\
\hline Big Trees Park & $0.014 \pm 93 \%$ & $0.075 \pm 33 \%$ & $0.011 \pm 136 \%$ & $0.164 \pm 24 \%$ \\
\hline Sycamore Grove Park & $0.012 \pm 8 \%$ & $0.046 \pm 4 \%$ & $-0.004 \pm 200 \%$ & $0.009 \pm 111 \%$ \\
\hline $\begin{array}{l}\text { Neighborhood Park on } \\
\text { Sunflower Street }\end{array}$ & $0.013 \pm 23 \%$ & $0.007 \pm 114 \%$ & $-0.003 \pm 300 \%$ & $0.006 \pm 133 \%$ \\
\hline
\end{tabular}

The remaining four results (0-1 cm Pu-238 at all three parks and 0-1 cm Pu-239+240 at Sycamore Grove) have values that appear to be above fallout-background. These results have been interpreted by members of the community at large as evidence that these parks also are contaminated with plutonium from sources other than fallout.

However, this interpretation is not correct.

It is highly improbable that contamination other than recent air dispersion would be restricted to the $0-1 \mathrm{~cm}$ interval, and not also found in the $0-5 \mathrm{~cm}$ interval-which, except for Big Trees Park, it was not.

The fallout-background value for Pu-238 is based on sampling and analytical protocols (i.e., data quality objectives) that (1) covered sufficient surface area to be useful for measuring air dispersion, and (2) used sufficient soil in the analytical laboratory (200 to 1000 grams) to achieve representative results at low levels (EPRI, 1981). 
The sampling and analytical protocols used by NAREL in 1993 (1) did not cover as large a surface area as the fallout-background samples, and (2) used only 1 gram of soil in the analytical laboratory. As a result, the NAREL results are necessarily much more variable than those from fallout-background samples. Therefore, the NAREL results cannot be used to make confident assertions about air dispersion, nor can they validly be compared with the fallout-background values.

If the 1993 analyses are evaluated using the method described in Appendix 5, the results suggest that the 1993 sampling data quality objectives could produce $\mathrm{Pu}-238$ results above fallout-background as much as $34 \%$ of the time, in samples that in fact have no plutonium. Concentrations as high or higher than the actual 1993 results for $\mathrm{Pu}-238$ in the $1 \mathrm{~cm}$ interval could occur roughly $4 \%$ of the time in samples having no plutonium. Samples with plutonium at fallout-background levels would, of course, have such results more often.

Because the 1993 results could easily have come from samples having no plutonium whatsoever, the interpretation that they represent above-background levels is untenable.

In addition, many years of LLNL surveillance monitoring of soil in the same general directions as Sycamore Grove and Sunflower Street would have revealed evidence of contamination by air dispersion from LLNL had it occurred. The surveillance monitoring has not found such evidence.

For these reasons, the 1993 samples from the other two parks do not provide evidence of plutonium contamination from sources other than fallout at the other two parks. 


\section{Conclusion}

The extensive soil sampling conducted in 1998 in Big Trees Park provides an ample and accurate set of data on which to base a number of conclusions.

First, the data show that there is virtually no above-fallout-background plutonium at depths below $10 \mathrm{~cm}$.

Second, the data can be used to gain an understanding of the lateral extent of above-fallout-background plutonium at the park. The data clearly show the plutonium to be primarily associated with the ornamental tree wells and with grid Radial 1, with a secondary tendency along grid Perpendicular $\mathrm{H}$.

Third, the data can be used to deduce which of the three proposed pathways to the park is the most likely. The sewage sludge pathway is the most likely way for plutonium to have reached the park because it is the pathway hypotheses consistent with the data.

Finally, and most importantly, this large body of data provides substantial evidence that plutonium at the park is below the U.S. EPA Region IX residential preliminary remediation goal of $2.5 \mathrm{pCi} / \mathrm{g}$. This has the U.S. EPA to determine that there is no cause for health concern, and the ATSDR to recommend no further action. ${ }^{1}$

${ }^{1}$ Heffner, 1999, and ATSDR, 2000 


\section{References}

ATSDR (2000). "Health Consultation, Big Trees Park 1998 Sampling, Lawrence Livermore National Laboratory (USDOE), Livermore, Alameda County, California", Agency for Toxic Substances and Disease Registry (CERCLIS No. CA2890012584), January 10, 2000

CDHS-EHIB (1998). "Health Consultation, Plutonium Contamination in Big Trees Park, Lawrence Livermore National Laboratory, Livermore, Alameda County, California", California Department of Health Services, Environmental Investigations Branch (CERCLIS No. CA 28900124584), February 9, 1998 (Public Comment Release)

-- (1999). "Health Consultation, Plutonium Contamination in Big Trees Park, Lawrence Livermore National Laboratory, Livermore, Alameda County, California", California Department of Health Services Environmental Investigations Branch (CERCLIS No. CA 28900124584), May 17, 1999 (Final)

Dean, S. (1998). Personal communication.

DOE (1982). "Final Environmental Impact Statement, Lawrence Livermore National Laboratory and Sandia National Laboratories-Livermore, California", U.S. Department of Energy (DOE/EIS-0028), July, 1982

-- (1991). "Environmental Regulatory Guide for Radiological Effluent Monitoring and Environmental Surveillance", U.S. Department of Energy, Washington, DC (DOE/EH-0173T)

-- (1993). "Radiation Protection of the Public and the Environment", U.S. Department of Energy, Washington DC (DOE Orders 5400.5)

Ehmann, W. D. and D. E. Vance (1991). Radiochemistry and Nuclear Methods of Analysis. New York, John Wiley \& Sons.

Eidelberg (1998). Memorandum from Joe Eidelberg, Quality Assurance Office, EPA Region IX, to data reviewers, (December 18, 1998)

Eisenbud, M. and T. Gesell (1997). Environmental Radioactivity From Natural, Industrial, and Military Sources. New York, Academic Press. 
EPA (1984). "Soil Sampling Quality Assurance User's Guide", U.S. Environmental

Protection Agency, Environmental Research Center, Las Vegas NV (EPA-600/484-043), May 1984

- (1990). "Rationale for the Assessment of Errors in the Sampling of Soils", U.S.

Environmental Protection Agency, Environmental Research Center, Las Vegas, NV (EPA/600/4-90/013), July 1990

-- (1992). "Preparation of Soil Sampling Protocols: Sampling Techniques and

Strategies", U.S. Environmental Protection Agency, Office of Research and

Development, Washington DC (EPA/600/R-92/128), July 1992

EPA (1994a). "Guidance For the Data Quality Objectives Process", U.S. Environmental Protection Agency, Office of Research and Development, Washington, DC (EPA/600/R-96/055), September 1994

--- (1994b). "Radiation Site Cleanup Regulations: Technical Support Document for the Development of Radionuclide Cleanup Levels for Soil, Appendix O", U.S. Environmental Protection Agency, Office of Air and Radiation, Washington DC (EPA 402-R-96-011 C), September 1994

--- (1995). "Lawrence Livermore National Laboratory Plutonium Fact Sheet", Prepared by EPA Region 9, peer reviewed by LLNL and the State of Califonia Department of Health Services, September 1995

--- (1996). "Geostatistical Sampling and Evaluation Guidance for Soils and Solid Media", Review draft, US EPA, Office of Solid Waste, February, 1996

EPRI (1981). "Transuranium and Other Long-Lived Radionuclides in the Terrestrial Environs of Nuclear Power Plants", prepared by Battelle, Pacific Northwest Laboratories, Richland WA, Electric Power and Research Institute, Palo Alto, CA (EPRI EA-2045)

Gallegos, G., MacQueen, D. H., Surano, K. (1999). "Livermore Big Trees Park 1998 Summary Results", Lawrence Liveremore National Laboratory, Livermore CA (UCRL)

Gilbert, R. O., P. G. Doctor (1985). “Determining the Number and Size of Soil Aliquots for Assessing Particulate Contaminant Concentrations." Lournal of Environmental Quality 14(2): 286-292.

Gilbert, R. O. (1987). Statistical Methods for Environmental Pollution Monitoring. New York, NY, Van Nostrand Reinhold. 
Good, P. (1994). Permutation Tests, A Practical Guide to Resampling Methods for Testing Hypotheses. New York, Springer-Verlag.

Gudiksen, P. H., C. L. Lindeken, C. Gatrousis, L. R. Anspaugh (1972). "Environmental Levels of Radioactivity in the Vicinity of the Lawrence Livermore Laboratory January Through December 1971", Lawrence Liveremore Laboratory, Livermore, CA (UCRL-51242), June 14, 1972

HASL (1975). "Fallout Program Quarterly Summary Report (Sept. 1, 1974 through Dec. $1,1974) "$, Health and Saftey Labortory, U.S. Atomic Energy Commission, New York, NY (HASL-288, UC-11), January 1, 1975

Heffner, H. (1999). joint press release, EPA, DTSC, RWQCB, DOE, and LLNL.

Ingledue, J. (1997, 1998). Personal communications, (1997, 1998)

Johnson, N. L., S. Kotz, et al. (1993). Univariate Discrete Distributions. New York, John Wiley \& Sons.

Kaufman \& Broad (1969). "Report-Soil Investigation, Tract 3064, Livermore, California including letter from Cooper-Clark and Associates", December 11, 1969

-- (1970). "Report-Inspection and Testing of Lot Grading Proposed Residential Subdivision Tract 3064, Unit 1, Livermore, California", including letters from Cooper-Clark and Associates, September 24, July 14, and February 19, 1970

Kelly, J. (1995). fax transmittal of preliminary results of mass spectrometric analysis of soil samples, (April 30, 1995)

Kim, C. S., et. al. (1998). "90Sr, 137Cs, 239+240Pu and 238Pu Concentrations in Surface Soils of Korea." Journal of Environmental Radioactivity 40(1): 75-88.

Lamé, F. P. J., Deflze, Peter R. (1993). “Sampling of Contaminated Soil: Sampling Error in Relation to Sample Size and Segregation." Environmental Science and Technology 27(10): 2035-2044.

LARPD (1971). letter to prospective bidders on its "Wagoner Site Neighborhood Park" development, (March 11, 1971)

-- (1998). drawing "Big Trees Park—asphalt paths", (December 13, 1988) 
Liddle, R. (1998). letter report to Ms. Kathy Setian, U.S. EPA Region IX, and Mr. Steve Hsu, California Department of Health Services-Radiological Health Branch, regarding Big Trees Park 1998 actual field sampling, (November 18, 1998)

LLNL (1992). "Environmental Report for 1991", Lawrence Liveremore National Laboratory, Livermore, CA (UCRL-50027-91)

-- (1998). "Livermore Big Trees Park 1998 Sampling Plan", Lawrence Livermore National Laboratory, Livermore, CA (UCRL-ID-130551), July 31, 1998 (draft final), October 1998 (final)

Lougheed, R., and Moody, K. (1999). Memoradum: Source Interpretation on Big Trees Park Actinide Analyses, (August 17, 1999)

MacQueen, D. H. (1995). "Livermore Big Trees Park January 1995 Soil Survey Results", Lawrence Livermore National Laboratory, Livermore, CA (UCRL-ID-121045)

--- (1998). Personal communication with a nearby resident at LLNL-hosted public presentation of the draft sampling plan for the 1998 Big Trees Park sampling and related issues., (May 7, 1998)

McBride, M. B., B. K. Richards, T. Steenhuis, J. J. Russo, and S. Sauvé (1997). “Mobility and Solubility of Toxic Metals and Nutrients in Soil Fifteen Years After Sludge Application." Soil Science 162: 487-500.

McConachie, W. (1998). "Chronology of potential environmental impacts of plutonium at LLNL-a work in progress", Lawrence Liveremore National Laboratory, Livermore, CA (UCRL-MI-130704)

Meyers, J. C. (1997). Geostatistical Error Management-Quantifying Uncertainty for Environmental Sampling and Mapping. New York, Van Nostrand Reinhold.

Miller, R. G. (1981). Simultaneous Statistical Inference. New York, Springer-Verlag.

Montgomery, D. C. (1991). Design and Analysis of Experiments. New York, John Wiley \& Sons.

NAREL (1994). "Confirmatory Sampling of Plutonium in Soil from the Southeast Quadrant of the Lawrence Livermore National Laboratory", U.S. Environmental Protection Agency, National Air and Radiation Laboratory (WA No. 2-12), August 15, 1994 
NAREL (1995). "Data Summary Package, Analytical Results from Big Trees Park Soil Sampling", U.S. Environmental Protection Agency, National Air and Radiation Laboratory, Montgomery AL, April 6, 1995

NCRP (1999). "Recommended Screening Limits for Contaminated Surface Soil and Review of Factors Relevant to Site-specific Studies", National Council on Radiation Protection and Measurements, Bethesda, MD (NCRP Report No. 129)

Perkins, R. W., and C. W. Thomas (1980). "Worldside Fallout", in Transuranic Elements in the Environment, Washington, DC (DOE/TIC-22800)

Pitard, F. F. (1993). Pierre Gy's Sampling Theory and Sampling Pratice-Heterogeneity Sampling Correctness, and Statistical Process Control. New York, CRC Press.

R. M. Galloway \& Associates (1970). "Grading Plans for Tract 3064, Livermore Unit 1, California"

Sewell, D. C. (1967). "Report on the 1967 Release (need to get proper title)", Lawrence Liveremore National Laboratory, July 18, 1967

Silver, W. J., C. L. Lindeken, J. W. Meadows, W. H. Hutchin, and D. R. McIntyre (1974). "Environmental Levels of Radioactivity in the Vicinity of the Lawrence Livermore Laboratory, 1973 Annual Report", Lawrence Liveremore National Laboratory, Livermore, CA (UCRL-51547)

Velsko, C. (1999). memorandum to H. Galles "Final Results for Plutoniuim Isotope Ratios in Two Samples of Big Trees Park Soil", (January 18, 1999) 


\section{Acknowledgments}

The following people have made significant contributions to this document:

Robert Bainer, Lindee Berg, Art Biermann, Beverly Chamberlain, Bert Heffner, Kim Heyward, Albert Lamarre, Howard Lentzner, and William McConachie 


\section{Appendix 1 Variance Partition}

As mentioned in Section 3.2.5, the EPA (Region 9) requested that LLNL perform a "variance partition" calculation. The purpose of such a calculation is to estimate the relative contributions of different sources of uncertainty to the total uncertainty in the results.

When a sample is split into two or more portions, the portions do not contain the same soil, so it is not expected that they have identical concentrations.

Similarly, the analytical laboratory does not necessarily use the entire sample. Different laboratory sub-samples will have different concentrations because the soil is not (and can not possibly be) perfectly homogeneous.

As a result, the reported concentration has some variability depending on any splitting before sending the sample to the laboratory, and depending on the particular soil used for the sub-sample. This variability contributes to the overall uncertainty of the reported result, and the degree to which the reported result is representative of the area from which the sample was collected.

This section describes in some detail the formulas used to perform the variance partition calculation.

Consider a small area of soil, on the order of 4 square meters in extent and $5 \mathrm{~cm}$ deep.

That volume of soil has a true average concentration, represented by the symbol $\mu$. In practical applications the average is always unknown, because it is not practical to analyze such a large quantity of soil.

A sample of soil is collected from a distinct location within the area (for example, a single $10 \mathrm{~cm}$ diameter core collected to a depth of $5 \mathrm{~cm}$ ). The sample also has a true average concentration that will not in general be exactly the same as $\mu$, because the soil is not perfectly homogeneous.

Another such sample taken from a different location within the area will also have a true average concentration that will not in general be the same as the first sample, and not equal to $\mu$. 
This variability of sample concentrations from nearby locations is referred to as smallscale spatial variability.

If a single such sample is then split into two portions at any time before delivery to the laboratory, each of those portions will have a true average concentration that will not in general be the same as the average of the whole sample, because the sample is not perfectly homogeneous. This source of variability is referred to in this discussion as field heterogeneity, though it could also be referred to as sample heterogeneity.

The laboratory usually does not analyze the entire sample as received. Instead, it selects a sub-sample (aliquot) for analysis. The sub-sample will not in general have the same average concentration as the entire sample, again because the soil is not perfectly homogeneous. Two such sub-samples will not in general have the same average concentration. This source of variability is referred to in this discussion as laboratory heterogeneity, though it could also be referred to as sub-sampling variability or aliquot variability.

The aliquot is then analyzed in a series of steps that include chemical processing (dissolution with acids, chemical separations) and particle counting, leading to a reported concentration. Radioactive decay is a random process. Therefore, if the same sample is counted for 100 minutes today, and then again for 100 minutes tomorrow, the results will not in general be the same. There are other sources of variability in these steps as well (including, for example, factors such as the skill of the chemist in measuring quantities and preparing solutions). This variability is referred to as analytical variability in this discussion.

The value reported by the laboratory (represented by the symbol $y$ ) can thus be thought of as the result of a series of steps: starting with the true average of the area as a whole, each sample or sub-sample selection increases or decreases the concentration by some amount relative to the true average of the area as a whole. This is represented in an equation as:

$y=\mu+e_{s p c}+e_{f l d}+e_{l a b}+e_{a n l}$.

That is, the reported value is equal to a true value plus a contribution from each of four sources of variability. These four sources each reflect a step in the measurement process. They are considered to be random and independent. 


\section{Table 1.1 Definitions of variability model terms}

$\mu \quad$ true average over a small area

$e_{s p c} \quad$ spatial contribution to reported result

$e_{R d} \quad$ field (sample) contribution to reported result due to sample heterogeneity

$e_{l a b} \quad$ laboratory (aliquot) contribution to reported result due to sub-sample heterogeneity

$e_{\text {ant }} \quad$ analytical contribution to reported result due to measurement uncertainty, including radioactive counting uncertainty

$y$ measured value reported by the laboratory

The variance (squared uncertainty) of the measured value is given by the sum of the variances of the contributing factors:

$$
\sigma_{\text {total }}^{2}=\sigma_{s p c}^{2}+\sigma_{f d d}^{2}+\sigma_{\text {lab }}^{2}+\sigma_{a n l}^{2} \text {. }
$$

This equation is a "variance partition" equation. That is, it separates the total uncertainty into contributions from each of several sources.

The purpose of this section is to estimate the relative sizes of each of the terms on the right-hand side of the variance partition equation.

\section{Collocated pairs}

Let $y_{1}$ and $y_{2}$ be the reported results from a collocated pair of samples (i.e., any pair of samples collected within a small distance of each other). Each result has uncertainty from all of the sources described above, with different values for each.

$$
\begin{aligned}
& y_{1}=\mu+e_{1, s p c}+e_{1, f l d}+e_{1, l a b}+e_{1, a n l} \\
& \begin{aligned}
& y_{2}=\mu+e_{2, s p c}+e_{2, f l d}+e_{2, \text { lab }}+e_{2, a n l} \\
& y_{1}-y_{2}=\mu+e_{1, s p c}+e_{1, f d d}+e_{1, \text { lab }}+e_{1, a n l}-\left(\mu+e_{2, s p c}+e_{2, f l d}+e_{2, l a b}+e_{2, a n l}\right) \\
& \quad=\left(e_{1, s p c}-e_{2, s p c}\right)+\left(e_{1, f d d}-e_{2, f l d}\right)+\left(e_{1, l a b}-e_{2, l a b}\right)+\left(e_{1, a n l}-e_{2, a n l}\right)
\end{aligned}
\end{aligned}
$$

therefore

$$
\operatorname{var}\left(y_{1}-y_{2}\right)=2 \sigma_{s p c}^{2}+2 \sigma_{f l d}^{2}+2 \sigma_{l a b}^{2}+2 \sigma_{a n l}^{2}
$$

from which it follows that 
$\sigma_{s p c}^{2}+\sigma_{f d i}^{2}+\sigma_{l a b}^{2}+\sigma_{a n l}^{2}=\frac{\operatorname{var}\left(y_{1}-y_{2}\right)}{2}$

which can be calculated from the reported data.

Note that $\sigma_{s p c}^{2}+\sigma_{f l d}^{2}+\sigma_{l a b}^{2}+\sigma_{a n l}^{2}=\sigma_{\text {total }}^{2}$, so this is also an estimate of the total variance. In this step, $y_{1}$ and $y_{2}$ represent results from collocated sample pairs.

\section{Field-split pairs}

Field-split pairs are two parts of one sample collected from a single location. Because they are from a single location, their reported values have the same spatial contribution but different contributions from the other three sources.

$$
\begin{aligned}
& y_{1}=\mu+e_{s p c}+e_{1, f d d}+e_{1, l a b}+e_{1, a n l} \\
& y_{2}=\mu+e_{s p c}+e_{2, f l d}+e_{2, a b}+e_{2, a n l}
\end{aligned}
$$

Therefore,

$$
\begin{aligned}
& y_{1}-y_{2}=\mu+e_{s p c}+e_{1, f d d}+e_{1, l a b}+e_{1, a n l}-\left(\mu+e_{s p c}+e_{2, f l d}+e_{2, l a b}+e_{2, a n l}\right) \\
&=\left(e_{1, f d d}-e_{2, f l d}\right)+\left(e_{1, l a b}-e_{2, l a b}\right)+\left(e_{1, a n l}-e_{2, a n l}\right) \\
& \operatorname{var}\left(y_{1}-y_{2}\right)=2 \sigma_{f l d}^{2}+2 \sigma_{l a b}^{2}+2 \sigma_{a n l}^{2}
\end{aligned}
$$

and

$$
\sigma_{f l d}^{2}+\sigma_{l a b}^{2}+\sigma_{a n l}^{2}=\frac{\operatorname{var}\left(y_{1}-y_{2}\right)}{2}
$$

which can be calculated from the reported data. In this step, $y_{1}$ and $y_{2}$ represent results from field-split sample pairs.

\section{Lab-split pairs}

Lab-splits are two parts of one (possibly field-split or collocated) sample collected from a single location. Therefore, their reported values have the same spatial and field split contributions but different contributions from the other two sources.

$$
\begin{aligned}
& y_{1}=\mu+e_{s p c}+e_{f l d}+e_{1, l a b}+e_{1, a n l} \\
& y_{2}=\mu+e_{s p c}+e_{f l d}+e_{2, a b}+e_{2, a n l}
\end{aligned}
$$

Therefore, 


$$
\begin{aligned}
& \begin{array}{l}
y_{1}-y_{2}=\mu+e_{s p c}+e_{f d}+e_{1, a b}+e_{1, a n l}-\dot{y}\left(\mu+e_{s p c}+e_{f l d}+e_{2, a b}+e_{2, a n l}\right) \\
\quad=\left(e_{1, l a b}-e_{2, a b}\right)+\left(e_{1, a n l}-e_{2, a n l}\right)
\end{array} \\
& \operatorname{var}\left(y_{1}-y_{2}\right)=2 \sigma_{l a b}^{2}+2 \sigma_{a n l}^{2} \\
& \text { and }
\end{aligned}
$$

$$
\sigma_{l a b}^{2}+\sigma_{a n t}^{2}=\frac{\operatorname{var}\left(y_{1}-y_{2}\right)}{2}
$$

which can be calculated from the reported data. In this step $y_{1}$ and $y_{2}$ represent results from lab-split sample pairs.

\section{Analytical uncertainty}

In the 1998 sampling, multiple analyses of the same aliquot from which to estimate analytical uncertainty do not exist. In fact, it is literally impossible to analyze the same aliquot twice, because the chemical processing can not be repeated. However, the laboratory reports an estimate of the analytical uncertainty with each sample, and this can be used. This uncertainty varies from aliquot to aliquot, so the average of the reported uncertainties is used to represent this contribution to the total variability.

\section{Partitioning the variance}

As described above, the following quantities can be calculated directly from the available data:

$$
\begin{aligned}
\sigma_{s p c}^{2}+\sigma_{f l d}^{2}+\sigma_{l a b}^{2}+\sigma_{a n l}^{2} & =\frac{\operatorname{var}\left(y_{1}-y_{2}\right)}{2}\left[y_{1} \text { and } y_{2} \text { from collocated pairs }\right] \\
\sigma_{f l d}^{2}+\sigma_{l a b}^{2}+\sigma_{a n l}^{2} & =\frac{\operatorname{var}\left(y_{1}-y_{2}\right)}{2}\left[y_{1} \text { and } y_{2} \text { from field - split pairs }\right] \\
\sigma_{l a b}^{2}+\sigma_{a n l}^{2} & =\frac{\operatorname{var}\left(y_{1}-y_{2}\right)}{2}\left[y_{1} \text { and } y_{2} \text { from lab-split pairs }\right] \\
\sigma_{a n l}^{2} & =\text { [average of reported sample uncertainties }]
\end{aligned}
$$

The individual variance terms (whose values are the goals of this section) can be calculated by subtracting the above equations from each other. That is, 


$$
\begin{aligned}
& \sigma_{l a b}^{2}=\left(\sigma_{l a b}^{2}+\sigma_{a n i}^{2}\right)-\sigma_{a n l}^{2}=\frac{\text { var[lab-split pairs] }}{2}-\text { [average of reported sample uncertainties] } \\
& \sigma_{f l d}^{2}=\left(\sigma_{f l d}^{2}+\sigma_{l a b}^{2}+\sigma_{a n l}^{2}\right)-\left(\sigma_{l a b}^{2}+\sigma_{a n l}^{2}\right)=\frac{\text { var[field- split pairs] }}{2}-\frac{\operatorname{var[lab-split~pairs]~}}{2} \\
& \sigma_{s p c}^{2}=\left(\sigma_{s p c}^{2}+\sigma_{f d d}^{2}+\sigma_{l a b}^{2}+\sigma_{a n l}^{2}\right)-\left(\sigma_{f d d}^{2}+\sigma_{l a b}^{2}+\sigma_{l f d}^{2}\right)=\frac{\text { var[collocated pairs] }}{2}-\frac{\text { var[field- split pairs] }}{2}
\end{aligned}
$$

To get the relative uncertainty (the uncertainty as a percent of the concentration) of each type of variability, the square root of each of the variances $\left(\sigma_{s p c}^{2}, \sigma_{f d}^{2}, \sigma_{l a b}^{2}\right.$, and $\left.\sigma_{a n l}^{2}\right)$, is divided by a concentration value. Since the variances are calculated from many pairs of samples having various concentrations within a range, the mid-point of the concentration range was used to represent the range.

\section{Experimental design}

The Big Trees Park sampling was designed for the purpose of investigating the presence of plutonium at the park, not for the purpose of a variance-partition study. A more suitable design for a variance-partition study would have appropriate replication at each sampling level (EPA, 1984; EPA 1990). For example:

1) A small area would be selected

2) Several collocated pairs would be collected from the area

3) Each sample would be split, and the splits sent separately to the laboratory

4) The laboratory would be instructed to split each sample and analyze both portions

With such a design, all sub-samples would be working from the same true area average. Each lab-split would be working from the same average concentration as a field split.

Instead, the analytical laboratory chose samples to split based on its $Q C$ procedures. This is standard practice for a site investigation such as this. However, such splits may or may not come from a collocated or field-split sample. They will not be from the same small area, but are likely to come from areas with different average concentrations, and from different areas than the field-split and collocated samples.

Similarly, the field-split and collocated samples were from randomly chosen locations, and the field splits with perhaps one exception are not splits of collocated samples. These factors can lead to violations of the model, and in particular, negative estimates of variances. None the less, some estimates can be made from the Big Trees Park data. 
All of these uncertainties may vary with concentration. Therefore, these calculations should be performed separately at different concentrations. Since there aren't very many sample pairs to work with, they have to be done within fairly wide concentration ranges.

The concentration ranges for which the variance partition calculations were performed (see Section 3.2.5) were chosen in part because over these ranges model violations did not occur. The concentration ranges were also chosen so as to have enough pairs, and to reflect ranges of importance for data interpretation (i.e., (1) below the detection limit, and (2) from the detection limit to slightly above fallout background). 


\section{Appendix 2 \\ Air Dispersion Modeling}

The air dispersion modeling code HOTSPOT was used to make estimates of the activity concentration in soil at Big Trees Park that could have resulted from the 1980 plutonium air release at Building 332, had the wind been blowing towards Big Trees Park. HOTSPOT is one of several industry-standard computer programs widely used to model air dispersion. The code is specifically designed to model air concentration and deposition from a single plume.

A release of $0.3 \mu \mathrm{Ci}$ was used. For converting per-area concentrations to per-mass concentrations a soil depth of $5 \mathrm{~cm}$ and soil density of $1.5 \mathrm{~g} / \mathrm{cm}^{3}$ were used.

\section{HOTSPOT input parameters}

Release height $=15 \mathrm{~m}$

Wind speed $=1.25 \mathrm{~m} / \mathrm{s}$

Wind stability $=\mathrm{D}$

Particle deposition velocities for 1,2 , and 4 micron diameter particles

Particle density $=10 \mathrm{~g} / \mathrm{cm}^{3}$ (close to $\mathrm{PuO}_{2}$ )

Distance from source $=1700 \mathrm{~m}$

Plume blowing directly towards Big Trees Park

\section{HOTSPOT results}

The calculated activity concentrations were $3.7 \times 10^{-8}, 1.3 \times 10^{-7}$, and $4.5 \times 10^{-7} \mathrm{pCi} / \mathrm{g}$ for the 1,2 , and 4 micron particles respectively. Concentrations $200 \mathrm{~m}$ away from the plume centerline position were found to be $30 \%$ of those at the centerline.

Choosing the 4-micron particle diameter, the size with the most deposition, this is on the order of 2,000,000 times lower than $1 \mathrm{pCi} / \mathrm{g}$, the highest measured concentration in Big Trees Park, on the order of 25,000 times lower than the upper end of the range of fallout background, and on the order of 40,000 times lower than the average of grid radials 2 to 4 .

Estimates using the EPA-approved modeling code CAP88PC and annual average winds instead of a single unidirectional plume were about 5 to 60 times lower than the unidirectional modeling with HOTSPOT. 


\section{Appendix 3 Dose Calculations}

This appendix describes some relatively simple calculations that were used in Section 2 to compare human exposure to radiation from plutonium in soil and air to human exposure to naturally-occurring radiation.

\section{Soil - Section 2}

EHIB 1999 (p. 8) reported that 1 pCi/g of Pu-239+240 in Big Trees Park soil represents a radiation dose of "less than 1 millirem per year".

Human exposure to natural radiation varies greatly throughout the United States and the world. Using 100 millirem per year (a value that excludes exposure from radon, and is therefore at the low end of the range; see Eisenbud and Gesell, 1997, Chapter 6), it follows that $1 \mathrm{pCi} / \mathrm{g}$ of $\mathrm{Pu}-239+240$ in soil represents an exposure at least 100 times lower than that of natural radiation.

The average concentration of all of the 0 to $5 \mathrm{~cm}$ samples from 1998 is approximately $0.08 \mathrm{pCi} / \mathrm{g}$ (see Figure 2.2), or about 12 times smaller than the $1 \mathrm{pCi} / \mathrm{g}$ evaluated in EHIB 1999.

Thus, a more realistic estimate of radiation exposure from activities in Big Trees Park would be at least 1200 times lower than that of natural radiation. This is still conservative (an over-estimate), because the EHIB report based its exposure estimate on using the park 8 hours per day, 5 days per week, 50 weeks per year.

Fallout-background in the Livermore Valley is approximately 100 to 1000 times lower than the 1 pCi/g evaluated in EHIB 1999 (EHIB 1999, p. 4 used a range of 0.01 to 0.001 $\mathrm{pCi} / \mathrm{g}$ to describe fallout-background). Exposure due to fallout-background levels of $\mathrm{Pu}-239+240$ is therefore at least $10,000(100 \times 100)$ to $100,000(100 \times 1000)$ times lower than exposure due to natural radiation.

\section{Air - Section 2.2.3.2}

The U.S. DOE derived concentration guide (DCG) for plutonium in air is $0.02 \mathrm{pCi} / \mathrm{m}^{3}$. This value corresponds to an exposure 100 millirem per year. 
The maximum measured concentration in the air monitoring data presented in Section 2.2.3.2 is $2.87 \times 10^{-5} \mathrm{pCi} / \mathrm{m}^{3} .2 .87 \times 10^{-5}$ divided by 0.02 is 0.0014 , i.e., $0.14 \%$ of the DCG. $0.14 \%$ is approximately equal to $1 / 700$.

Therefore (again using 100 millirem to represent the low end of the range of exposure due to natural radiation) the maximum measured concentration in air in this data represents an exposure at least 700 times lower than that of natural radiation. 


\section{Appendix 4 \\ Statistical Methods}

This report uses standard statistical methods, primarily analysis of variance, for comparing results from different areas. Discussions of the concepts underlying analysis of variance, and its formulas, are found in many statistics books, including Montgomery, 1991.

Analysis of variance focuses on comparing arithmetic means or geometric means of different sets of samples with each other. Results of analysis of variance are summarized in an "analysis of variance table" (Table 2.3 is an example).

The "arithmetic mean" is more commonly known as the average. The geometric mean is calculated by taking the logarithms of the values, calculating the simple average of those values, and taking the anti-logarithm of the average. Arithmetic means are compared by calculating the differences between them; geometric means are compared by taking calculating their ratios.

In analysis of variance, the primary result is a "significance level." A significance level that is a very small number (typically smaller than 0.01 or 0.05 ) indicates a "statistically significant" result. This means that observed differences between areas are so large as to strongly contradict the idea that there are in fact no differences between the areas. Significance levels are labeled " $\operatorname{Pr}(\mathrm{F})$ " in the tables in this report, and are referred to with an expression like " $p \leq$ significance level" in the text.

When more than two areas or groups are compared using analysis of variance, and statistically significant results are found, it is often of interest to find out which pairs of areas are different. This is referred to as a "multiple comparisons" analysis. The multiple comparison method used in this report is "Tukey's Honestly Significant Difference" (HSD) method (Miller, 1981).

The results of multiple comparisons in this report are summarized in tables of "simultaneous $95 \%$ confidence intervals" (Table 2.4 is an example). A confidence interval for the arithmetic average that excludes zero indicates strong statistical evidence of a difference between the areas. Similarly, a confidence interval for the ratio of geometric means that excludes one (1.0) indicates strong statistical evidence of differences between areas. 
In Section 2.1.1.2 an alternate method of statistical analysis, known as a "permutation test" (Good, 1994) was used to verify the results from the ordinary analysis of variance and multiple comparisons shown in Tables 2.3 and 2.4. Permutation tests are a wellestablished method of performing statistical analyses; some of them are also known as "non-parametric" tests.

As applied to the question of lateral distribution of Pu-239+240 in Big Trees Park, the permutation tests starts with the hypothesis that there is no spatial pattern of plutonium concentrations. If there is no spatial pattern then any result, whether high, low, or in between, should be equally likely to come from any location-there is no dependence between location and concentration.

To find out if the data are consistent with this hypothesis, a computer is used to randomly reassign the results to different locations, and this is done many times. Each time, the spatial pattern is evaluated (for example, by subtracting the average of Radial 2 from the average of Radial 1). This gives a large set of differences between radials (some larger, some smaller) that represents the hypothesis that there is no dependence between location and concentration: every combination of location and concentration is equally likely. If the hypothesis of no dependence is correct then the difference that was actually observed should be just one among many; it should not stand out as unusual among the large set of differences that was generated.

If, on the other hand, the difference that was actually observed is one of the most extreme, then the data contradict the hypothesis of no dependence. In this case the conclusion would be that the spatial pattern that was actually observed did not occur "by accident", but is real.

When this method was applied to the grid sample results of Section 2.1.1.2, the observed difference between Radial 1 and Radial 2 was more extreme than any of 2000 random assignments. Like Table 2.4, the comparisons between Radial 1 and each of Radials 3 and 4 were statistically significant by this method, and none of the comparisons between Radials 2, 3, and 4 were statistically significant. Thus, the differences between these radials are too large to have occurred by chance and should be understood to represent the result of some physical process that was dependent upon location (i.e., the use of sludge planting ornamental trees along Radial 1). 


\section{Appendix 5 \\ Instrumental Background, Analytical Data Quality Objectives, and Counting Statistics: A Cautionary Perspective}

This appendix describes the effect of "instrumental background" on the interpretation of analyses of plutonium in soil. That is, what range of results can be expected when analyzing a soil sample that in fact has no plutonium at all?

In order to assess the potential effect of instrumental background it is necessary to examine the process of measuring plutonium in some detail.

Radioactive decay and the Poisson distribution

Radioactive decay is a physical process in which atoms of a radioactive element spontaneously and randomly emit, or lose, sub-atomic particles.

When a large number of atoms of the same element are grouped together, the time intervals between emissions are random. The intervals between emissions are accurately modeled by an equation referred to as an "exponential distribution." The number of unchanged atoms remaining after a period of time is well modeled by a decreasing exponential curve (Ehmann, 1991).

If the times between emissions tend to be short, there will be a relatively large number of emissions in a given period of time. Conversely, if the times between emissions tend to be long, there will be relatively few emissions in a given period of time. This relationship between emission times and number of emissions results in an accurate model for the number of emissions in a given time period. This model, known as a "Poisson distribution", will be used later in this appendix to help assess the effect of instrumental background on the measurement of plutonium in soil. 


\section{Measuring plutonium in soil}

A plutonium atom emits, or releases, an alpha particle ${ }^{1}$ when it decays. Different isotopes of plutonium emit alpha particles with different characteristic energies. The level of radioactivity in a sample is measured by counting how many alpha particles of the isotope's characteristic energy are emitted in a fixed period of time.

Even when no sample material is present in a counting device, the device sometimes records the presence of natural particles or events of the same energy as the particular alpha energy of interest. This is sometimes referred to "background" in laboratory analytical reports. It is not the same as the "fallout-background" for plutonium mentioned elsewhere in this report, so it is referred to as "instrumental background" in this appendix.

Because an alpha counter may record particles when sample material is not present, some of the counts recorded when sample material is present may in fact come from the instrumental background, not from the sample.

That is, if there is in fact no plutonium in a sample, then any sample counts are actually instrumental background counts. This makes it appear as if there is plutonium in the sample when there is actually none.

Therefore, it is necessary to subtract an estimate of the instrumental background count from the sample count to obtain the net counts due to the sample alone. This is done for every sample; if it is not done measured values will tend to be too high. The instrumental background is estimated by separately counting background, i.e., counting alpha particle emissions without sample material present.

In order to accurately count alpha particles from plutonium, samples must be properly prepared. The two primary reasons for this are (1) alpha particles are easily blocked from the counter by even a very thin layer of soil itself, and (2) other radionuclides emit alpha particles with almost the same energy. Therefore (1), the plutonium must be extracted from the soil, and (2) the other radionuclides, if present, must be removed so that their radioactivity does not interfere with the measured value of plutonium. Thorium, which is naturally present in many soils, is one such radionuclide.

The analytical process is outlined in Table 5.1, along with the values reported by the 1995 analytical laboratories (see Section 6) for one of the 1995 Big Trees Park samples.

${ }^{1}$ An alpha particle is two neutrons and two protons bound together, e.g., a nucleus of a helium atom. 
Table 5.1 Analytical process; repeated separately for each sample.

\begin{tabular}{|c|c|c|c|}
\hline Step & Symbol & Laboratory B & Laboratory A \\
\hline Dry the sample, then weigh it & $M_{D}$ & 405.4 grams (dry) & Pre-dried \\
\hline Ash the sample, then weigh it & $M_{A}$ & 397.3 grams (ash) & Not applicable \\
\hline $\begin{array}{l}\text { Remove a portion of the } \\
\text { sample (an aliquot) and weigh } \\
\text { the portion }\end{array}$ & $G_{A}$ & 0.5297 grams (ash) & 5.0022 grams \\
\hline $\begin{array}{l}\text { Add a known quantity of } \\
\text { Pu-242 tracer }\end{array}$ & $T R_{A D D}$ & $\begin{array}{l}4.4 \text { tracer counts per } \\
\text { minute }\end{array}$ & $\begin{array}{l}3.54 \text { tracer counts per } \\
\text { minute }\end{array}$ \\
\hline $\begin{array}{l}\text { Chemically extract the } \\
\text { plutonium from the aliquot into } \\
\text { a solution }\end{array}$ & . & & \\
\hline \multicolumn{4}{|l|}{$\begin{array}{l}\text { Plate plutonium from the } \\
\text { solution onto a stainless steel } \\
\text { disk }\end{array}$} \\
\hline $\begin{array}{l}\text { Place the disk in an aipha } \\
\text { counter for a specified time, } \\
\text { count the number of alpha } \\
\text { particles }\end{array}$ & $\begin{array}{l}T_{s} \\
C_{s} \\
T R_{s}\end{array}$ & $\begin{array}{l}1000 \text { minutes } \\
8 \text { sample counts } \\
590 \text { tracer counts }\end{array}$ & $\begin{array}{l}1440 \text { minutes } \\
5 \text { sample counts } \\
931 \text { tracer counts }\end{array}$ \\
\hline $\begin{array}{l}\text { Count instrumental } \\
\text { background }\end{array}$ & $\begin{array}{l}T_{B} \\
C_{B}\end{array}$ & $\begin{array}{l}3000 \text { minutes } \\
5 \text { counts }\end{array}$ & $\begin{array}{l}1440 \text { minutes } \\
0 \text { counts }\end{array}$ \\
\hline $\begin{array}{l}\text { Calculate the sample } \\
\text { concentration using the } \\
\text { formulas given below }\end{array}$ & & $0.0393 \mathrm{pCi} / \mathrm{g}(\mathrm{dry})$ & $0.0017 \mathrm{pCi} / \mathrm{g}(\mathrm{dry})$ \\
\hline
\end{tabular}

The concentration of plutonium in soil is calculated from the measured quantities shown in Table 5.1 using the formulas

$$
\begin{aligned}
& \text { Concentration }=\frac{\left(\frac{C_{S}}{T_{S}}-\frac{C_{B}}{T_{B}}\right)}{\left.2.22 G_{A}\left(\frac{M_{D}}{M_{A}}\right) \frac{T R_{S}}{T R_{A D D}}\right)} \text { (Laboratory B) or } \\
& \text { Concentration }=\frac{\left(\frac{C_{S}}{T_{S}}-\frac{C_{B}}{T_{B}}\right)}{2.22 G_{A}\left(\frac{T R_{S}}{T R_{A D D}}\right)} \text { (Laboratory A). }
\end{aligned}
$$


The calculated concentrations are

$0.0393 \frac{\mathrm{pCi}}{\text { dry gram }}=\frac{\left(8 \frac{\text { counts }}{\text { aliquot } 1000 \text { minutes }}-5 \frac{\text { counts }}{\text { aliquot } 3000 \text { minutes }}\right)}{\left(2.22 \frac{\text { counts }}{\text { minute } \mathrm{pCi}}\left(0.5297 \frac{\text { ash gram }}{\text { aliquot }}\right)\left(\frac{405.4 \text { dry gram }}{397.3}\right)\left(\frac{0.59}{4.4} \frac{\text { counts } / \text { minute }}{\text { ashgram }}\right)\right.}$

from Laboratory B and

$0.0017 \frac{\mathrm{pCi}}{\text { dry gram }}=\frac{\left(5 \frac{\text { counts }}{\text { aliquot } 1440 \text { minutes }}-0 \frac{\text { counts }}{\text { aliquot } 1440 \text { minutes }}\right)}{\left(2.22 \frac{\text { counts }}{\text { minutepCi }}\right)\left(5.0022 \frac{\text { dry gram }}{\text { aliquot }}\right)\left(\frac{931 / 1440}{3.54} \frac{\text { counts } / \text { minute }}{\text { counts } / \text { minute }}\right)}$

from Laboratory A.

\section{Instrumental Background}

When there is a very small amount of plutonium in the sample, the instrumental background count rate can be comparable to the sample count rate. This will often result in a failure to detect the presence of plutonium in the sample. For this reason, analyses of low-level samples require laboratories with low instrumental backgrounds.

When there is no plutonium in the sample at all, the measurement process is equivalent to measuring the instrumental background count rate twice, and subtracting one result from the other.

- Sometimes both measured counts will be about the same, yielding in a result near zero.

- Sometimes the first count will be low and the second high, resulting in a negative number.

- Sometimes the first count will be high and the second low, resulting in a positive number.

This is the nature of the randomness of the background rates. The larger the instrumental background, the larger the two extremes (negative and positive) can be. The Poisson model provides estimates of the sizes of these extremes. 


\section{Modeling the Effect of Instrumental Background}

Since radioactive decay is a random process, a computer random number generator can be used to simulate ${ }^{2}$ many measurements of a hypothetical sample containing no plutonium.

This can then be used to evaluate whether or not it is appropriate to compare measured concentrations with a level of interest, such as the EPA Region 9 PRG $(2.5 \mathrm{pCi} / \mathrm{g})$ or an estimate of the upper range of fallout-background (one such estimate, used in CDHSEHIB 1998, is $0.01 \mathrm{pCi} / \mathrm{g}$ ). Examples of such comparisons are found, for example, in Sections 1.1 and 6.1.

Results from two simulations are shown below. The first, based on Laboratory B's analysis, uses an instrumental background rate of 5 counts per 3000 minutes. The second, based on Laboratory A's analysis, uses an instrumental background rate of 2 counts per 1440 minutes (the largest instrumental background reported by Laboratory A among the 1995 Big Trees Park analyses). In both cases, the other values used in the simulations (aliquot mass, count time, tracer counts, etc.) are from Table 5.1.

Figure 5.1 shows that Laboratory B's data quality objectives (aliquot mass, counting time), together with the instrumental background count rate of this sample, are such that $19 \%$ of results from instrumental background alone would exceed $0.01 \mathrm{pCi} / \mathrm{g}$. In other words, samples without any plutonium in them at all have about a 1 in 5 chance of erroneously being identified as "above fallout-background".

In contrast, Figure 5.2 shows that Laboratory A's data quality objectives, together with its largest instrumental background, are such that samples without plutonium are extremely unlikely to be erroneously identified as exceeding $0.01 \mathrm{pCi} / \mathrm{g}$ due to instrumental background ${ }^{3}$.

These simulations demonstrate that it is not appropriate to use Laboratory B's analyses for comparisons with $0.01 \mathrm{pCi} / \mathrm{g}^{4}$. On the other hand, nothing in this simulation suggests that it would be inappropriate to use Laboratory B's analyses for comparison with the US EPA Region 9 PRG of $2.5 \mathrm{PCi} / \mathrm{g}$.

\footnotetext{
${ }^{2}$ A mathematical solution exists (Johnson et. al., 1993) but is not easy to calculate; simulations are easier and just as effective.

${ }^{3}$ The simulation indicates they have less than a 1 in $1,000,000$ chance of exceeding $0.01 \mathrm{pCi} / \mathrm{g}$.

4 Using Laboratory B's average background rate of 2.6 counts in 3000 minutes, and the other values shown in Table 5.1, results from instrumental background alone would exceed $0.01 \mathrm{pCi} / \mathrm{g}$ about $10 \%$ of the time.
} 


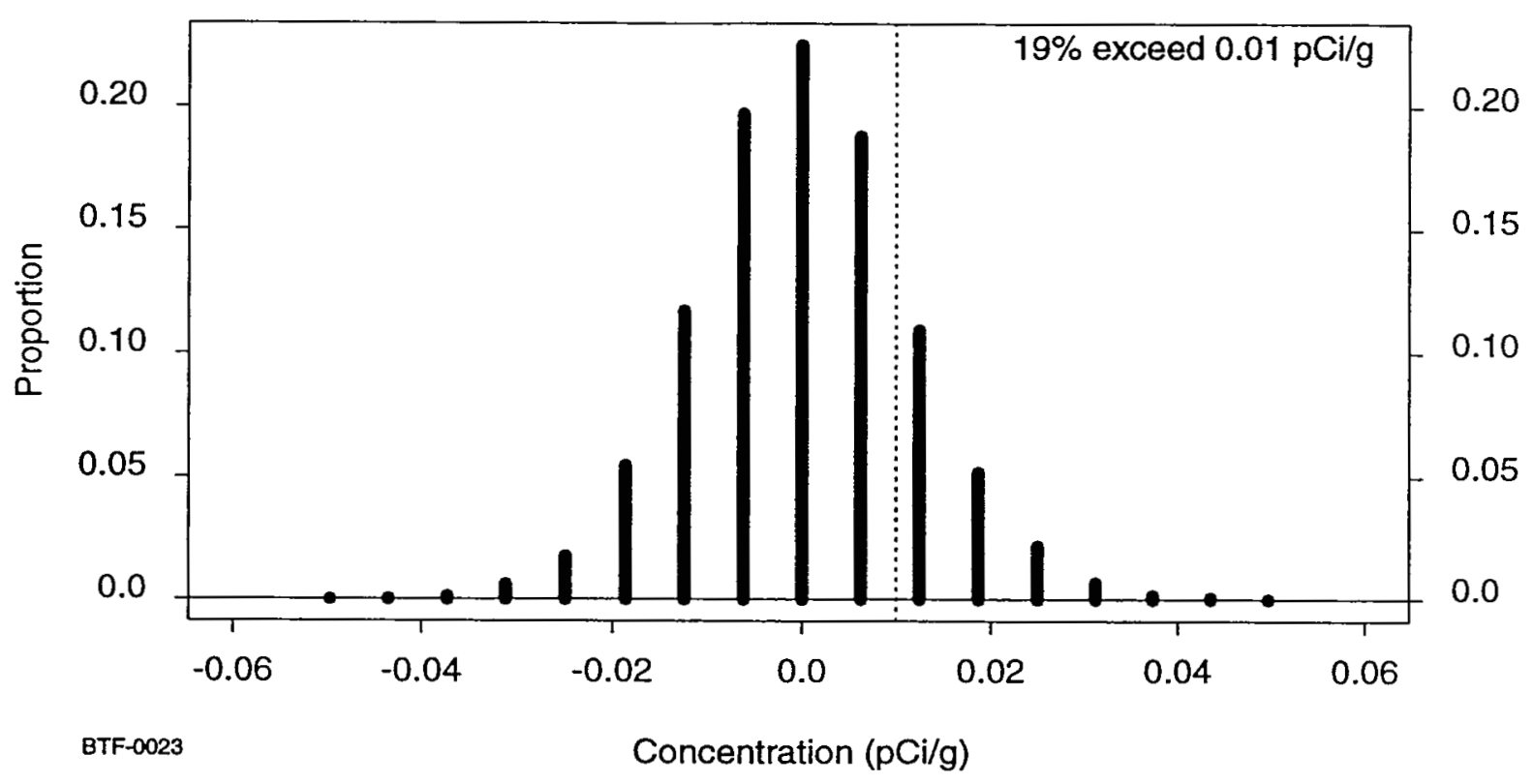

Figure 5.1 Effect of Laboratory B Instrumental Background on Plutonium Measurement

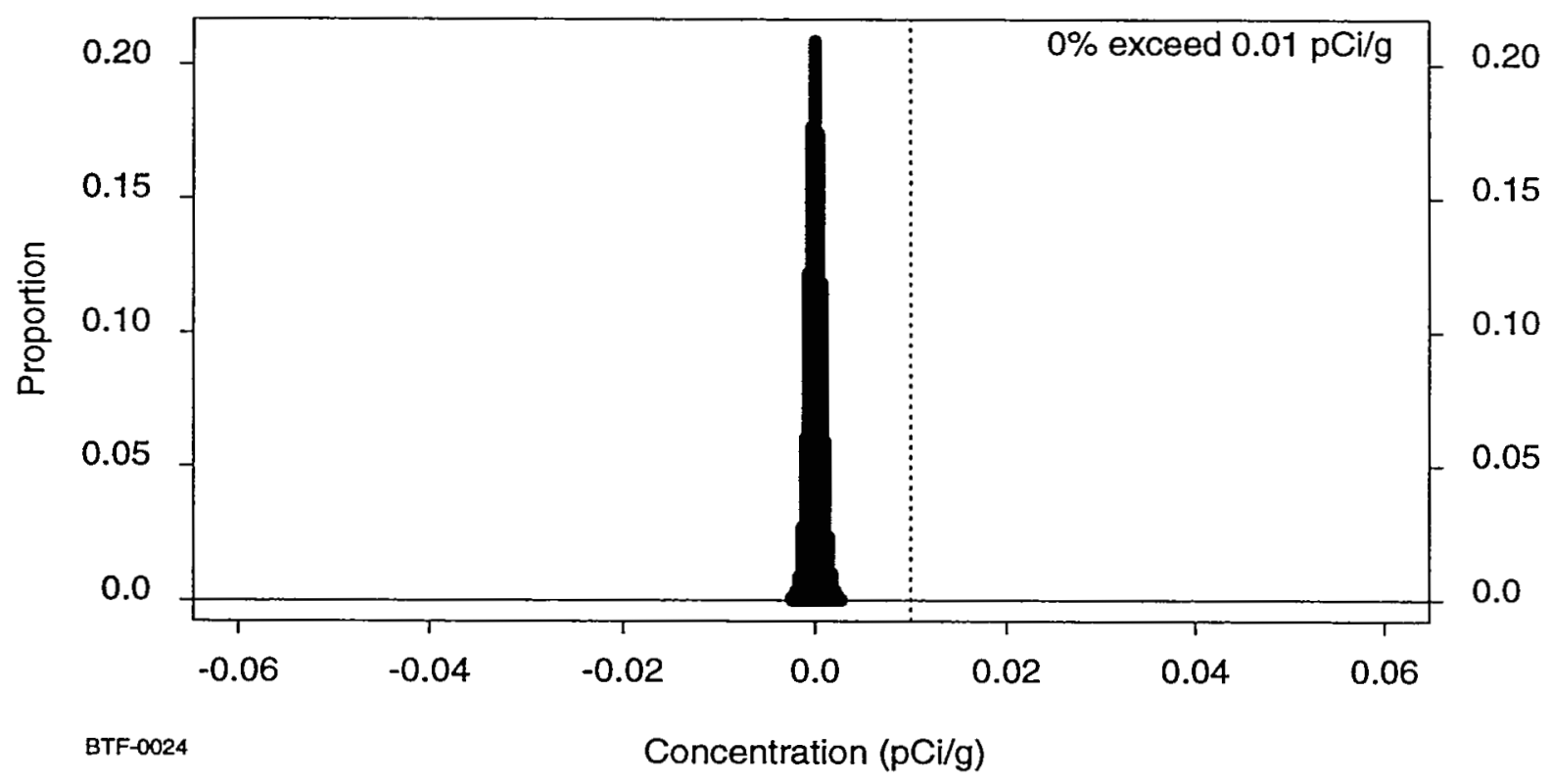

Figure 5.2 Effect of Laboratory A Instrumental Background on Plutonium Measurement 


\section{Appendix 6 Additional Data Tables}

This appendix contains tables of analytical results not included earlier in the document.

In the tables in which radionuclides are reported (Pu-239+240, $\mathrm{Pu}-238$ or $\mathrm{Am}-241)$ values in regular typeface indicate detections and values in italic indicate nondetections. See the beginning of Section 2 for the convention used to identify detections.

When calculating a ratio between two radiological measurement, the ratio is not meaningful if either or both of the estimated activities (measured values) is less than or equal to zero. In these cases, a negative value is replaced by a positive substitute value that is calculated from the measured value and its uncertainty.

Table 6.1 Pu-238 (pCi/g) on the grid

\begin{tabular}{|c|c|c|c|c|c|c|c|c|c|c|c|}
\hline \multirow[b]{2}{*}{ Radial } & \multirow{2}{*}{$\begin{array}{l}\text { Depth } \\
\text { interval } \\
\text { (cm) }\end{array}$} & \multicolumn{10}{|c|}{ Perpendicular } \\
\hline & & $\mathbf{J}$ & 1 & H & $\mathbf{G}$ & $\bar{F}$ & $\bar{E}$ & D & $\mathrm{c}$ & B & A \\
\hline \multirow[t]{5}{*}{$\overline{1}$} & $0-5$ & 0.00046 & 0.013 & 0.027 & 0.036 & 0.068 & 0.052 & 0.026 & -0.000015 & 0.0013 & 0.019 \\
\hline & $5-10$ & 0.0013 & 0.007 & 0.013 & 0.02 & 0.026 & 0.086 & 0.00093 & 0.0012 & 0.0091 & 0.0015 \\
\hline & $10-20$ & 0.0021 & 0.0022 & 0.0016 & 0.0034 & 0.0016 & 0.0042 & 0.00046 & 0 & 0.0021 & -0.00037 \\
\hline & $20-30$ & 0.00013 & 0.00088 & 0 & 0.0043 & 0 & 0.0012 & 0.0014 & 0.00053 & 0.00082 & 0.00061 \\
\hline & $30-40$ & -0.00011 & -0.00035 & 0.0024 & -0.0006 & 0.0024 & 0.0003 & 0.00097 & -0.000067 & 0 & $o$ \\
\hline \multirow[t]{5}{*}{2} & $0-5$ & 0.002 & 0.003 & 0.00014 & 0.00017 & 0.001 & 0.0019 & 0.002 & 0.00077 & 0.001 & 0.00082 \\
\hline & $5-10$ & 0.0019 & 0.00072 & 0.021 & -0.00087 & 0.0016 & 0.0008 & -0.0012 & 0.0013 & 0.004 & 0.00011 \\
\hline & $10-20$ & 0.00021 & 0.00086 & 0.012 & 0.0015 & 0.00083 & 0.002 & 0.0078 & -0.000033 & -0.00036 & 0.00085 \\
\hline & $20-30$ & 0.00025 & 0.00083 & 0.00053 & 0.0009 & 0.00062 & 0.00018 & 0 & 0 & 0.000057 & 0.00044 \\
\hline & $30-40$ & -0.00097 & 0.0015 & 0.00069 & 0 & 0.00059 & 0.00097 & 0.00012 & 0.00032 & 0.00085 & 0.00029 \\
\hline \multirow[t]{5}{*}{$\overline{3}$} & $0-5$ & 0.0023 & 0.00052 & 0.0021 & -0.00054 & 0.00083 & 0.0015 & 0.0016 & 0.000093 & 0.00099 & -0.00092 \\
\hline & $5-10$ & 0.00018 & 0 & 0.0011 & 0.0013 & -0.00026 & 0 & -0.00051 & 0.0038 & 0.00046 & 0.00099 \\
\hline & $10-20$ & 0.00011 & 0.0019 & 0.00083 & 0 & 0.0014 & 0.0019 & 0.00074 & -0.00014 & 0.0012 & 0.0011 \\
\hline & $20-30$ & -0.00019 & 0.00017 & 0.000038 & 0.0012 & 0.0016 & 0.00065 & 0.0025 & 0.00015 & & 0.0015 \\
\hline & $30-40$ & 0.00096 & 0.00023 & 0.0046 & 0.00082 & 0.0015 & 0 & 0.0097 & -0.00013 & & 0.0015 \\
\hline \multirow[t]{5}{*}{4} & $0-5$ & & & 0.015 & 0.0015 & 0.00057 & -0.00077 & 0.0024 & -0.00025 & 0.0017 & 0 \\
\hline & $5-10$ & & & 0.0087 & 0.00085 & 0.0034 & 0.00069 & 0.0011 & -0.00055 & 0.0019 & -0.00028 \\
\hline & $10-20$ & & & 0.0014 & 0 & 0.0021 & 0.000065 & 0.0028 & 0.0023 & 0.00055 & 0.00045 \\
\hline & $20-30$ & & & 0.0011 & 0.00061 & 0.0044 & 0.000071 & 0.00086 & 0.0011 & 0.00066 & 0.0016 \\
\hline & $30-40$ & & & 0.00086 & 0.00058 & 0.0076 & 0 & 0.0023 & -0.0009 & 0.00047 & -0.00049 \\
\hline
\end{tabular}


Table 6.2 Am-241 (pCi/g) on the grid.

\begin{tabular}{|c|c|l|l|l|l|l|l|l|l|l|l|}
\hline Radial & $\begin{array}{c}\text { Depth } \\
\text { interval } \\
\text { (cm) }\end{array}$ & $\mathbf{J}$ & $\mathbf{I}$ & $\mathbf{H}$ & $\mathbf{G}$ & $\mathbf{F}$ & $\mathbf{E}$ & $\mathbf{D}$ & $\mathbf{C}$ & $\mathbf{B}$ & $\mathbf{A}$ \\
\hline $\mathbf{1}$ & $\mathbf{0 - 5}$ & 0.012 & 0.033 & 0.061 & 0.076 & 0.21 & 0.18 & $\mathbf{0 . 1 1}$ & 0.11 & 0.0076 & 0.077 \\
\hline $\mathbf{2}$ & $\mathbf{0 - 5}$ & -0.00037 & 0.0051 & 0.0067 & 0.0054 & 0.0088 & 0.01 & 0.0066 & 0.0098 & 0.000055 & 0.0069 \\
\hline $\mathbf{3}$ & $\mathbf{0 - 5}$ & 0.0014 & -0.0022 & 0.018 & 0.0077 & -0.0046 & -0.0022 & 0.002 & 0.00012 & 0.0021 & -0.0052 \\
\hline $\mathbf{4}$ & $\mathbf{0 - 5}$ & & & 0.082 & 0.0014 & 0.0019 & -0.0023 & 0.0019 & -0.0035 & 0.0029 & 0.017 \\
\hline
\end{tabular}


Table 6.3 Pu-239+240 Tree Well Results (pCi/g).

\begin{tabular}{|c|c|c|c|c|}
\hline Depth $(\mathrm{cm})$ & Tree & Pu-239+240 Inside & Pu-239+240 Outside & Ratio \\
\hline $0-45$ & 2 & $0.0294 \pm 0.00595$ & $0.00182 \pm 0.00183$ & $16.1 \pm 16.6$ \\
\hline $0-45$ & 3 & $0.0534 \pm 0.00903$ & $0.00185 \pm 0.00248$ & $28.9 \pm 39$ \\
\hline $0-45$ & 4 & $0.00393 \pm 0.00196$ & $0.00468 \pm 0.00212$ & $0.84 \pm 0.566$ \\
\hline $0-45$ & 5 & $0.0667 \pm 0.011$ & $0.00323 \pm 0.00236$ & $20.7 \pm 15.5$ \\
\hline $0-45$ & 6 & $0.0322 \pm 0.00387$ & $0.00131 \pm 0.00108$ & $24.6 \pm 20.5$ \\
\hline $0-45$ & 8 & $0.0881 \pm 0.0152$ & $0.00455 \pm 0.00258$ & $19.4 \pm 11.5$ \\
\hline $0-45$ & 11 & $0.0582 \pm 0.00903$ & $0.00171 \pm 0.00122$ & $34 \pm 24.8$ \\
\hline $0-45$ & 12 & $0.0638 \pm 0.00697$ & $0.00368 \pm 0.00275$ & $17.3 \pm 13.1$ \\
\hline $0-45$ & 14 & $0.0391 \pm 0.00845$ & $-0.000449 \pm 0.00116$ & $118 \pm 412$ \\
\hline $0-45$ & 15 & $0.0273 \pm 0.00634$ & $0.00177 \pm 0.00167$ & $15.4 \pm 15$ \\
\hline $45-90$ & 2 & $-0.00207 \pm 0.00197$ & $-0.000538 \pm 0.00151$ & $0.802 \pm 5.21$ \\
\hline 45-90 & 3 & $0.0015 \pm 0.00141$ & $0.000443 \pm 0.00145$ & $3.39 \pm 11.5$ \\
\hline $45-90$ & 4 & $0.00106 \pm 0.00159$ & $-0.00068 \pm 0.00115$ & $3.76 \pm 16.3$ \\
\hline $45-90$ & 5 & $0.000696 \pm 0.0015$ & $0.000377 \pm 0.00164$ & $1.85 \pm 8.96$ \\
\hline $45-90$ & 6 & $-0.000346 \pm 0.00111$ & $0.000428 \pm 0.00111$ & $1.9 \pm 5.56$ \\
\hline $45-90$ & 8 & $-0.0000881 \pm 0.000912$ & $-0.000226 \pm 0.00165$ & $0.573 \pm 2.25$ \\
\hline $45-90$ & 11 & $0.00324 \pm 0.0022$ & $0.00028 \pm 0.00107$ & $11.6 \pm 44.9$ \\
\hline $45-90$ & 12 & $0.000534 \pm 0.00139$ & $0.00155 \pm 0.00131$ & $0.344 \pm 0.942$ \\
\hline $45-90$ & 14 & $0.00144 \pm 0.00165$ & $0.000188 \pm 0.00107$ & $7.66 \pm 44.5$ \\
\hline $45-90$ & 15 & $0.000342 \pm 0.00138$ & $0.000254 \pm 0.00051$ & $1.35 \pm 6.07$ \\
\hline $90-135$ & 2 & $0.000571 \pm 0.000663$ & $-0.000121 \pm 0.00189$ & $0.802 \pm 2.32$ \\
\hline $90-135$ & 3 & $0.000673 \pm 0.00121$ & $-0.000964 \pm 0.00112$ & $2.95 \pm 15.4$ \\
\hline $90-135$ & 4 & $0.00397 \pm 0.00244$ & $0.000105 \pm 0.00148$ & $37.8 \pm 533$ \\
\hline $90-135$ & 5 & $0.00134 \pm 0.00135$ & $-0.000352 \pm 0.000991$ & $4.61 \pm 16.4$ \\
\hline $90-135$ & 6 & $0.00073 \pm 0.00131$ & $0.00183 \pm 0.0014$ & $0.399 \pm 0.778$ \\
\hline $90-135$ & 8 & $0.000518 \pm 0.000735$ & $-0.000432 \pm 0.00112$ & $1.61 \pm 6.08$ \\
\hline $90-135$ & 11 & $0.00667 \pm 0.00224$ & $0.00101 \pm 0.00117$ & $6.57 \pm 7.88$ \\
\hline $90-135$ & 12 & $0.000713 \pm 0.00114$ & $-0.00000483 \pm 0.00105$ & $0.417 \pm 0.713$ \\
\hline $90-135$ & 14 & $0.000679 \pm 0.00168$ & $0.00156 \pm 0.00129$ & $0.435 \pm 1.14$ \\
\hline $90-135$ & 15 & $-0.000176 \pm 0.00129$ & $0.000237 \pm 0.000474$ & $1.92 \pm 6.67$ \\
\hline
\end{tabular}

Table 6.4 Pu-239+240 geometric means and standard deviations (pCi/g) in tree wells.

\begin{tabular}{lll}
\hline Depth & Inside & Outside \\
\hline 0 to 45 & $0.0369(1.32)$ & $0.00202(1.28)$ \\
45 to 90 & $0.000787(1.27)$ & $0.000401(1.2)$ \\
90 to 135 & $0.00101(1.33)$ & $0.000534(1.38)$ \\
\hline
\end{tabular}

Table 6.5 Pu-239+240 arithmetic means and standard deviations (pCi/g) in tree wells.

\begin{tabular}{lll}
\hline Depth & Inside & Outside \\
\hline 0 to 45 & $0.0462(0.00771)$ & $0.00242(0.000505)$ \\
45 to 90 & $0.000631(0.000438)$ & $0.000208(0.000197)$ \\
90 to 135 & $0.00157(0.000666)$ & $0.000287(0.000285)$ \\
\hline
\end{tabular}


Table 6.6 Pu-238 Tree Well Results (pCi/g).

\begin{tabular}{|c|c|c|c|c|}
\hline Depth (cm) & Tree & Pu-238 Inside & Pu-238 Outside & Ratio \\
\hline $0-45$ & 2 & $0.00197 \pm 0.0021$ & $0 \pm 0.00137$ & $3.98 \pm 11.8$ \\
\hline $0-45$ & 3 & $0.0048 \pm 0.00224$ & $0.00136 \pm 0.00228$ & $3.53 \pm 6.14$ \\
\hline 0.45 & 4 & $0.000158 \pm 0.000898$ & $0.000936 \pm 0.00164$ & $0.169 \pm 1$ \\
\hline $0-45$ & 5 & $0.00802 \pm 0.00299$ & $0.000396 \pm 0.00227$ & $20.2 \pm 116$ \\
\hline $0-45$ & 6 & $0.00405 \pm 0.00121$ & $0.00109 \pm 0.000986$ & $3.72 \pm 3.54$ \\
\hline $0-45$ & 8 & $0.00887 \pm 0.00378$ & $0.00153 \pm 0.00228$ & $5.8 \pm 8.99$ \\
\hline $0-45$ & 11 & $0.0073 \pm 0.00277$ & $0.00153 \pm 0.0015$ & $4.75 \pm 4.98$ \\
\hline $0-45$ & 12 & $0.00605 \pm 0.00177$ & $0 \pm 0.000974$ & $17.2 \pm 47.8$ \\
\hline $0-45$ & 14 & $0.00363 \pm 0.00288$ & $-0.0000878 \pm 0.000909$ & $10.9 \pm 31$ \\
\hline $0-45$ & 15 & $0.00328 \pm 0.00193$ & $-0.00017 \pm 0.00124$ & $7.49 \pm 21.7$ \\
\hline $45-90$ & 2 & $0.000146 \pm 0.00167$ & $0.00077 \pm 0.00109$ & $0.19 \pm 2.19$ \\
\hline $45-90$ & 3 & $0.000826 \pm 0.00117$ & $-0.0000555 \pm 0.000866$ & $2.53 \pm 7.63$ \\
\hline $45-90$ & 4 & $0.000151 \pm 0.00151$ & $-0.0000644 \pm 0.00159$ & $0.247 \pm 2.55$ \\
\hline $45-90$ & 5 & $0.000536 \pm 0.00286$ & $0.00383 \pm 0.00272$ & $0.14 \pm 0.753$ \\
\hline $45-90$ & 6 & $0.000489 \pm 0.00105$ & $0.00103 \pm 0.00186$ & $0.475 \pm 1.33$ \\
\hline $45-90$ & 8 & $0.0000993 \pm 0.0014$ & $0.000707 \pm 0.001$ & $0.141 \pm 1.99$ \\
\hline $45-90$ & 11 & $0.0012 \pm 0.00152$ & $0.00133 \pm 0.00146$ & $0.907 \pm 1.52$ \\
\hline $45-90$ & 12 & $0.00287 \pm 0.00194$ & $0.000638 \pm 0.00128$ & $4.5 \pm 9.53$ \\
\hline $45-90$ & 14 & $0.00241 \pm 0.00173$ & $0.000565 \pm 0.00186$ & $4.26 \pm 14.4$ \\
\hline $45-90$ & 15 & $0.000757 \pm 0.000878$ & $-0.00151 \pm 0.00181$ & $2.02 \pm 10$ \\
\hline $90-135$ & 2 & $0.0000763 \pm 0.00124$ & $0.00122 \pm 0.00173$ & $0.0625 \pm 1.02$ \\
\hline $90-135$ & 3 & $-0.00124 \pm 0.00185$ & $0.00338 \pm 0.0023$ & $0.127 \pm 0.554$ \\
\hline $90-135$ & 4 & $0.00217 \pm 0.00253$ & $0.000117 \pm 0.00231$ & $18.6 \pm 367$ \\
\hline $90-135$ & 5 & $-0.000201 \pm 0.00181$ & $-0.000504 \pm 0.00169$ & $1.26 \pm 5.37$ \\
\hline $90-135$ & 6 & $-0.000535 \pm 0.00147$ & $0.000524 \pm 0.000744$ & $0.819 \pm 3.04$ \\
\hline $90-135$ & 8 & $-0.00102 \pm 0.00198$ & $0.000444 \pm 0.00115$ & $1.16 \pm 5.37$ \\
\hline $90-135$ & 11 & $0.000114 \pm 0.00167$ & $0.00264 \pm 0.00153$ & $0.043 \pm 0.633$ \\
\hline $90-135$ & 12 & $0.000509 \pm 0.00111$ & $0.000266 \pm 0.00115$ & $1.92 \pm 9.29$ \\
\hline $90-135$ & 14 & $0.0023 \pm 0.00165$ & $0.00104 \pm 0.00105$ & $2.21 \pm 2.74$ \\
\hline $90-135$ & 15 & $0.000188 \pm 0.00107$ & $-0.000626 \pm 0.000889$ & $0.935 \pm 6.74$ \\
\hline
\end{tabular}

Table 6.7 Pu-238 geometric means and standard deviations $(\mathrm{pCi} / \mathrm{g})$ in tree wells.

\begin{tabular}{lll}
\hline Depth & Inside & Outside \\
\hline 0 to 45 & $0.00343(1.45)$ & $0.00071(1.22)$ \\
45 to 90 & $0.000559(1.44)$ & $0.000774(1.25)$ \\
90 to 135 & $0.000437(1.42)$ & $0.000621(1.41)$ \\
\hline
\end{tabular}

Table 6.8 Pu-238 arithmetic means and standard deviations $(\mathrm{pCi} / \mathrm{g})$ in tree wells.

\begin{tabular}{lll}
\hline Depth & Inside & Outside \\
\hline 0 to 45 & $0.00481(0.000872)$ & $0.000659(0.000223)$ \\
45 to 90 & $0.000949(0.000304)$ & $0.000723(0.000426)$ \\
90 to 135 & $0.000236(0.000375)$ & $0.00085(0.000407)$ \\
\hline
\end{tabular}


Table 6.9 Am-241 Tree Well Results (pCi/g).

\begin{tabular}{|c|c|c|c|c|}
\hline Depth (cm) & Tree & Am-241 Inside & Am-241 Outside & Ratio \\
\hline $0-45$ & 2 & $0.0107 \pm 0.0094$ & $0.00143 \pm 0.00228$ & $7.48 \pm 13.6$ \\
\hline $0-45$ & 3 & $0.013 \pm 0.00834$ & $0.194 \pm 0.0346$ & $0.067 \pm 0.0446$ \\
\hline $0-45$ & 4 & $-0.00951 \pm 0.0159$ & $0.00324 \pm 0.00477$ & $I .2 \pm 5.2 I$ \\
\hline $0-45$ & 5 & $0.0222 \pm 0.00953$ & $-0.000226 \pm 0.000881$ & $79 \pm 250$ \\
\hline $0-45$ & 6 & $0.00874 \pm 0.00584$ & $0.00373 \pm 0.00477$ & $2.35 \pm 3.38$ \\
\hline $0-45$ & 8 & $0.0283 \pm 0.0119$ & $-0.000151 \pm 0.000407$ & $240 \pm 833$ \\
\hline $0-45$ & 11 & $0.025 \pm 0.00883$ & $0.005 \pm 0.00341$ & $5 \pm 3.83$ \\
\hline $0-45$ & 12 & $0.0148 \pm 0.00704$ & $-0.000533 \pm 0.0039$ & $10.7 \pm 30.7$ \\
\hline $0-45$ & 14 & $0.0145 \pm 0.0129$ & $-0.0029 \pm 0.0435$ & $1.75 \pm 9.29$ \\
\hline $0-45$ & 15 & $0.00337 \pm 0.00615$ & $0.13 \pm 0.027$ & $0.0259 \pm 0.0476$ \\
\hline $45-90$ & 2 & $0.000994 \pm 0.00284$ & $0.00199 \pm 0.00272$ & $0.499 \pm 1.58$ \\
\hline $45-90$ & 3 & $0.00726 \pm 0.00641$ & $0.00476 \pm 0.00453$ & $1.53 \pm 1.98$ \\
\hline $45-90$ & 4 & $0.00938 \pm 0.00693$ & $0.00644 \pm 0.00661$ & $1.46 \pm 1.84$ \\
\hline $45-90$ & 5 & $0.137 \pm 0.0276$ & $0.00417 \pm 0.00537$ & $32.9 \pm 42.8$ \\
\hline $45-90$ & 6 & $0.00502 \pm 0.00344$ & $0.00349 \pm 0.00574$ & $1.44 \pm 2.56$ \\
\hline $45-90$ & 8 & $0.00251 \pm 0.00403$ & $-0.0156 \pm 0.0124$ & $1.26 \pm 8.12$ \\
\hline $45-90$ & 11 & $-0.00323 \pm 0.00913$ & $-0.00119 \pm 0.0223$ & $0.912 \pm 5.45$ \\
\hline 45-90 & 12 & $-0.00027 \pm 0.000864$ & $-0.00184 \pm 0.00984$ & $0.0116 \pm 0.0385$ \\
\hline $45-90$ & 14 & $0.00472 \pm 0.00869$ & $0.0224 \pm 0.0112$ & $0.211 \pm 0.402$ \\
\hline $45-90$ & 15 & $0.00483 \pm 0.0065$ & $0.00112 \pm 0.00291$ & $4.31 \pm 12.6$ \\
\hline $90-135$ & 2 & $0.00972 \pm 0.0086$ & $0.00268 \pm 0.0027$ & $3.63 \pm 4.86$ \\
\hline $90-135$ & 3 & $-0.000658 \pm 0.00132$ & $-0.0036 \pm 0.0113$ & $0.11 \pm 0.571$ \\
\hline $90-135$ & 4 & $0.00229 \pm 0.00467$ & $-0.000367 \pm 0.00091$ & $8.91 \pm 36.4$ \\
\hline $90-135$ & 5 & $0.00149 \pm 0.0031$ & $0.0043 \pm 0.00359$ & $0.347 \pm 0.777$ \\
\hline $90-135$ & 6 & $-0.00212 \pm 0.06$ & $0.00434 \pm 0.00462$ & $1.63 \pm 13.9$ \\
\hline $90-135$ & 8 & $0.0389 \pm 0.0133$ & $0.000422 \pm 0.000979$ & $92.2 \pm 216$ \\
\hline $90-135$ & 11 & $0.00271 \pm 0.00328$ & $-0.00163 \pm 0.00992$ & $0.841 \pm 2.78$ \\
\hline $90-135$ & 12 & $0.00555 \pm 0.00415$ & $0.00709 \pm 0.00746$ & $0.783 \pm 1.01$ \\
\hline $90-135$ & 14 & $0.000749 \pm 0.00297$ & $0.0113 \pm 0.00888$ & $0.0663 \pm 0.268$ \\
\hline $90-135$ & 15 & $0.00433 \pm 0.0061$ & $0.00447 \pm 0.00481$ & $0.969 \pm 1.72$ \\
\hline
\end{tabular}

Table 6.10 Am-241 geometric means and standard deviations (pCi/g) in tree wells.

\begin{tabular}{llll}
\hline Depth & Inside & Outside & Outside, omitting outliers \\
\hline 0 to 45 & $0.0118(1.26)$ & $0.00391(2.1)$ & $0.00155(1.68)$ \\
45 to 90 & $0.00438(1.66)$ & $0.00459(1.36)$ & \\
90 to 135 & $0.0033(1.53)$ & $0.00269(1.46)$ & \\
\hline
\end{tabular}

Table 6.11 Am-241 arithmetic means and standard deviations $(\mathrm{pCi} / \mathrm{g})$ in tree wells.

\begin{tabular}{llll}
\hline Depth & Inside & Outside & Outside, omitting outliers \\
\hline 0 to 45 & $0.0131(0.00348)$ & $0.0334(0.022)$ & $0.0012(0.000933)$ \\
45 to 90 & $0.0168(0.0134)$ & $0.00257(0.00295)$ & \\
90 to 135 & $0.0063(0.00377)$ & $0.0029(0.00139)$ & \\
\hline
\end{tabular}


Table 6.12 Chromium Tree Well Results (mg/kg).

\begin{tabular}{lllll}
\hline Depth $(\mathrm{cm})$ & Tree & Cr Inside & Cr Outside & Difference \\
\hline $0-45$ & 2 & 28.8 & 23.9 & 4.9 \\
$0-45$ & 3 & 36.4 & 3.68 & 32.7 \\
$0-45$ & 4 & 27.2 & 29.9 & -2.7 \\
$0-45$ & 5 & 34.4 & 24.3 & 10.1 \\
$0-45$ & 6 & 26.6 & 18.7 & 7.9 \\
$0-45$ & 8 & 23.6 & 14.2 & 9.4 \\
$0-45$ & 11 & 34.6 & 30.5 & 4.1 \\
$0-45$ & 12 & 34.4 & 29.5 & 4.9 \\
$0-45$ & 14 & 35.2 & 30.5 & 4.7 \\
$0-45$ & 15 & 33 & 14.4 & 18.6 \\
\hline $45-90$ & 2 & 31.4 & 23.4 & 8 \\
$45-90$ & 3 & 29.1 & 23.2 & 5.9 \\
$45-90$ & 4 & 38.9 & 29.3 & 9.6 \\
$45-90$ & 5 & 28.5 & 33.7 & -5.2 \\
$45-90$ & 6 & 33.9 & 31.5 & 2.4 \\
$45-90$ & 8 & 32 & 29.4 & 2.6 \\
$45-90$ & 11 & 32.9 & 34.2 & -1.3 \\
$45-90$ & 12 & 33.2 & 35.3 & -2.1 \\
$45-90$ & 14 & 34.6 & 32.5 & 2.1 \\
$45-90$ & 15 & 34 & 33.9 & 0.1 \\
\hline $90-135$ & 2 & 40 & 40.3 & -0.3 \\
$90-135$ & 3 & 36.5 & 38.9 & -2.4 \\
$90-135$ & 4 & 39.5 & 35.7 & 3.8 \\
$90-135$ & 5 & 35.2 & 34 & 1.2 \\
$90-135$ & 6 & 39.8 & 36.6 & 3.2 \\
$90-135$ & 8 & 44.9 & 43.1 & 1.8 \\
$90-135$ & 11 & 66.3 & 39.4 & 26.9 \\
$90-135$ & 12 & 40.5 & 39.4 & 1.1 \\
$90-135$ & 14 & 40.2 & 40 & 0.2 \\
$90-135$ & 15 & 37.5 & 36.8 & 0.7 \\
\hline & & & & \\
\hline
\end{tabular}

Table 6.13 Chromium arithmetic means and standard deviations $(\mathrm{mg} / \mathrm{kg})$ in tree wells.

\begin{tabular}{lll}
\hline Depth & Inside & Outside \\
\hline 0 to 45 & $31.4(1.41)$ & $22(2.86)$ \\
45 to 90 & $32.9(0.931)$ & $30.6(1.37)$ \\
90 to 135 & $42(2.82)$ & $38.4(0.836)$ \\
\hline
\end{tabular}


Table 6.14 Copper Tree Well Results (mg/kg).

\begin{tabular}{|c|c|c|c|c|}
\hline Depth (cm) & Tree & Cr Inside & Cr Outside & Difference \\
\hline $0-45$ & 2 & 22 & 14.2 & 7.8 \\
\hline $0-45$ & 3 & 21.4 & 2.39 & 19 \\
\hline $0-45$ & 4 & 18.1 & 19.4 & -1.3 \\
\hline $0-45$ & 5 & 28.8 & 15.6 & 13.2 \\
\hline $0-45$ & 6 & 17.6 & 11.1 & 6.5 \\
\hline $0-45$ & 8 & 21.2 & 7.97 & 13.2 \\
\hline $0-45$ & 11 & 27.3 & 17.7 & 9.6 \\
\hline $0-45$ & 12 & 24.6 & 16.6 & 8 \\
\hline $0-45$ & 14 & 23.1 & 17.9 & 5.2 \\
\hline $0-45$ & 15 & 23.6 & 8.78 & 14.8 \\
\hline $45-90$ & 2 & 19.5 & 15.8 & 3.7 \\
\hline $45-90$ & 3 & 20.3 & 12.9 & 7.4 \\
\hline $45-90$ & 4 & 20 & 18.2 & 1.8 \\
\hline $45-90$ & 5 & 18.9 & 23.1 & -4.2 \\
\hline $45-90$ & 6 & 22.2 & 20.9 & 1.3 \\
\hline $45-90$ & 8 & 21.6 & 20.3 & 1.3 \\
\hline $45-90$ & 11 & 21.3 & 21 & 0.3 \\
\hline $45-90$ & 12 & 20.8 & 21.6 & -0.8 \\
\hline $45-90$ & 14 & 21.1 & 17.4 & 3.7 \\
\hline $45-90$ & 15 & 22.9 & 22.9 & 0 \\
\hline $90-135$ & 2 & 24.5 & 25.1 & -0.6 \\
\hline $90-135$ & 3 & 23.8 & 25.1 & -1.3 \\
\hline $90-135$ & 4 & 24.4 & 22.4 & 2 \\
\hline $90-135$ & 5 & 23.5 & 22.7 & 0.8 \\
\hline $90-135$ & 6 & 25.7 & 23.6 & 2.1 \\
\hline $90-135$ & 8 & 27.7 & 27.9 & -0.2 \\
\hline $90-135$ & 11 & 24.1 & 22.8 & 1.3 \\
\hline $90-135$ & 12 & 22.7 & 23.4 & -0.7 \\
\hline $90-135$ & 14 & 21.8 & 22.6 & -0.8 \\
\hline $90-135$ & 15 & 23.4 & 24.4 & -1 \\
\hline
\end{tabular}

Table 6.15 Copper arithmetic means and standard deviations $(\mathrm{mg} / \mathrm{kg})$ in tree wells.

\begin{tabular}{lll}
\hline Depth & Inside & Outside \\
\hline 0 to 45 & $22.8(1.13)$ & $13.2(1.72)$ \\
45 to 90 & $20.9(0.387)$ & $19.4(1.04)$ \\
90 to 135 & $24.2(0.516)$ & $24(0.537)$ \\
\hline
\end{tabular}


Table 6.16 Lead Tree Well Results (mg/kg).

\begin{tabular}{lllll}
\hline Depth $(\mathrm{cm})$ & Tree & Cr Inside & Cr Outside & Difference \\
\hline $0-45$ & 2 & 14.9 & 9.26 & 5.64 \\
$0-45$ & 3 & 12 & 1.42 & 10.6 \\
$0-45$ & 4 & 10.6 & 11.2 & -0.6 \\
$0-45$ & 5 & 12.8 & 6.78 & 6.02 \\
$0-45$ & 6 & 8.86 & 5.53 & 3.33 \\
$0-45$ & 8 & 12.9 & 4.52 & 8.38 \\
$0-45$ & 11 & 13.1 & 7.25 & 5.85 \\
$0-45$ & 12 & 10.4 & 7.91 & 2.49 \\
$0-45$ & 14 & 10.7 & 7.11 & 3.59 \\
$0-45$ & 15 & 10 & 4.75 & 5.25 \\
\hline $45-90$ & 2 & 7.43 & 5.72 & 1.71 \\
$45-90$ & 3 & 7.17 & 4.99 & 2.18 \\
$45-90$ & 4 & 7.91 & 7.12 & 0.79 \\
$45-90$ & 5 & 7.4 & 8.27 & -0.87 \\
$45-90$ & 6 & 7.43 & 7.49 & -0.06 \\
$45-90$ & 8 & 7.23 & 6.58 & 0.65 \\
$45-90$ & 11 & 8.02 & 7.8 & 0.22 \\
$45-90$ & 12 & 7.55 & 8.16 & -0.61 \\
$45-90$ & 14 & 8 & 7 & 1 \\
$45-90$ & 15 & 7.62 & 7.2 & 0.42 \\
\hline $90-135$ & 2 & 8.77 & 8.77 & 0 \\
$90-135$ & 3 & 8.18 & 8.86 & -0.68 \\
$90-135$ & 4 & 8.64 & 8.31 & 0.33 \\
$90-135$ & 5 & 8.22 & 7.9 & 0.32 \\
$90-135$ & 6 & 8.29 & 8.35 & -0.06 \\
$90-135$ & 8 & 8.82 & 8.97 & -0.15 \\
$90-135$ & 11 & 9.27 & 8.21 & 1.06 \\
$90-135$ & 12 & 7.9 & 8.41 & -0.51 \\
$90-135$ & 14 & 8.15 & 8.06 & 0.09 \\
$90-135$ & 15 & 7.86 & 7.64 & 0.22 \\
\hline & & & & \\
\hline
\end{tabular}

Table 6.17 Lead arithmetic means and standard deviations $(\mathrm{mg} / \mathrm{kg})$ in tree wells.

\begin{tabular}{lll}
\hline Depth & Inside & Outside \\
\hline 0 to 45 & $11.6(0.575)$ & $6.57(0.859)$ \\
45 to 90 & $7.58(0.0971)$ & $7.03(0.329)$ \\
90 to 135 & $8.41(0.142)$ & $8.35(0.135)$ \\
\hline
\end{tabular}


Table 6.18 Nickel Tree Well Results (mg/kg).

\begin{tabular}{|c|c|c|c|c|}
\hline Depth $(\mathrm{cm})$ & Tree & Cr Inside & Cr Outside & Difference \\
\hline $0-45$ & 2 & 42 & 29.1 & 12.9 \\
\hline $0-45$ & 3 & 42.6 & 4.43 & 38.2 \\
\hline $0-45$ & 4 & 34.8 & 37.3 & -2.5 \\
\hline $0-45$ & 5 & 43.3 & 29.4 & 13.9 \\
\hline $0-45$ & 6 & 29.1 & 22.3 & 6.8 \\
\hline $0-45$ & 8 & 28.1 & 17.2 & 10.9 \\
\hline $0-45$ & 11 & 36.8 & 34.6 & 2.2 \\
\hline $0-45$ & 12 & 43.2 & 32.9 & 10.3 \\
\hline $0-45$ & 14 & 36.1 & 34.5 & 1.6 \\
\hline $0-45$ & 15 & 41.4 & 18.4 & 23 \\
\hline $45-90$ & 2 & 36.7 & 30.1 & 6.6 \\
\hline $45-90$ & 3 & 35.9 & 26 & 9.9 \\
\hline $45-90$ & 4 & 46.1 & 37.2 & 8.9 \\
\hline $45-90$ & 5 & 35.8 & 42.4 & -6.6 \\
\hline $45-90$ & 6 & 40 & 37.7 & 2.3 \\
\hline $45-90$ & 8 & 38 & 35.7 & 2.3 \\
\hline $45-90$ & 11 & 37.8 & 38.2 & -0.4 \\
\hline $45-90$ & 12 & 37.2 & 39.4 & -2.2 \\
\hline $45-90$ & 14 & 38.4 & 38.3 & 0.1 \\
\hline $45-90$ & 15 & 40.9 & 40 & 0.9 \\
\hline $90-135$ & 2 & 47.4 & 46.5 & 0.9 \\
\hline $90-135$ & 3 & 46 & 47.9 & -1.9 \\
\hline $90-135$ & 4 & 49.1 & 44.5 & 4.6 \\
\hline $90-135$ & 5 & 45.2 & 44 & 1.2 \\
\hline $90-135$ & 6 & 48.2 & 45.6 & 2.6 \\
\hline $90-135$ & 8 & 53 & 50.6 & 2.4 \\
\hline 90-135 & 11 & 44.1 & 45.2 & -1.1 \\
\hline $90-135$ & 12 & 43.5 & 46.1 & -2.6 \\
\hline $90-135$ & 14 & 45.8 & 45.1 & 0.7 \\
\hline $90-135$ & 15 & 47.5 & 45.3 & 2.2 \\
\hline
\end{tabular}

Table 6.19 Nickel arithmetic means and standard deviations $(\mathrm{mg} / \mathrm{kg})$ in tree wells.

\begin{tabular}{lll}
\hline Depth & Inside & Outside \\
\hline 0 to 45 & $37.7(1.81)$ & $26(3.26)$ \\
45 to 90 & $38.7(0.973)$ & $36.5(1.55)$ \\
90 to 135 & $47(0.873)$ & $46.1(0.608)$ \\
\hline
\end{tabular}


Table 6.20 Zinc Tree Well Results (mg/kg).

\begin{tabular}{cclll}
\hline Depth $(\mathrm{cm})$ & Tree & Cr Inside & Cr Outside & Difference \\
\hline $0-45$ & 2 & 68.4 & 50.6 & 17.8 \\
$0-45$ & 3 & 61 & 8.91 & 52.1 \\
$0-45$ & 4 & 55.6 & 57.5 & -1.9 \\
$0-45$ & 5 & 73.4 & 50.6 & 22.8 \\
$0-45$ & 6 & 47.1 & 37.3 & 9.8 \\
$0-45$ & 8 & 52.8 & 31 & 21.8 \\
$0-45$ & 11 & 60.3 & 41.3 & 19 \\
$0-45$ & 12 & 54.7 & 41.7 & 13 \\
$0-45$ & 14 & 54 & 45 & 9 \\
$0-45$ & 15 & 56.1 & 33.7 & 22.4 \\
\hline $45-90$ & 2 & 54.3 & 44.2 & 10.1 \\
$45-90$ & 3 & 54.3 & 37 & 17.3 \\
$45-90$ & 4 & 57.4 & 52.9 & 4.5 \\
$45-90$ & 5 & 53.6 & 59.7 & -6.1 \\
$45-90$ & 6 & 47.8 & 54.4 & -6.6 \\
$45-90$ & 8 & 49.3 & 45.6 & 3.7 \\
$45-90$ & 11 & 44.6 & 44 & 0.6 \\
$45-90$ & 12 & 43.5 & 45.9 & -2.4 \\
$45-90$ & 14 & 44 & 39.2 & 4.8 \\
$45-90$ & 15 & 49.3 & 51.7 & -2.4 \\
\hline $90-135$ & 2 & 62 & 64.2 & -2.2 \\
$90-135$ & 3 & 63 & 62.2 & 0.8 \\
$90-135$ & 4 & 67 & 61.9 & 5.1 \\
$90-135$ & 5 & 63 & 58.3 & 4.7 \\
$90-135$ & 6 & 52.7 & 59 & -6.3 \\
$90-135$ & 8 & 57.5 & 58.5 & -1 \\
$90-135$ & 11 & 50.5 & 47.6 & 2.9 \\
$90-135$ & 12 & 47.9 & 49.1 & -1.2 \\
$90-135$ & 14 & 47 & 47.5 & -0.5 \\
$90-135$ & 15 & 50.9 & 53.7 & -2.8 \\
\hline & & & & \\
\hline
\end{tabular}

Table 6.21 Zinc arithmetic means and standard deviations $(\mathrm{mg} / \mathrm{kg})$ in tree wells.

\begin{tabular}{lll}
\hline Depth & Inside & Outside \\
\hline 0 to 45 & $58.3(2.45)$ & $39.8(4.29)$ \\
45 to 90 & $49.8(1.55)$ & $47.5(2.24)$ \\
90 to 135 & $56.1(2.29)$ & $56.2(1.99)$ \\
\hline
\end{tabular}

